Cochrane Database of Systematic Reviews

\title{
Education of family members to support weaning to solids and nutrition in later infancy in term-born infants (Review)
}

Ojha S, Elfzzani Z, Kwok TC, Dorling J

Ojha S, Elfzzani Z, Kwok TC, Dorling J.

Education of family members to support weaning to solids and nutrition in later infancy in term-born infants.

Cochrane Database of Systematic Reviews 2020, Issue 7. Art. No.: CD012241.

DOI: 10.1002/14651858.CD012241.pub2.

www.cochranelibrary.com 
TABLE OF CONTENTS

HEADER 1

ABSTRACT

PLAIN LANGUAGE SUMMARY

SUMMARY OF FINDINGS

BACKGROUND

OBJECTIVES

METHODS

RESULTS

Figure 1.

Figure 2.

Figure 3.

Figure 4.

Figure 5.

Figure 6.

Figure 7.

Figure 8.

Figure 9.

DISCUSSION

AUTHORS' CONCLUSIONS

ACKNOWLEDGEMENTS

REFERENCES

CHARACTERISTICS OF STUDIES

DATA AND ANALYSES

Analysis 1.1. Comparison 1: Nutrition education versus conventional management, Outcome 1: Change in weight in the first 2 years of life

Analysis 1.2. Comparison 1: Nutrition education versus conventional management, Outcome 2: Change in height in the first 2 years of life

Analysis 1.3. Comparison 1: Nutrition education versus conventional management, Outcome 3: Change in height in the first 6 years of life

Analysis 1.4. Comparison 1: Nutrition education versus conventional management, Outcome 4: Weight-for-age z score at 12 months of age

Analysis 1.5. Comparison 1: Nutrition education versus conventional management, Outcome 5: Weight-for-age z score at 18 months of age

Analysis 1.6. Comparison 1: Nutrition education versus conventional management, Outcome 6: Height-for-age z score at 12 months of age

Analysis 1.7. Comparison 1: Nutrition education versus conventional management, Outcome 7: Height-for-age z score at 18 months of age

Analysis 1.8. Comparison 1: Nutrition education versus conventional management, Outcome 8: Height-for-age z score at 6 years of age

Analysis 1.9. Comparison 1: Nutrition education versus conventional management, Outcome 9: Weight-for-height z score at 12 months of age

Analysis 1.10. Comparison 1: Nutrition education versus conventional management, Outcome 10: Weight-for-height z score at 18 months of age

Analysis 1.11. Comparison 1: Nutrition education versus conventional management, Outcome 11: BMI z score at 6 years of age

Analysis 1.12. Comparison 1: Nutrition education versus conventional management, Outcome 12: Prevalence of anaemia (serum haemoglobin $<110 \mathrm{~g} / \mathrm{L}$ ) at 12 months of age

Analysis 1.13. Comparison 1: Nutrition education versus conventional management, Outcome 13: Death before 1 year of age .

Analysis 1.14. Comparison 1: Nutrition education versus conventional management, Outcome 14: Exclusive breastfeeding at 6 months of age

Analysis 2.1. Comparison 2: Correction for cluster effect, Outcome 1: Change in weight in the first 2 years of life Analysis 2.2. Comparison 2: Correction for cluster effect, Outcome 2: Change in height in the first 2 years of life

Analysis 2.3. Comparison 2: Correction for cluster effect, Outcome 3: Weight-for-age z score at 12 months of age

Analysis 2.4. Comparison 2: Correction for cluster effect, Outcome 4: Weight-for-age z score at 18 months of age 
Analysis 2.5. Comparison 2: Correction for cluster effect, Outcome 5: Height-for-age z score at 12 months of age

Analysis 2.6. Comparison 2: Correction for cluster effect, Outcome 6: Height-for-age z score at 18 months of age

Analysis 2.7. Comparison 2: Correction for cluster effect, Outcome 7: Weight-for-height z score at 12 months of age

Analysis 2.8. Comparison 2: Correction for cluster effect, Outcome 8: Weight-for-height $z$ score at 18 months of age

Analysis 2.9. Comparison 2: Correction for cluster effect, Outcome 9: Death before 1 year of age

Analysis 2.10. Comparison 2: Correction for cluster effect, Outcome 10: Exclusive breastfeeding at 6 months of age

HISTORY

CONTRIBUTI

DECLARATIONS OF INTEREST 
[Intervention Review]

\title{
Education of family members to support weaning to solids and nutrition in later infancy in term-born infants
}

\author{
Shalini Ojha1,2, Zenab Elfzzani³, T'ng Chang Kwok, Jon Dorling5
}

1Division of Medical Sciences and Graduate Entry Medicine, School of Medicine, University of Nottingham, Nottingham, UK. ${ }^{2}$ Children's Hospital, University Hospitals of Derby and Burton, Derby, UK. ${ }^{3}$ Academic Division of Child Health, Obstetrics and Gynaecology, University of Nottingham, Nottingham, UK. ${ }^{4}$ Nottingham University Hospitals NHS Trust, Nottingham, UK. ${ }^{5}$ Division of NeonatalPerinatal Medicine, Department of Pediatrics, Faculty of Medicine, Dalhousie University, Halifax, Canada

Contact address: Shalini Ojha, shalini.ojha@nottingham.ac.uk, sojha@nhs.net.

Editorial group: Cochrane Neonatal Group.

Publication status and date: New, published in Issue 7, 2020.

Citation: Ojha S, Elfzzani Z, Kwok TC, Dorling J. Education of family members to support weaning to solids and nutrition in later infancy in term-born infants. Cochrane Database of Systematic Reviews 2020, Issue 7. Art. No.: CD012241. DOI: 10.1002/14651858.CD012241.pub2.

Copyright @ 2020 The Cochrane Collaboration. Published by John Wiley \& Sons, Ltd.

\section{A B S T R A C T}

\section{Background}

Education of family members about infant weaning practices could affect nutrition, growth, and development of children in different settings across the world.

\section{Objectives}

To compare effects of family nutrition educational interventions for infant weaning with conventional management on growth and neurodevelopment in childhood.

\section{Search methods}

We used the standard strategy of Cochrane Neonatal to search the Cochrane Central Register of Controlled Trials (CENTRAL; 2018, Issue 5), MEDLINE via PubMed (1966 to 26 June 2018), Embase (1980 to 26 June 2018), and the Cumulative Index to Nursing and Allied Health Literature (CINAHL; 1982 to 26 June 2018). We searched clinical trials databases, conference proceedings, and references of retrieved articles.

We ran an updated search from 1 January 2018 to 12 December 2019 in the following databases: CENTRAL via CRS Web, MEDLINE via Ovid, and CINAHL via EBSCOhost.

\section{Selection criteria}

We included randomised controlled trials that examined effects of nutrition education for weaning practices delivered to families of infants born at term compared to conventional management (standard care in the population) up to one year of age.

\section{Data collection and analysis}

Two review authors independently identified eligible trial reports from the literature search and performed data extraction and quality assessments for each included trial. We synthesised effect estimates using risk ratios (RRs), risk differences (RDs), and mean differences (MDs), with 95\% confidence intervals (CIs). We used the GRADE approach to assess the certainty of evidence.

\section{Main results}

We included 21 trials, recruiting 14,241 infants. Five of the trials were conducted in high-income countries and the remaining 16 were conducted in middle- and low-income countries. Meta-analysis showed that nutrition education targeted at improving weaning-related 
feeding practices probably increases both weight-for-age z scores (WAZ) (MD 0.15 standard deviations, 95\% $\mathrm{Cl} 0.07$ to $0.22 ; 6$ studies; 2551 infants; $I^{2}=32 \%$; moderate-certainty evidence) and height-for-age $\mathrm{z}$ scores ( 0.12 standard deviations, $95 \% \mathrm{Cl} 0.05$ to $0.19 ; 7$ studies; 3620 infants; $I^{2}=49 \%$; moderate-certainty evidence) by 12 months of age. Meta-analysis of outcomes at 18 months of age was heterogeneous and inconsistent in the magnitude of effects of nutrition education on WAZ and weight-for-height $z$ score across studies. One trial that assessed effects of nutrition education on growth at six years reported an uncertain effect on change in height and body mass index z score. Two studies investigated effects of nutrition education on neurodevelopment at 12 to 24 months of age with conflicting results. No trials assessed effects of nutrition education on long-term neurodevelopmental outcomes.

\section{Authors' conclusions}

Nutrition education for families of infants may reduce the risk of undernutrition in term-born infants (evidence of low to moderate certainty due to limitations in study design and substantial heterogeneity of included studies). Modest effects on growth during infancy may not be of clinical significance. However, it is unclear whether these small improvements in growth parameters in the first two years of life affect long-term childhood growth and development. Further studies are needed to resolve this question.

\section{PLAIN LANGUAGE SUMMARY}

\section{Nutrition education to support weaning of term-born infants}

\section{Review question}

We reviewed the evidence for effects of nutrition education about appropriate feeding practices during weaning on growth and development in children born at term gestation.

\section{Background}

Around the world, over 150 million children are undernourished and over 42 million are overweight and obese. Providing families with appropriate education about feeding practices during weaning may help to optimise nutrition while helping to protect children who are at risk of undernutrition, as well as those susceptible to being overweight and obese.

\section{Study characteristics}

We examined research published up to December 2019 and found 21 clinical trials recruiting 14,241 babies. The nutrition education provided in all included studies, whereby analysis could be pooled together, was aimed at reducing the risk of undernutrition in childhood. Five studies were undertaken in high-income countries, but the findings reported could not be included and pooled together in this review.

\section{Key results}

We found that giving nutrition education about appropriate feeding practices during weaning to families in low- to moderate-income settings may improve weight and height at 12 months of age. We are very uncertain about the effects of nutrition education on children's development and risk of anaemia at one year of age, as only two studies reported each of these outcomes. Therefore, these results are described only in the text. We did not find any studies that assessed the effects of nutrition education on children's risk of overweight and obesity and reported outcomes that could be pooled together in this review.

\section{Certainty of evidence}

The certainty of evidence for the reduction in risk of childhood undernutrition with nutrition education is low to moderate at best due to limitations in study design and differences among the studies included in our review. The amount of improvement in growth noted is small and of unclear clinical significance. More long-term studies are needed to see if this improvement continues into later life, leading to bigger improvements. We rated the certainty of evidence for other outcomes included in this study as low due to the limited number of included studies.

Further research is needed to determine whether nutrition education can reduce risks of overnutrition and obesity in children. 


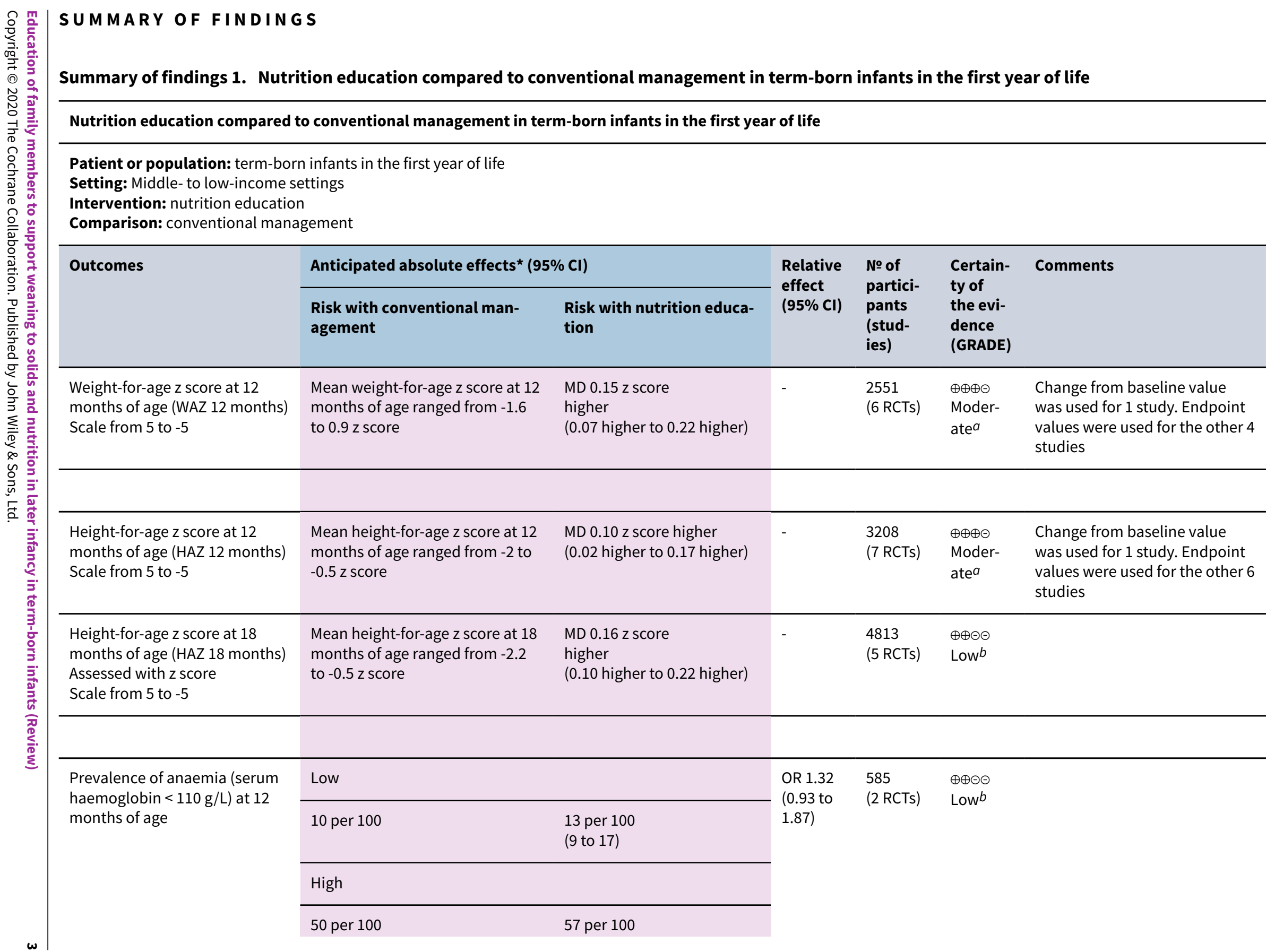




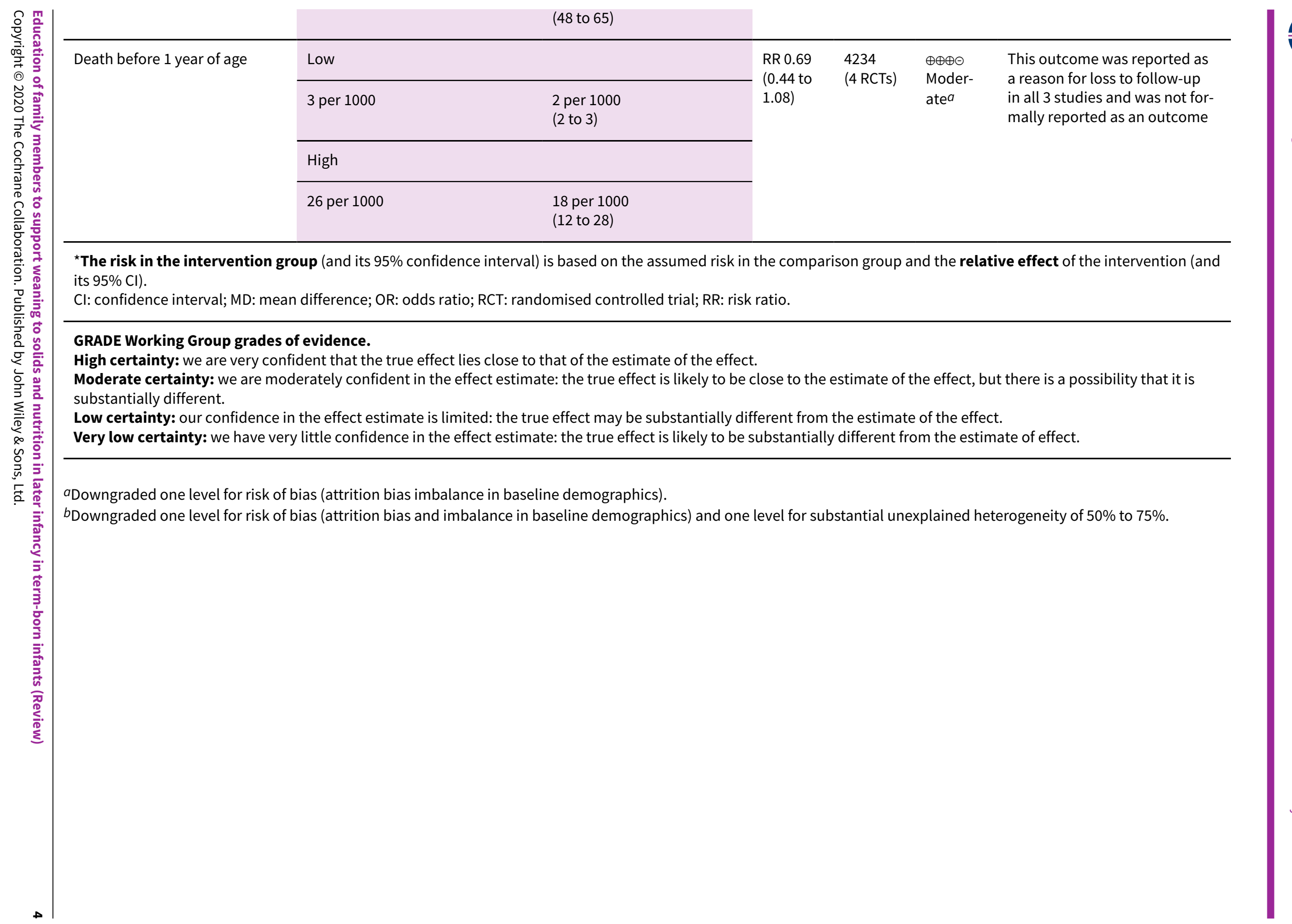




\section{B A C K G R O U N D}

\section{Description of the condition}

The World Health Organization (WHO) defines weaning, or the introduction of complementary feeding, as the period when the child's diet changes from complete breastfeeding to eating normal family food. This transition usually starts at four to six months of age and is finished at around one year (WHO 1988). More broadly, the term is used to describe the period when solid foods are introduced to complement human or formula milk. The decision made by WHO to include everything except breast milk as complementary food is intended to emphasise the importance of exclusive breastfeeding; however this may be misleading. Infants are frequently fed human milk substitutes such as infant formula even from the first week of life. Complementary feeding is generally used to describe giving any nutrient-containing foods or liquids other than breast milk, infant formula, or follow-on formula (Agostoni 2008), and weaning is the process by which such complementary foods are introduced into the infant's diet.

Although WHO, the United Nations Children's Fund (UNICEF), and the American Academy of Pediatrics recommend exclusive breastfeeding for the first six months of life (AAP 2012; Kramer 2002; UNICEF 2005), most guidelines, particularly from high-income countries (World Bank 2015), recommend that weaning should not occur before 17 weeks, should not be delayed beyond 26 weeks, and should be guided by the individual infant's nutritional needs and developmental abilities (Agostoni 2008). Weaning should be timely, safe, and adequate in nutritional content and in the variety of food items offered, and it should be offered to the infant at the correct frequency and in an appropriate manner (Weaver 2001). Adequate renal, gastrointestinal, immunological, and neurodevelopmental maturation should have been achieved for the transition from milk to solid foods.

Undernutrition and faltering growth may occur unintentionally due to delayed weaning or weaning with low-energy density foods and may increase the risk of iron deficiency and iron deficiency anaemia in late infancy (Hopkins 2007). Furthermore, inappropriate weaning has been linked to several other health problems, such as increased risk of allergic disorders, dental caries, and poor neurocognitive outcomes.

At the other end of the spectrum, early weaning, particularly with inappropriately high-energy food, can increase the risk of childhood obesity and cardiovascular illness in later life. In high-income countries, where feeding practices are determined mainly by parental beliefs and understanding of infant feeding, observational evidence shows that early weaning to solid foods is significantly associated with overweight or obesity at three years of age (Baughcum 2001; Hawkins 2009).

The nutritional challenges faced by populations in low- and middleincome countries usually differ from those seen in high-income countries. In low- and middle-income countries, gains attained by promoting exclusive breastfeeding for the first six months of life need to be sustained by encouraging appropriate weaning, as it is well recognised that between six and 24 months of age, children are particularly vulnerable to malnutrition due to limitations in the quality and quantity of foods (Lassi 2013). Families are faced with limited availability and access to food along with lack of information about correct choices for weaning. In high-income countries, parents face anxieties and challenges despite adequate availability of food for weaning (Redsell 2010).

Parents make infant feeding choices based on a variety of influences including advice from family members and health professionals, leaflets, magazines, and, increasingly, information from the Internet (Gage 2012). Evidence suggests that compliance with weaning guidelines is low and mothers often experience conflict in deciding when and how to wean their infants (Arden 2010; Moore 2012). Surveys of parents demonstrate that they feel unsupported and experience anxiety due to a variety of factors such as inadequate knowledge and understanding of the physiological needs of the infant and confusing information from multiple commercially oriented sources, as well as social pressures, controversial cultural patterns and expectations, lack of information about healthy diet, and apprehension about cooking even the simplest weaning foods (Redsell 2010).

Weaning practices impact the long-term eating habits of children. Parental anxieties about infant-feeding also manifest as control of feeding practices and attempts to impose the amount or types of foods the infant eats. Studies show that parents who lack awareness of infant hunger cues are more likely to force their child to eat more (pressure/control feeding) or to refrain from certain foods or to take in limited amounts due to anxieties about weight gain (restriction for weight) (Musher-Eizenman 2007). Such practices have been shown to be associated with food neophobia (avoidance and rejection of novel foods), which is associated with reduced dietary quality and lower nutrient intake in later life (Cassells 2014). Empowering parents with the knowledge to recognise and respond to their infant's hunger cues may reduce the use of controlling feeding practices and may improve lifelong dietary habits.

Despite differences in opinion and lack of consensus among experts, parents and families need information and support while weaning their infants. Parents are receptive to advice but need better support in accessing and understanding best practices around infant feeding (Redsell 2010). Inadequate nutrition may be caused by limited access to sufficient food; however, caregivers may not be able to make the best use of available resources because of lack of knowledge and inappropriate beliefs and advice. Education of caregivers may have an impact and may improve nutritional status among children by empowering parents/ caregivers to provide the best possible diet and to use the most appropriate feeding styles to wean their infants.

\section{Description of the intervention}

Nutrition education has been defined as "any combination of educational strategies, accompanied by environmental supports, designed to facilitate voluntary adoption of food choices" (Contento 2010). Educational interventions may be provided to the individual parent or caregiver or may be delivered via community-based programmes, and could include nutritional counselling of caregivers; dissemination of information via verbal, written, or audiovisual aids; and/or any other strategy that provides information about weaning practices to families. Environmental supports may include changes in healthcare and food policies, as well as in social structure in the community, to create a conducive environment for nutrition education, such as arrangement of home visits, a suitable accessible location to carry out group educational activities, and provision of visual aids. 


\section{How the intervention might work}

Nutrition education is an essential component of health promotion and disease prevention. Several theories of behaviour change, such as the theory of planned behaviour - Ajzen 1980 - and the social-cognitive theory - Bandura 2004 - explain the complex relationship between knowledge, beliefs, and perceived social norms, and how nutrition education can induce behavioural changes in a given set of circumstances. Interventions that provide relevant information and education to parents and caregivers could induce changes in behaviour that may impact nutritional practices, thereby improving nutrition, growth, and long-term metabolic health outcomes among children (Lassi 2013). The nutritional messages often emphasise the importance of breastfeeding duration, initiation of weaning to food, frequency of feeding, or the composition of food (in terms of protein, energy, and micronutrient content), which will improve nutrition intake and growth. The dietary supply of specific nutrients may influence the maturation of cortical function. Feeding breast milk has often been associated with better later cognitive outcomes; however, some studies have shown that certain foods provided during weaning are associated with improved outcomes, such as an increase in the Bayley Psychomotor Developmental Index (Morgan 2004), in visual acuity (Hoffman 2003), and in higher behavioural indices (Krebs 2006). In older children, nutrition education modifies eating behaviour and optimises growth, and parental education can have a positive impact on child nutrition (Luepker 1996).

\section{Why it is important to do this review}

Previous systematic reviews have evaluated the impact of nutrition education and have demonstrated improvement in both weight and linear growth (Dewey 2008; Imdad 2011). However, both of these reviews concentrated on populations in low- and middleincome countries and included non-randomised studies as well as studies that included children older than 12 months of age. This review will collate the current evidence to determine whether use of nutrition educational interventions to support families during the weaning process optimises growth and nutrition among infants born at term gestation in all parts of the world.

The need for educational programmes to improve infant nutrition has been highlighted by several studies (Hoare 2002; Redsell 2010), particularly as infant nutrition is subjected to strong pressures by commercial as well as non-profit motivated self-help groups. The double threat of childhood undernutrition and obesity and their potential long-term impact on health has prompted attention to effective interventions that improve the nutritional status of children in all parts of the world (Black 2013). Nutrition education has the potential to improve child health at both ends of the malnutrition spectrum. It is imperative that parents and families have access to nutrition education through scientifically correct, culturally sensitive, and economically appropriate advice about healthy diet for infants (Caroli 2012). It is also vital to ensure that such interventions are effective, as significant resources could be saved by eliminating time- and resource-intensive educational programmes that prove to be of no benefit.

\section{O B JECTIVES}

To compare effects of family nutrition educational interventions for infant weaning with conventional management on growth and neurodevelopment in childhood.

\section{METHODS}

\section{Criteria for considering studies for this review}

\section{Types of studies}

We included published randomised and quasi-randomised trials, including cluster-randomised trials. We described any imbalances in baseline characteristics and outcome measurements between clusters in both groups. We did not include non-randomised trials such as controlled before-and-after studies. The review was not limited to any particular region or socio-economic category, and we included studies published in any language.

\section{Types of participants}

Parents and families of infants born at term gestation (37 to 42 weeks' gestation) and younger than one year of age at recruitment are included.

\section{Types of interventions}

We included studies comparing any nutrition educational intervention for parents or families of infants born at term (37 to 42 weeks' gestation) and younger than one year of age at recruitment with conventional management for weaning. We included studies that use any form of nutrition educational intervention such as nutrition counselling, face-to-face sessions, audiovisual packages, support groups, additional input from health visitors or other allied professionals, and any other form of support involving nutrition education provided to families. We looked at nutrition educational messages emphasising the importance of breastfeeding duration, initiation of weaning to food, frequency of feeding, or composition of food (in terms of protein, energy, and micronutrient content). Conventional management was defined as standard clinical support and/or appointments without a nutrition educational focus.

\section{Types of outcome measures}

\section{Primary outcomes}

1. Growth rates (weight gain, linear growth, and head growth) in the first two years of life; change in weight, height, or head circumference $z$ scores

2. Neurodevelopmental scores in children aged 12 months or older based on validated assessment tools, using neurological examination and the Bayley Scale Index II (Black 2000). These scores were considered abnormal if the Bayley II Mental Developmental Index was less than 70, if the Psychomotor Developmental Index was less than 70 , or if there was visual impairment and/or hearing impairment. Neurological examination was considered abnormal if motor and/or sensory functions were impaired

\section{Secondary outcomes}

1. Duration of exclusive breastfeeding - defined as exclusive breastfeeding at six months of age

2. Compliance with advice regarding timing of weaning

3. Cognitive ability in children at five, six, or seven years of age, based on validated assessment tools such as the Weschler Intelligence Scale for Children - Wechsler 1974 - and school examinations 
4. Long-term growth: weight, height, skinfold thickness, or body mass index at five, six, or seven years of age

5. Serum ferritin (< 12 micrograms/L) and haemoglobin $(<110$ grams/L) levels in children six months of age or older (WHO 2011)

6. Parental stress when the child was six months of age or older, measured by validated assessment tools such as the Parenting Stress Index (Grotevant 1989)

7. Infant quality of life when the child was six months of age or older, measured by the Infant and Toddler Quality of Life Questionnaire (ITQOL) (Bowling 2004)

8. Prevalence of atopic conditions in childhood

9. Prevalence of food neophobia or 'picky/fussy eating'

10.Death before one and five years of age

\section{Search methods for identification of studies}

We used the criteria and standard methods of Cochrane and Cochrane Neonatal (see the Cochrane Neonatal search strategy for specialised register). We did not limit the search to any particular geographical region, language, or timing of publication.

\section{Electronic searches}

We conducted a comprehensive search including the Cochrane Central Register of Controlled Trials (CENTRAL; 2018, Issue 5), in the Cochrane Library; MEDLINE via PubMed (1966 to 26 June 2018); Embase (1980 to 26 June 2018); and the Cumulative Index to Nursing and Allied Health Literature (CINAHL; 1982 to 26 June 2018), using the following search terms: ("Weaning"[Mesh] OR wean* OR ((Feed*[tiab] OR food[tiab]) AND (complementary[tiab] OR supplementary[tiab]))) AND ("Education"[MeSH] OR program*[tiab] OR education*[tiab] OR training[tiab] OR intervention*[tiab] OR counseling[tiab] OR support[tiab] OR information[tiab] OR recommendation[tiab] OR guideline[tiab] OR advice[tiab]), plus database-specific limiters for randomised controlled trials (RCTs) and neonates (see Appendix 1 for previous full search strategies for each database). We did not apply language restrictions.

We searched clinical trials registries for ongoing and recently completed trials (clinicaltrials.gov; World Health Organization International Trials Registry and Platform - www.whoint/ictrp/ search/en/; and the ISRCTN Registry). We searched clinical trials registries for relevant studies using the search words (feeding AND education AND infant) OR (weaning AND education AND infant).

We re-conducted a comprehensive update search including the Cochrane Central Register of Controlled Trials (CENTRAL; 2019, Issue 12), in the Cochrane Library; Ovid MEDLINE(R) and Epub Ahead of Print, In-Process \& Other Non-Indexed Citations, Daily and Versions(R) (1 January 2018 to 12 December 2019); and the Cumulative Index to Nursing and Allied Health Literature (CINAHL; 1 January 2018 to 12 December 2019). We have included the search strategies for each database in Appendix 2. We did not apply language restrictions.

We searched clinical trials registries for ongoing and recently completed trials. We searched the World Health Organization International Clinical Trials Registry Platform (ICTRP) (www.who.int/ictrp/search/en/), and the US National Library of Medicine ClinicalTrials.gov (clinicaltrials.gov) via Cochrane
CENTRAL. Additionally, we searched the ISRCTN Registry for any unique trials not found through the Cochrane CENTRAL search.

\section{Searching other resources}

We examined the reference lists of included studies and previous reviews, and we examined proceedings of annual meetings of the Paediatric American Societies (1993 to 12 December 2019), the European Society for Paediatric Research (1995 to 12 December 2019), the Royal College of Paediatrics and Child Health (2000 to 12 December 2019), and the Perinatal Society of Australia and New Zealand (2000 to 12 December 2019). Trials reported only as abstracts were eligible for inclusion if sufficient information was available from the report, or from contact with study authors, to fulfil the inclusion criteria.

\section{Data collection and analysis}

We used the standard methods of Cochrane Neonatal.

\section{Selection of studies}

Three review authors (SO, ZE and TK) screened the title and abstract of studies and potentially- relevant reports identified from the above search. The review authors independently assessed the full articles for all potentially relevant trials and any disagreements were resolved by discussion and input from the fourth author (JD).

\section{Data extraction and management}

Three review authors (SO, ZE, and TK) independently extracted data from the full-text articles of included studies using a data collection form for details of design, methods, participants, interventions, outcomes, and educational effects. We crosschecked information and resolved any discrepancies by discussion until we reached agreement.

We contacted study authors if additional information was required.

\section{Assessment of risk of bias in included studies}

We used Cochrane Neonatal criteria and standard methods to assess the methodological quality of included trials. Three review authors (SO, ZE, and TK) independently assessed risk of bias (low, high, or unclear) of all included trials using the Cochrane 'Risk of bias' tool for the following domains (Higgins 2019).

1. Sequence generation (selection bias).

2. Allocation concealment (selection bias).

3. Blinding of participants and personnel (performance bias).

4. Blinding of outcome assessment (detection bias).

5. Incomplete outcome data (attrition bias).

6. Selective reporting (reporting bias).

7. Any other bias.

We resolved disagreements by discussion or by consultation with a fourth assessor (JD). See Appendix 3 for a detailed description of risk of bias for each domain.

\section{Measures of treatment effect}

We analysed effects of educational interventions provided in individual trials using Review Manager 5.3 (RevMan 2014). We reported risk ratios (RRs) and risk differences (RDs) for dichotomous data, and mean differences (MDs) for continuous data, along with 
respective 95\% confidence intervals (Cls). We also reported the number needed to treat for an additional beneficial outcome (NNTB) or an additional harmful outcome (NNTH) for analyses with a statistically significant difference in RD.

For categorical outcomes, we calculated typical estimates for relative risk, RD, NNTB, and NNTH and used $95 \% \mathrm{Cls}$.

\section{Unit of analysis issues}

The unit of analysis was the participating infant in individually randomised trials. An infant was considered only once in an analysis. We excluded infants with multiple enrolments from analysis unless we obtained data from the report or from investigators related to the first episode of randomisation. If data from the first randomisation could not be identified, we excluded the study, as we were not able to address unit of analysis issues that arose from multiple enrolments of the same infant. We included infants from multiple births.

We intended to conduct intention-to-treat analyses. The participating health organisation was the unit of analysis in clusterrandomised trials. We analysed these trials using 'approximate analyses' to obtain 'effective sample sizes' as described in the Cochrane Handbook for Systematic Reviews of Interventions (Higgins 2019). The intracluster correlation coefficient (ICC) does vary, depending on geographical area as well as one size of the cluster used. External estimates of the ICC from similar studies done in developing countries range from 0.01 in Shi 2009 to 0.05 in Handa 2018. Hence, we used an ICC of 0.05 to reduce the unit of analysis error as much as possible by reducing the 'effective sample size'. We did not use a summary measurement from each cluster along with the cluster as the unit of analysis as this would have considerably and unnecessarily reduced the power of studies (Higgins 2019).

\section{Dealing with missing data}

If data were missing or were reported unclearly, we requested additional data on important outcomes from trial authors. When data were still missing, we examined the impact on effect size estimates in sensitivity analyses using the 'best-worst case scenario' technique.

\section{Assessment of heterogeneity}

We examined intervention effects of individual trials and heterogeneity between trial results by inspecting forest plots. We calculated the $I^{2}$ statistic for each RR analysis to quantify inconsistency across studies and to describe the percentage of variability in effect estimates that may be due to heterogeneity rather than to sampling error. Degree of heterogeneity has been classified according to the $\mathrm{I}^{2}$ statistic as follows: < 25\%: none, $25 \%$ to $49 \%$ : low, $50 \%$ to $74 \%$ : moderate, $75 \%$ or higher: high.

If we detected moderate or high heterogeneity $\left(1^{2}>50 \%\right)$, we explored the possible causes (e.g. differences in study design, participants, interventions, or completeness of outcome assessments). In addition, we employed a $\mathrm{Chi}^{2}$ test of homogeneity to determine the strength of evidence that heterogeneity is genuine.

\section{Assessment of reporting biases}

If we included more than ten trials in a meta-analysis, we checked a funnel plot for asymmetry to assess potential reporting bias.

\section{Data synthesis}

We used the fixed-effect model in Review Manager 5.3 for metaanalyses (as per Cochrane Neonatal Group recommendations) (RevMan 2014). We used standard methods of the Cochrane Neonatal Review Group to synthesise data using RR, RD, NNTB, NNTH, MD, and 95\% Cls. When substantial heterogeneity existed, we tested for potential causes in subgroup and sensitivity analyses.

\section{Subgroup analysis and investigation of heterogeneity}

We had planned to perform the following subgroup analyses, if data were available.

1. Infants and families living in middle- and low-income countries.

2. Infants and families living in high-income countries.

However, no study from a high-income country was eligible for inclusion in the meta-analyses. We also performed the following a posteriori subgroup analyses to investigate for heterogeneity.

1. Age of infants when intervention was started (antenatally, during first six months of age, or after six months of age).

2. Duration of intervention (12 months or longer than 12 months).

3. Delivery of intervention in terms of setting (one-to-one, group, or combination of one-to-one and group) and person delivering the intervention (professional health workers and community workers).

\section{Sensitivity analysis}

We performed sensitivity analyses to determine whether findings are affected by including only studies using adequate methods (low risk of bias), defined as adequate randomisation and allocation concealment, blinding of intervention and measurement, and less than $10 \%$ loss to follow-up.

\section{Summary of findings and assessment of the certainty of the evidence}

We used the GRADE approach, as outlined in the GRADE Handbook (Schünemann 2013), to assess the certainty of evidence for the following (clinically relevant) outcomes.

1. Growth rates (weight gain, linear growth, and head growth) in the first two years of life; change in weight, height, or head circumference $z$ scores.

2. Cognitive development based on Bayley Mental Development Index greater than 70 during follow-up at 12 months.

3. Iron deficiency seen as serum ferritin less than 12 micrograms/ L during follow-up at six months.

Two review authors independently assessed the certainty of evidence for each of the outcomes above. We considered evidence from RCTs as high certainty but downgraded evidence by one level for serious (or two levels for very serious) limitations based upon the following: design (risk of bias), consistency across studies, directness of evidence, precision of estimates, and presence of publication bias. We used the GRADEpro GDT Guideline Development Tool to create a 'Summary of findings' table to report the certainty of evidence.

The GRADE approach results in an assessment of the certainty of a body of evidence according to one of four grades. 
1. High certainty: further research is very unlikely to change our confidence in the estimate of effect.

2. Moderate certainty: further research is likely to have an important impact on our confidence in the estimate of effect and may change the estimate.

3. Low certainty: further research is very likely to have an important impact on our confidence in the estimate of effect and is likely to change the estimate.

Figure 1. Study flow diagram.

Additional articles
identified through
other sources
$n=2$

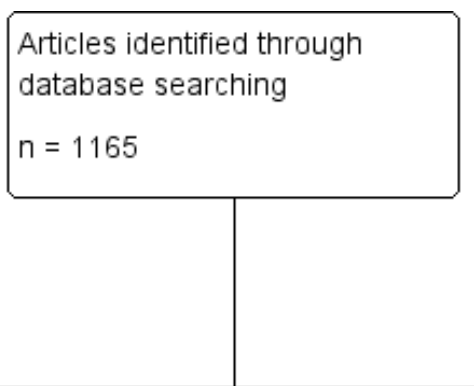

477 articles identified through updated database searches (January 2018 to December 2019)

\section{RE S U L T S}

\section{Description of studies}

\section{Results of the search}

We identified 75 studies for full-text screening (Figure 1). Of these, we excluded 53 studies (see Characteristics of excluded studies table). We conducted the last search on 12 December 2019.
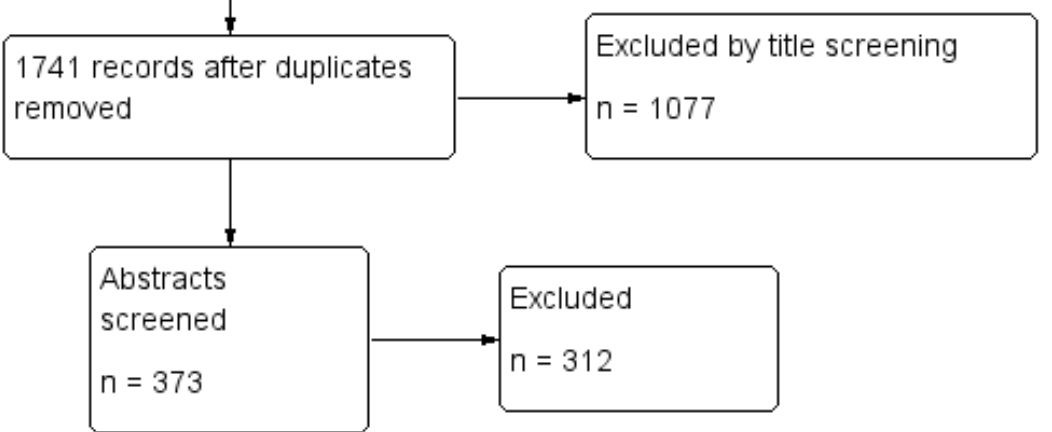

\section{Included studies}

We included 21 studies in the review (Muhoozi 2018; Bhadari 2001; Bhandari 2004; Bortolini 2012; de Oliveira 2012; Ferreira 2019; Fildes 2015; Koehler 2007; Morandi 2019; Murthy 2019; Nair 2017;
Nikiema 2017; Olaya 2013; Palacios 2019; Penny 2005; RafieyaKopaei 2019; Roy 2007; Saleem 2014; Shi 2009; Vazir 2013; Watt 2009). Of the 21 included studies, 12 were cluster-RCTs (Muhoozi 2018; Bhandari 2004; Ferreira 2019; Morandi 2019; Nair 2017; Nikiema 2017; Penny 2005; Rafieya-Kopaei 2019; Roy 2007; Saleem 
2014; Shi 2009; Vazir 2013), and participants were randomised individually in nine (Bhadari 2001; Bortolini 2012; de Oliveira 2012; Fildes 2015; Koehler 2007; Murthy 2019; Olaya 2013; Palacios 2019; Watt 2009). The unit of randomisation was the participating infant in Bhadari 2001; Fildes 2015, and Palacios 2019; the unit of analysis was the mother in Bortolini 2012; de Oliveira 2012; Koehler 2007; Murthy 2019; Olaya 2013, and Watt 2009.

Five studies were undertaken to address obesity or were conducted in high-income countries: Germany (Koehler 2007), United Kingdom (Watt 2009), Italy (Morandi 2019), Hawaii/Puerto Rico (Palacios 2019), and a combination of United Kingdom, Portugal, and Greece (Fildes 2015). Of the five studies done in highincome countries, only three studies reported growth parameters (Morandi 2019; Palacios 2019; Watt 2009), and two studies reported breastfeeding outcomes (Morandi 2019; Palacios 2019). However, reported information was insufficient for inclusion of study results in the meta-analysis. The other two studies reported dietary intake outcomes (Fildes 2015; Koehler 2007).

The remaining 16 studies were conducted in middle- and lowincome countries. Five studies were conducted in India (Bhadari 2001; Bhandari 2004; Murthy 2019; Nair 2017; Vazir 2013), and one took place in each of Bangladesh (Roy 2007), Pakistan (Saleem 2014), and Iran (Rafieya-Kopaei 2019), respectively. Shi 2009 was set in China. Five studies were set in South America: Peru (Penny 2005), Brazil (Bortolini 2012; de Oliveira 2012; Ferreira 2019), and Colombia (Olaya 2013). Two studies were set in Africa: the first in Burkina Faso (Nikiema 2017), and the other in Uganda (Muhoozi 2018).

Two studies included infants who were exclusively breastfeeding at recruitment (Olaya 2013; Rafieya-Kopaei 2019). Breastfeeding status was not included in the recruitment criteria for other studies.

A total of 14,241 infants were included (7730 in the nutrition intervention group and 6511 in control groups).

\section{Interventions and comparisons}

The intervention consists of nutrition education delivered via the following.

1. Voice messages (Murthy 2019) or text messages/short messaging service (Palacios 2019; Rafieya-Kopaei 2019) via mobile phones in three studies.

2. Training of healthcare professionals looking after caregivers with written information for participants in two studies (Ferreira 2019; Morandi 2019).

3. Nutritional counselling in the remaining 16 studies

a. Except one study wherein nutrition counselling was delivered via telephone or written information (Koehler 2007), the intervention in the remaining 14 included studies was nutritional counselling delivered face-to-face with variation in the intensity of counselling.

The intensity of interventions in the included studies was categorised according to the following.

\section{Age of infant when the intervention was started}

Mothers were enrolled in the study during the third trimester of pregnancy in Fildes 2015; Murthy 2019; Nair 2017; Nikiema 2017, and Vazir 2013. Women in Fildes 2015 were recruited in the final trimester of their pregnancy, and infants younger than six months were recruited as part of a larger study. Although enrolment was done antenatally in Vazir 2013, the intervention did not begin until infants were three months of age.

Infants were enrolled during the neonatal period in Bhandari 2004; Bortolini 2012; de Oliveira 2012; Morandi 2019, and Penny 2005; and between one and six months of age in Bhadari 2001; Koehler 2007; Olaya 2013; Palacios 2019; Rafieya-Kopaei 2019; Saleem 2014; Shi 2009 and Watt 2009. Infants were enrolled between six and nine months of age in Muhoozi 2018; Ferreira 2019and Roy 2007.

\section{Duration of the intervention}

The intervention was continued up to 12 months of age in Muhoozi 2018; Bhadari 2001; Bhandari 2004; Bortolini 2012; de Oliveira 2012; Fildes 2015; Koehler 2007; Murthy 2019; Olaya 2013; Palacios 2019; Rafieya-Kopaei 2019; Roy 2007; Saleem 2014; Shi 2009; and Watt 2009. The intervention was delivered up to 15 months of age in Vazir 2013, and up to 18 to 24 months of age in Ferreira 2019; Morandi 2019; Nair 2017; Nikiema 2017; and Penny 2005.

\section{Delivery of the intervention}

\section{Setting of the intervention}

Nutritional counselling was delivered individually via home visits in Bhandari 2004; Bortolini 2012; de Oliveira 2012; Saleem 2014; Vazir 2013, and Watt 2009; during clinic visits in Olaya 2013; Nikiema 2017, and Penny 2005; during either home or clinic visits in Fildes 2015; or by telephone in Koehler 2007. Group counselling sessions were delivered in Muhoozi 2018; Bhadari 2001; and Roy 2007. Study participants in Shi 2009 and Nair 2017 received both group counselling and individual home visits.

\section{Person delivering the intervention}

The intervention in most included studies consisted of locally developed nutrition messages delivered via local professional health workers, except in three studies (Nair 2017; Vazir 2013; Watt 2009), which reported nutrition messages delivered by community women who completed a period of training.

Control groups received usual care with routine health messages such as continued breastfeeding promoted in both groups. A summary of the interventions and other features of these studies are presented in Characteristics of included studies tables.

\section{Outcomes}

One primary outcome of the review - growth rate in the first two years of life - was reported by all included studies except Bortolini 2012; de Oliveira 2012; Fildes 2015, and Koehler 2007. Data on growth in the first two years of life were presented in different ways: Bhadari 2001; Bhandari 2004; Morandi 2019; Murthy 2019; and Watt 2009 reported changes in absolute weights and heights; Muhoozi 2018; Nair 2017; Nikiema 2017; Olaya 2013; Penny 2005; and Roy 2007 reported z scores; and changes in both absolute weight and height and in z scores were available from Palacios 2019; Vazir 2013; Rafieya-Kopaei 2019; Saleem 2014, and Shi 2009. However, Saleem 2014 reported growth parameters and growth parameter $z$ scores at various time points of the study without referencing the age of infants when measurement was done. Watt 2009 reported absolute weights and heights at baseline (three months) and at 12 and 18 months of age only. Palacios 2019 and Rafieya-Kopaei 2019 reported absolute and $z$ scores of growth parameters only at 
six and eight months, respectively. Growth parameters were not reported fully in Murthy 2019. Hence, data from these five studies were insufficient for inclusion in the meta-analysis (Murthy 2019; Palacios 2019; Rafieya-Kopaei 2019; Saleem 2014; Watt 2009).

Neurodevelopmental scores in children aged 12 months of age or older based on validated assessment tools were reported by two studies only (Muhoozi 2018: Vazir 2013).

Seven studies reported exclusive breastfeeding at six months of age (Bhandari 2004; Bortolini 2012; Murthy 2019; Nair 2017; Nikiema 2017; Palacios 2019; Rafieya-Kopaei 2019). Penny 2005 reported exclusive breastfeeding at four to six months of age. Morandi 2019 and Watt 2009 reported exclusive breastfeeding at three and four months, respectively. Most others reported some outcomes related to breastfeeding such as rate and duration of any breastfeeding (Bhadari 2001; de Oliveira 2012; Ferreira 2019; Olaya 2013; Roy 2007; Shi 2009), but these outcomes are not included in the metaanalysis. The remaining five studies did not report breastfeeding outcomes (Muhoozi 2018; Fildes 2015; Koehler 2007; Saleem 2014; Vazir 2013).

Measures of iron deficiency anaemia were reported by two studies (Bortolini 2012; Olaya 2013). Anaemia was defined as serum haemoglobin less than 110 grams/L in both studies, but the cutoff for serum ferritin levels to define iron deficiency differed between the two. Olaya 2013 reported serum ferritin less than 12 micrograms/L, which is in keeping with outcomes for the review, but the cut-off in Bortolini 2012 was less than 15 micrograms/L.

Most included studies reported death as a reason for loss to followup. Data for death before one year of life were available for four studies (Bhadari 2001; Nair 2017; Roy 2007; Vazir 2013). Other studies reported death at different time points: 9 and 18 months of age in Bhandari 2004, and 18 months of age in Penny 2005. Vitolo 2005, the supplementary paper for Bortolini 2012, reported death as a combined outcome of "death in mother or baby". Death was not reported in Olaya 2013 and Shi 2009, nor in de Oliveira 2012 Fildes 2015 Koehler 2007 Nikiema 2017 Saleem 2014, and Watt 2009.

Other predetermined outcomes of the review (compliance with advice regarding timing of weaning; cognitive ability; long-term growth; parental stress; infant quality of life; prevalence of atopic conditions; and prevalence of food neophobia) were not reported in any of the included studies.

Two studies did not report any of the predetermined outcome measures investigated in this review (Fildes 2015; Koehler 2007).
Fildes 2015 found that nutrition education did not have an effect on intake of vegetables during weaning. Koehler 2007 showed that nutrition counselling, especially telephone counselling over written information, may improve the dietary habits of infants in the first year of life as assessed by dietary scores.

\section{Excluded studies}

Most of the studies set in high-income countries and those that aimed to investigate the effectiveness of nutrition education in reducing risk of childhood overweight and obesity were ineligible for inclusion in this review and were excluded. The intervention in Cupples 2010 was peer-to-peer mentoring, and nutrition education was not defined. Daniels 2013 and Daniels 2015 describe results of the Australian NOURISH RCT, wherein mothers were randomised to usual care versus two six-session interactive group education modules that provided guidance on early feeding practices. However, this study included healthy infants at greater than 35 weeks' gestation (i.e. some preterm infants would have been included). Participants were four months old at baseline. Daniels 2013 reported weight and weight $z$ score, length and length $z$ score, and body mass index (BMI) and BMI z score at 18 months from baseline (i.e. 22 months of age). Daniels 2015 reported outcomes at 3.5 years and at five years, showing no statistically significant differences between groups for any anthropometric outcomes.

Gross 2016, an RCT conducted among Hispanic/Latina women in New York City, in the USA, included a small number of preterm infants (5 of 266 in the control group and 10 of 263 in the intervention group) and reported outcomes at three months of age only. The intervention was aimed at breastfeeding counselling - not at complementary feeding.

Outcomes in Jonsdottir 2012 in Iceland (serum ferritin and other laboratory indices at six months of age) were not suitable for inclusion in the review.

Krebs 2006 and Krebs 2013 in the USA (meat and fortified cereals); Makrides 2002 in Australia (egg yolks); and Paul 2010 in the USA (education about hunger cues, satiety, and infant sleep) provided interventions that did not consist of nutrition education.

A brief description of each study and reasons for exclusion for all excluded studies are described in the Characteristics of excluded studies table.

\section{Risk of bias in included studies}

The included studies were of variable quality (Figure 2 and Figure 3). 
Figure 2. Risk of bias summary: review authors' judgements about each risk of bias item for each included study.

Bhandari 2004

Bortolini 2012

de Oliveira 2012

Ferreira 2019

Fildes 2015

Koehler 2007

Morandi 2019

Muhoozi 2018

Murthy 2019

Nair 2017

Nikiema 2017

Olaya 2013

Palacios 2019

Penny 2005

Rafieya-Kopaei 2019

Roy 2007

Saleem 2014

Shi 2009

Vazir 2013

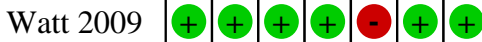
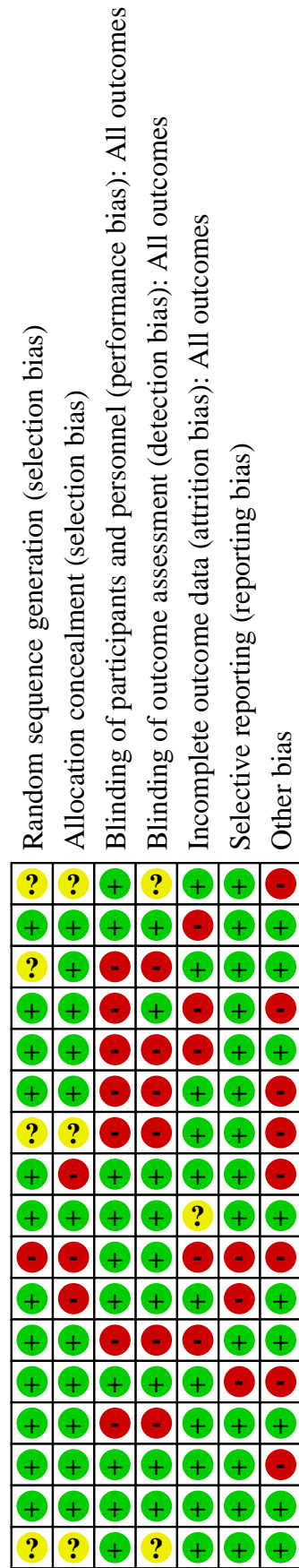

$+$

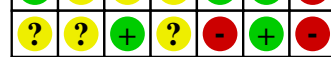

\begin{tabular}{llllllll}
\hline+ & + & + & + & + & + & + \\
\hline
\end{tabular} 
Figure 3. Risk of bias graph: review authors' judgements about each risk of bias item presented as percentages across all included studies.

$\begin{array}{r}\text { Random sequence generation (selection bias) } \\ \text { Allocation concealment (selection bias) } \\ \text { Blinding of participants and personnel (performance bias): All outcomes } \\ \text { Blinding of outcome assessment (detection bias): All outcomes } \\ \text { Incomplete outcome data (attrition bias): All outcomes } \\ \text { Selective reporting (reporting bias) } \\ \text { Other bias } \\ \hline \text { Low risk of bias }\end{array}$

\section{Allocation}

All studies except Murthy 2019 stated that treatment was allocated randomly. However, methods used to generate the random sequence were not specified in Bhadari 2001; Bortolini 2012; Koehler 2007; Roy 2007, or Shi 2009. Similarly, allocation concealment was not mentioned in four of these reports (Bhadari 2001; Koehler 2007; Roy 2007; Shi 2009), nor in Saleem 2014. Risk of bias for allocation concealment was high in Morandi 2019 and Nair 2017, as allocation was not concealed.

\section{Blinding}

Although most outcome measures for this study such as anthropometric and laboratory measures are unlikely to be affected by blinding, some such as reporting of exclusive breastfeeding may be influenced by knowledge of treatment allocation. Blinding of participants and personnel is not feasible with an educational intervention, although Penny 2005 and Roy 2007 stated that "families were not told whether they were in the intervention or control group". Hence, bias may be introduced in studies that looked at exclusive breastfeeding rates or infant diet based on maternal report (Bortolini 2012; de Oliveira 2012; Ferreira 2019; Fildes 2015; Koehler 2007; Nikiema 2017; Palacios 2019). Blinding of participants and personnel was not reported in Saleem 2014.

Outcome assessors were reported to be blinded in Bhandari 2004; de Oliveira 2012; Nair 2017; Penny 2005; Vazir 2013, and Watt 2009; no information was available for Bhadari 2001; Roy 2007; Saleem 2014, or Shi 2009. Olaya 2013 stated that laboratory staff were blinded. Although Bortolini 2012 mentioned blinding of study personnel, the other report of the same study (Vitolo 2005) stated that study personnel were not blinded. Nikiema 2017 and Fildes 2015 stated that outcome assessors were not blinded to the intervention. In Koehler 2007, outcome assessment relied on recall of the infant's diet by a parent who was not blinded to the allocation.

\section{Incomplete outcome data}

Five studies reported attrition of $20 \%$ and above with an imbalance of the attrition rate between intervention and control groups (Bhandari 2004; de Oliveira 2012; Ferreira 2019; Murthy 2019; Shi 2009). Nikiema 2017 and Watt 2009 found attrition rates above $30 \%$, with no reason for attrition reported for Nikiema 2017. However,
Nikiema 2017 reported no difference in demographics between intervention and control groups among patients lost to follow-up. Risk of attrition bias was unclear in Muhoozi 2018, as proportionate sampling was used to obtain ten sub-counties (six out of 19 in Kabale, and four out of 14 in Kisoro) that would participate in the study. These researchers used a three-stage procedure to obtain households for the study. Hence, only a sub-sample of the population that received the intervention participated in the study and had outcome measures obtained. However, this is an appropriate method for a large-scale community study,

\section{Selective reporting}

Study protocols were accessible for Bortolini 2012; Nair 2017; Nikiema 2017, and Olaya 2013. Two of these studies had some outcomes relevant for this review that were not presented in the reports included in this study (Nair 2017; Olaya 2013). No anthropometry data were presented in Murthy 2019, although this was one of the study's three main outcome measures. No study protocol is available for the other included studies, but they reported all proposed outcomes.

\section{Other potential sources of bias}

Some potentially important variables, such as gender, growth parameter, dietary intake, literacy, and social economic background, were statistically significantly different at baseline between the two groups in Bhadari 2001; de Oliveira 2012; Morandi 2019; Murthy 2019; Olaya 2013; Penny 2005; Saleem 2014; and Shi 2009. Participants in Fildes 2015 were recruited from a random sub-sample of participants in a larger study. However, It is unclear how the sub-sample of participants was selected, and this may introduce bias to the study. In Koehler 2007, only $37 \%$ and $54 \%$ accessed the telephone hotline and personal telephone counselling, respectively; Olaya 2013 and Shi 2009 received support from companies that may have a commercial interest in the results of these studies.

Growth parameters for Penny 2005 were presented as graphs, and values were calculated using the scales in Adobe Acrobat software. This may account for the high standard deviation in the corresponding analyses seen for Penny 2005. 


\section{Effects of interventions}

See: Summary of findings 1 Nutrition education compared to conventional management in term-born infants in the first year of life

\section{Primary outcomes}

\section{Growth in the first two years of life}

\section{Weight and weight for age}

Data from five studies were available to analyse effects of nutrition education on change in weight between six and 12 months of life (Bhadari 2001; Bhandari 2004; Morandi 2019; Shi 2009; Vazir 2013). Meta-analysis of the four studies in low-income countries demonstrates that nutrition education did not show an effect on the change in weight (mean difference (MD) $0.03 \mathrm{~kg}$, 95\% confidence interval (CI) -0.02 to $0.08 ; P=0.23 ; 4$ studies; 2246 infants; $I^{2}=61 \%$ ) (Analysis 1.1; Bhadari 2001; Bhandari 2004; Shi 2009; Vazir 2013). We rated this as low-certainty evidence due to inconsistency in the direction and magnitude of effects across the study $\left(I^{2}=61 \%\right)$ and methodological limitations of these studies. Morandi 2019 was carried out to address obesity. Hence, it was not included in the meta-analysis (Analysis 1.1), as the intended direction of effect (i.e. change in weight) is opposite that of the previous four studies addressing undernutrition (Bhadari 2001; Bhandari 2004; Shi 2009; Vazir 2013). Morandi 2019 found a reduction in the change in weight between six and 12 months of life in the intervention group as compared to the control group (MD $-0.22,95 \% \mathrm{Cl}-0.34$ to $-0.10 ; \mathrm{P}=$ 0.0002; 1 study; 562 infants).

Six studies reported weight-for-age z score (WAZ) at 12 months (Muhoozi 2018; Olaya 2013; Penny 2005; Roy 2007; Shi 2009; Vazir 2013), and meta-analysis shows that infants in the nutrition education group had higher WAZ at 12 months of age when compared to those in the conventional management group (MD $0.15,95 \% \mathrm{Cl} 0.07$ to $0.22 ; \mathrm{P}<0.0001 ; 6$ studies; 2551 infants; $I^{2}=32 \%$ ) (Analysis 1.4 Figure 4). We downgraded the certainty of evidence to moderate due to limitations in the methods of some of the included studies (Summary of findings 1 ). Four studies reported effects of the intervention on WAZ at 18 months (Nair 2017; Penny 2005; Roy 2007; Shi 2009). Meta-analysis reveals considerable heterogeneity and inconsistency in the magnitude of effects across the study $\left(\mathrm{I}^{2}=\right.$ 92\%) (Analysis 1.5). Hence, meta-analysis results are not reported, as we are very uncertain of these results (Summary of findings 1 ).

Figure 4. Forest plot of comparison: 1 Nutrition education versus conventional management, outcome: 1.4 Weightfor-age $z$ score at 12 months of age.

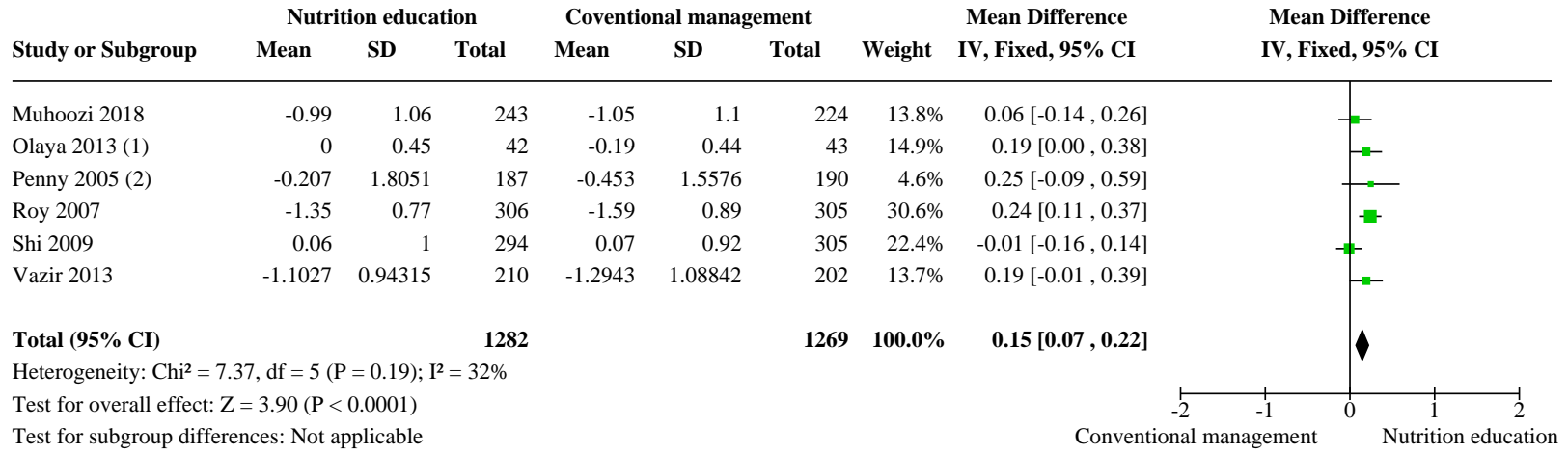

Footnotes

(1) Change from baseline measure (change in WAZ between 6 and 12 months of age) due to significant differences at baseline

(2) WAZ at 12 months was presented in a graph and values were calculated using the scales provided in Adobe Acrobat software. The SE estimated from these measurements w

\section{Height (length) and height for age}

Data from five studies were available to analyse effects of nutrition education on change in height (length) between six and 12 months of life (Bhadari 2001; Bhandari 2004; Morandi 2019; Shi 2009; Vazir 2013). Meta-analysis reveals considerable heterogeneity and inconsistency in the magnitude and direction of effects across the study $\left(I^{2}=76 \%\right.$ ) (Analysis 1.2). Hence, results of the meta-analysis are not reported, as we are very uncertain of these results. Morandi 2019 was not included in the meta-analysis (Analysis 1.2), as the aim of this study was to address obesity. Morandi 2019 found a reduction in the change in weight between six and 12 months of life in the intervention group as compared to the control group (MD $-0.30,95 \% \mathrm{Cl}-0.58$ to $-0.02 ; \mathrm{P}=0.03 ; 1$ study; 562 infants).

Seven studies reported height-for-age z score (HAZ) at 12 months (Muhoozi 2018; Nikiema 2017; Olaya 2013; Penny 2005; Roy 2007; Shi 2009; Vazir 2013), and meta-analysis shows a similar effect: infants in the nutrition education group had higher HAZ at 12 months of age when compared to those in the conventional management group (MD 0.12, 95\% Cl 0.05 to $0.19 ; \mathrm{P}=0.0008$; 7 studies; 3620 infants; $1^{2}=49 \%$ ) (Analysis 1.6; Figure 5). We downgraded the certainty of evidence to moderate due to limitations in the methods of some of the included studies (Summary of findings 1). The effect of the intervention on HAZ was reported at 18 months by five studies (Nair 2017; Nikiema 2017; Penny 2005; Roy 2007; Shi 2009). Meta-analysis shows that at 18 months, infants in the nutrition education group also had higher HAZ when compared to those in the conventional management group (MD 0.16, $95 \% \mathrm{Cl} 0.10$ to $0.22 ; \mathrm{P}<0.00001 ; 5$ studies; 4813 infants) (Analysis 1.7; Figure $6 I^{2}=67 \%$ ). We rated this evidence as low certainty due to substantial inconsistency in the magnitude of effects $\left(I^{2}=67 \%\right)$ and methodological limitations of these studies (Summary of findings 1 ). 
Figure 5. Forest plot of comparison: 1 Nutrition education versus conventional management, outcome: 1.6 Heightfor-age $z$ score at 12 months of age.

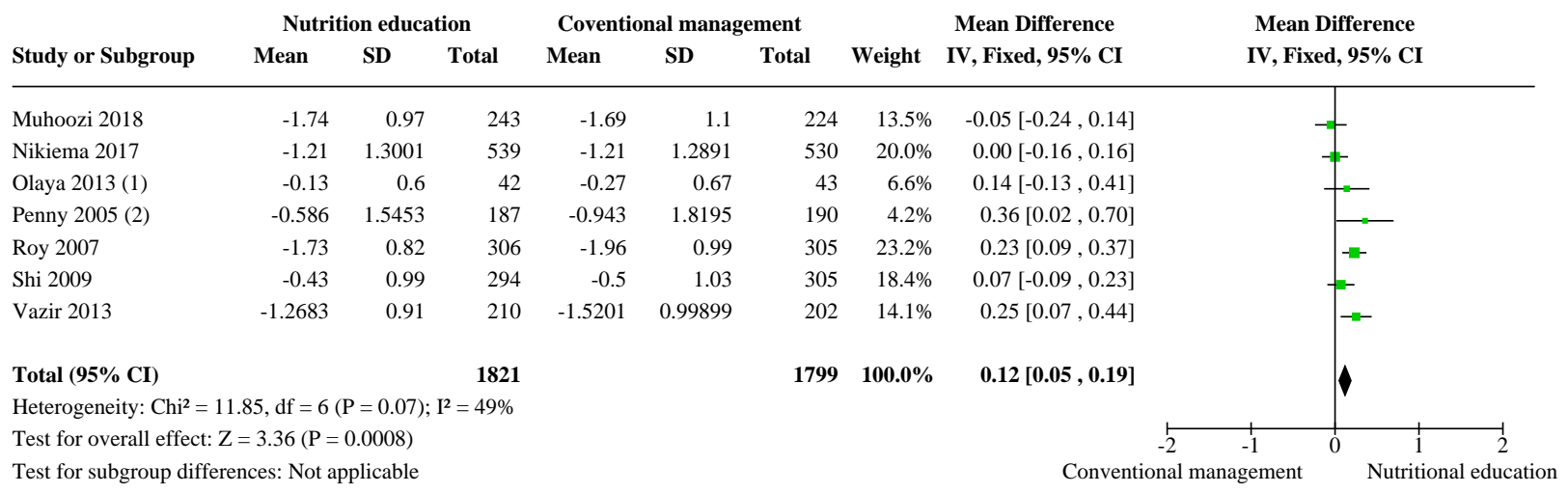

\section{Footnotes}

(1) Change from baseline measure (change in HAZ between 6 and 12 months of age) due to significant differences at baseline

(2) HAZ at 12 months was presented in a graph and values were calculated using the scales provided in Adobe Acrobat software (Adobe Systems Software Ireland Ltd). The stan

Figure 6. Forest plot of comparison: 1 Nutrition education versus conventional management, outcome: 1.7 Heightfor-age $z$ score at 18 months of age.

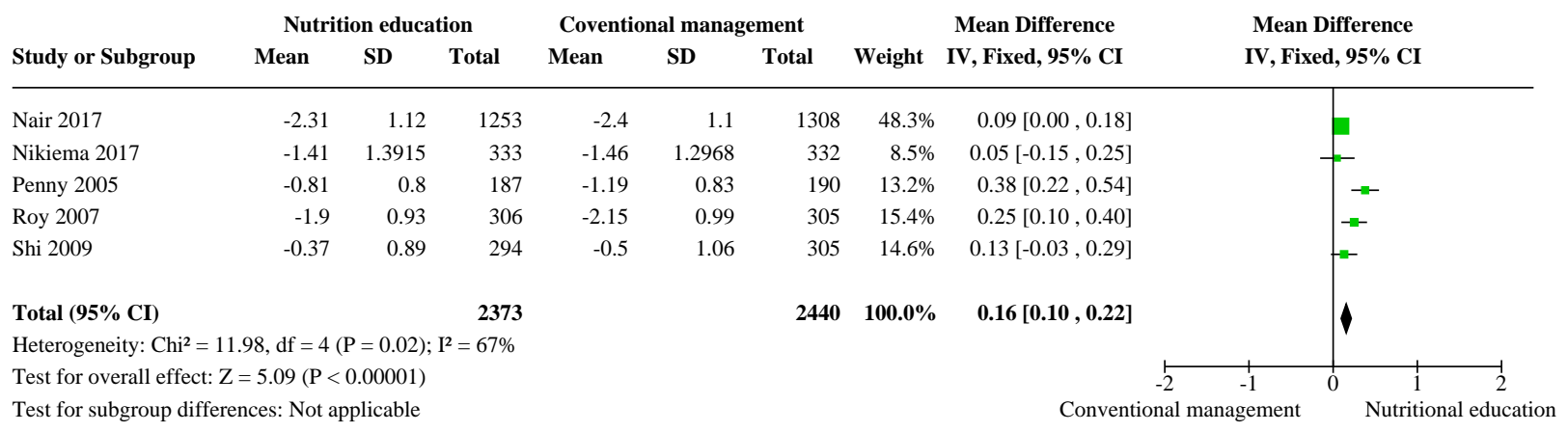

\section{Weight for height}

Five studies reported data on weight-for-height z score (WHZ) at 12 months (Muhoozi 2018; Nikiema 2017; Olaya 2013; Roy 2007; Shi 2009). Meta-analysis demonstrates that nutrition education did not show an effect on WHZ at 12 months (MD 0.05, 95\% $\mathrm{Cl}-0.03$ to $0.13 ; \mathrm{P}=0.24 ; 5$ studies; 2831 infants; $I^{2}=11 \%$ ) (Analysis 1.9). We downgraded the certainty of evidence to low due to limitations in the methods of some of the included studies and imprecision with a wide confidence interval. However, WHZ at 18 months was reported by five studies (Nair 2017; Nikiema 2017; Penny 2005; Roy 2007; Shi 2009). Meta-analysis reveals considerable heterogeneity and inconsistency in the direction and magnitude of effects across these studies $\left(I^{2}=90 \%\right.$ ) (Analysis 1.10). Hence, we have not reported results of the meta-analysis as we are very uncertain of these results (Summary of findings 1 ).

\section{Head circumference}

Muhoozi 2018 reported that nutrition education did not show an effect on the head circumference $\mathrm{z}$ score at 12 months due to imprecision (MD $0.17,95 \% \mathrm{Cl}-0.04$ to $0.38 ; \mathrm{P}=0.11 ; 1$ study; 467 infants).

\section{Other findings not included in the meta-analysis}

Saleem 2014 reported growth parameters and growth parameter $z$ scores, but data were insufficient for inclusion in the metaanalysis. At the end of the study (which occurs 7.5 months after the intervention), infants in the control group were found to be $0.35 \mathrm{~kg}$ lighter and $0.66 \mathrm{~cm}$ shorter in terms of mean weight and height. There was no difference on the proportions of infants, with WAZ more than 2 standard deviations below the World Health Organization (WHO) standard (adjusted odds ratio (ORadj) 0.75, $95 \% \mathrm{Cl} 0.40$ to 1.79). Saleem 2014 found that infants in the control group were more likely to have HAZ more than 2 standard deviations below the WHO standard (ORadj 8.36, 95\% Cl 5.6 to 12.42) at the end of the study.

Murthy 2019 reported that nutrition education did not have an effect on a malnourished infant at one year of age (odds ratio (OR) $0.823,95 \% \mathrm{Cl} 0.590$ to $1.147 ; \mathrm{P}=0.2$ ). However, information was insufficient for inclusion of this study in the meta-analysis.

Rafieya-Kopaei 2019 reported that nutrition education did not have an effect on the absolute value and $z$ score of growth status 
between intervention and control groups (weight, height, and head circumference) at four, six, and eight months of age.

Palacios 2019 and Watt 2009 were nutrition education studies that were carried out in high-income countries to address obesity and were not included in the meta-analysis. Watt 2009 found that nutrition education did not have an effect on the difference in weight and height at 12 and 18 months of age. However, insufficient information was reported to incorporate growth parameter findings into the meta-analysis as growth at six months and $z$ scores were not reported.

Palacios 2019 reported that nutrition education did not have an effect on the differences in weight at the end of the trial (four to six months old), as well as changes in weight between the first visit at zero to two months old and the second visit at four to six months of age.

\section{Neurodevelopmental scores in children 12 months of age or older based on validated assessment tools}

Muhoozi 2018 and Vazir 2013 reported neurodevelopmental scores that were measured by the Bayley Scales of Infant Development (BSD) III and BSD II, respectively, administered at 12 and 15 months of age, respectively. Muhoozi 2018 found improvement in the cognitive BSD III score at 12 months of age (MD 7.50, 95\% Cl 5.21 to 9.79; $\mathrm{P}<0.00001 ; 1$ study; 467 infants), which persisted until 24 months of age (MD 15.60, 95\% Cl 12.11 to 19.09; P < 0.00001; 1 study; 467 infants). However, Vazir 2013 reported that nutrition education did not have an effect on the motor development scores (MD $1.20,95 \% \mathrm{Cl}-0.44$ to $2.84 ; \mathrm{P}=0.15 ; 1$ study; 412 infants) or on the mental development (MD 1.40, $95 \% \mathrm{Cl}-1.34$ to $4.14 ; \mathrm{P}=0.32 ; 1$ study; 412 infants) due to the small sample size. Meta-analysis was not possible as different assessment tools were used at different ages between both studies.

\section{Secondary outcomes}

\section{Duration of exclusive breastfeeding}

Rates of exclusive breastfeeding at six months of age were reported by six studies (Bhandari 2004; Bortolini 2012; Nair 2017; Nikiema 2017; Palacios 2019; Rafieya-Kopaei 2019). Meta-analysis from three studies reveals considerable heterogeneity and inconsistency in the direction of effects across studies $\left(I^{2}=83 \%\right.$ ) (Analysis 1.14) (Bhandari 2004; Bortolini 2012; Nair 2017). Hence, meta-analysis results are not reported, as we are very uncertain of these results (Summary of findings 1).

\section{Other findings not included in meta-analysis}

\section{Exclusive breastfeeding at six months}

Rafieya-Kopaei 2019 reported that the frequency of exclusive breastfeeding at six months was significantly higher in one of the intervention groups (loss-framed) $(P=0.03)$, but the number of exclusively breastfeeding infants and the measure of effects were not reported.

In Palacios 2019, there were only six babies who were six months of age at final follow-up - all in the intervention group. Only one of the six babies was exclusively breastfeeding at six months of age.

Although Nikiema 2017 found that nutrition education improved exclusive breastfeeding rates at six months of age (risk ratio (RR) $1.28,95 \% \mathrm{Cl} 1.20$ to $1.37 ; \mathrm{P}=0.020 ; 3514$ visits), this has to be interpreted with caution as the result was reported for the proportion of completed questionnaires for all follow-up visits (3514 visits) rather than for the number of infants (2253 infants).

\section{Exclusive breastfeeding at three months}

Morandi 2019 reported that nutrition education did not have an effect on exclusive breastfeeding at three months of age due to imprecision (odds ratio (OR) $1.34,95 \% \mathrm{Cl} 0.96$ to $1.88 ; \mathrm{P}=0.08 ; 562$ infants).

\section{Other breastfeeding measures}

de Oliveira 2012 found that mothers in the intervention group exclusively breastfed longer (median $153,95 \% \mathrm{Cl} 114.6$ to 191.4 days) than those in the control group (median 95, 95\% Cl 78.7 to 111.3 days) $(P=0.002)$. Data for exclusive breastfeeding at six months were not reported by de Oliveira 2012. Watt 2009 reported that nutrition education did not have an effect on the percentage of infants exclusive breastfeeding at four months of age (RR 0.9, 95\% $\mathrm{Cl} 0.7$ to 1.3$)$.

Ferreira 2019 and Murthy 2019 reported no effects of nutrition education on infants receiving any breastfeeding at six months of age (RR $1.03,95 \% \mathrm{Cl} 0.95$ to 1.11 ; OR $0.82,95 \% \mathrm{Cl} 0.48$ to 1.4 , respectively).

\section{Compliance with advice regarding the timing of weaning}

This outcome was not reported in any of the included studies.

\section{Cognitive ability in children at five, six, or seven years of age based on validated assessment tools such as the Weschler Intelligence Scale for Children (Wechsler 1974) and school examinations}

This outcome was not reported in any of the included studies.

Long-term growth: weight, height, skinfold thickness, or body mass index at five, six, or seven years of age

Only Olaya 2013 reported long-term growth at six years. These researchers reported that nutrition education did not have an effect on the change in height $\mathrm{z}$ score (MD $-0.22,95 \% \mathrm{Cl}-0.60$ to $0.16 ; 50$ infants) and on body mass index (BMI) z score (MD $-0.24,95 \% \mathrm{Cl}$ -0.75 to $0.27 ; 50$ infants) at six years of age, respectively. However, this study did show that nutrition education led to reduction in HAZ (MD $-0.75,95 \% \mathrm{Cl}-1.25$ to $-0.25 ; 50$ infants) at six years of life. The reason for this is unclear, and these results should be interpreted with caution due to the very small sample size.

\section{Serum ferritin (<12 microg/L) and haemoglobin ( $<110 \mathrm{~g} / \mathrm{L}$ ) levels in children six months of age and older (WHO 2011)}

Two studies reported anaemia (serum haemoglobin levels $<110$ $\mathrm{g} / \mathrm{L})$ at 12 months of age. Meta-analysis reveals that nutrition education did not have an effect on this outcome (Analysis 1.12) (RR 1.16, 95\% Cl 0.96 to $1.39 ; \mathrm{P}=0.12 ; 2$ studies; 585 infants; $I^{2}$ $=67 \%$ ). This evidence is of low certainty due to inconsistency in the direction and magnitude of effects, substantial heterogeneity across studies $\left(1^{2}=67 \%\right)$, small sample size, and methodological limitations of studies. Only one study reported iron deficiency as measured by serum ferritin levels $<12$ micrograms/L (Olaya 2013). This study demonstrated that nutrition education did not have an effect on this outcome due to imprecision (RR $0.92,95 \% \mathrm{Cl} 0.42$ to 2.04; $\mathrm{P}=0.84 ; 1$ study; 85 infants). 
Parental stress when the child is six months of age or older, measured by validated assessment tools such as the Parenting Stress Index (Grotevant 1989)

These outcomes were not reported in any of the included studies.

Infant quality of life when the child is six months of age or older measured by the Infant and Toddler Quality of Life Questionnaire (ITQOL) (Bowling 2004)

This outcome was not reported in any of the included studies.

\section{Prevalence of atopic conditions in childhood}

This outcome was not reported in any of the included studies.

\section{Prevalence of food neophobia or 'picky/fussy eating'}

This outcome was not reported in any of the included studies.

\section{Death before one year of age}

Four studies provided data for death by one year of age (Bhadari 2001; Nair 2017; Roy 2007; Vazir 2013). Meta-analysis shows that nutrition education did not have an effect on the risk of dying by one year of age (RR $0.69,95 \% \mathrm{Cl} 0.44$ to 1.08 ; 4 studies; 4234 infants; $I^{2}=0 \%$ ) (Analysis 1.13 Figure 7 ). The certainty of evidence for this finding is moderate due to methodological limitations of these studies (Summary of findings 1 ).

Figure 7. Forest plot of comparison: 1 Nutrition education versus conventional management, outcome: 1.13 Death before 1 year of age.

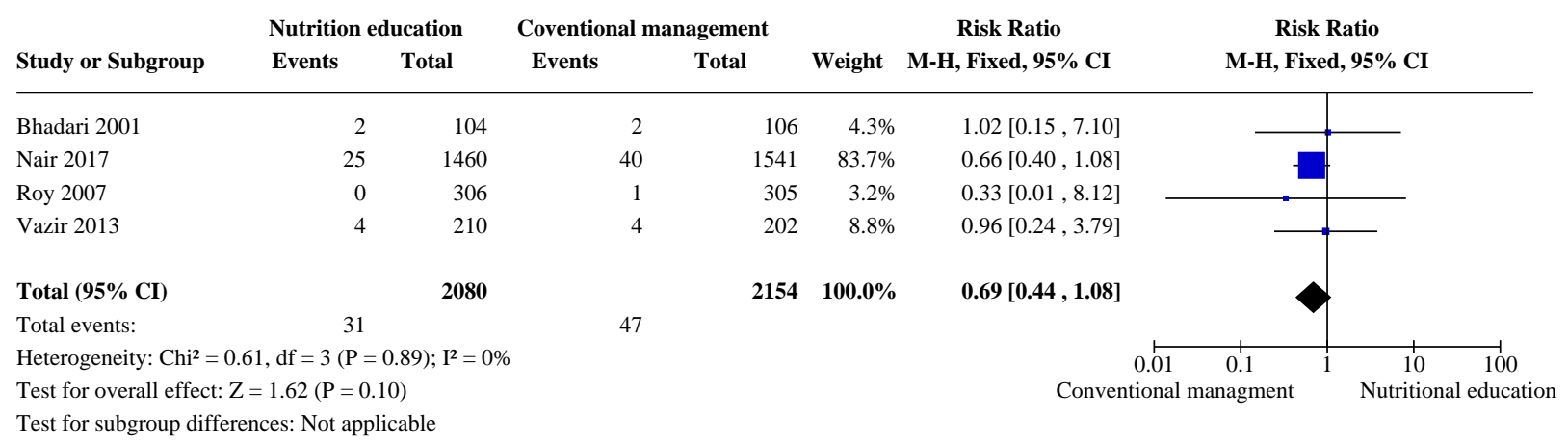

\section{Subgroup analyses \\ A priori subgroup analyses}

High- versus low- and moderate-income countries

Our a priori subgroup analysis was done to compare studies conducted in high- versus low- and moderate-income countries. However, for various reasons that are described in the Characteristics of excluded studies table, no studies from a highincome country were eligible for inclusion in meta-analyses.

\section{Growth in the first two years of life}

Three studies carried out in high-income countries reported this outcome with conflicting results (Morandi 2019; Palacios 2019; Watt 2009). Information from all three studies was insufficient for inclusion in the meta-analysis.

Palacios 2019 and Watt 2009 reported that nutrition education did not have an effect on the differences in growth parameters at six months of age (Palacios 2019), as well as at 12 and 18 months of age (Watt 2009),. However, Morandi 2019 found a reduction in changes in weight and height between six and 12 months of life in the intervention group as compared to the control group (MD - 0.22 , $95 \% \mathrm{Cl}-0.35$ to $-0.09 ; \mathrm{P}=0.0007 ; \mathrm{MD}-0.30,95 \% \mathrm{Cl}-0.58$ to $-0.02 ; \mathrm{P}=$ 0.03 ; 1 study; 562 infants, respectively).

\section{Breastfeeding}

Similarly, three studies conducted in high-income countries reported breastfeeding outcomes with conflicting results (Morandi 2019; Palacios 2019; Watt 2009). Information was insufficient for inclusion in the meta-analysis.
Morandi 2019 and Watt 2009 reported that nutrition education did not have an effect on the percentage of infants exclusively breastfeeding at three and four months of age, respectively. In Palacios 2019, there were only six babies who were six months of age at final follow-up. All were in the intervention group, and only one of the six babies was exclusively breastfeeding at six months of age.

\section{A posteriori subgroup analyses}

Following our review, we noted that there were differences in how the studies were carried out. Hence, we performed further subgroup analyses to explore these differences further.

\section{Age of infant when intervention was started}

We split the studies into three groups in terms of when nutrition education was given, ranging from antenatally (Nair 2017; Nikiema 2017), during the first six months of life when weaning is normally commenced (Bhadari 2001; Bhandari 2004; Bortolini 2012; Olaya 2013; Penny 2005; Shi 2009; Vazir 2013), and after six months of age (Muhoozi 2018; Roy 2007). Subgroup analyses for this aspect were possible only for the following analyses.

\section{Weight for age}

For studies in which nutrition education was carried out during the first six months of life, infants in the nutrition education group had higher WAZ at 12 months (MD $0.11,95 \% \mathrm{Cl} 0.02$ to $0.21 ; \mathrm{P}=0.02 ; 4$ studies; 1473 infants; $I^{2}=30 \%$ ) and at 18 months (MD $0.28,95 \% \mathrm{Cl}$ 0.17 to $0.39 ; P<0.0001 ; 2$ studies; 976 infants; $\left.I^{2}=0 \%\right)$. Findings at 12 months of age were similar to initial analyses (Analysis 1.4, Figure 4). Analysing the WAZ at 18 months by age of the infant when the 
intervention was carried out reduced heterogeneity of the metaanalysis (Analysis 1.5 Figure 8).

Figure 8. Forest plot of comparison: 1 Nutrition education versus conventional management, outcome: 1.5 Weightfor-age $z$ score at 18 months of age.

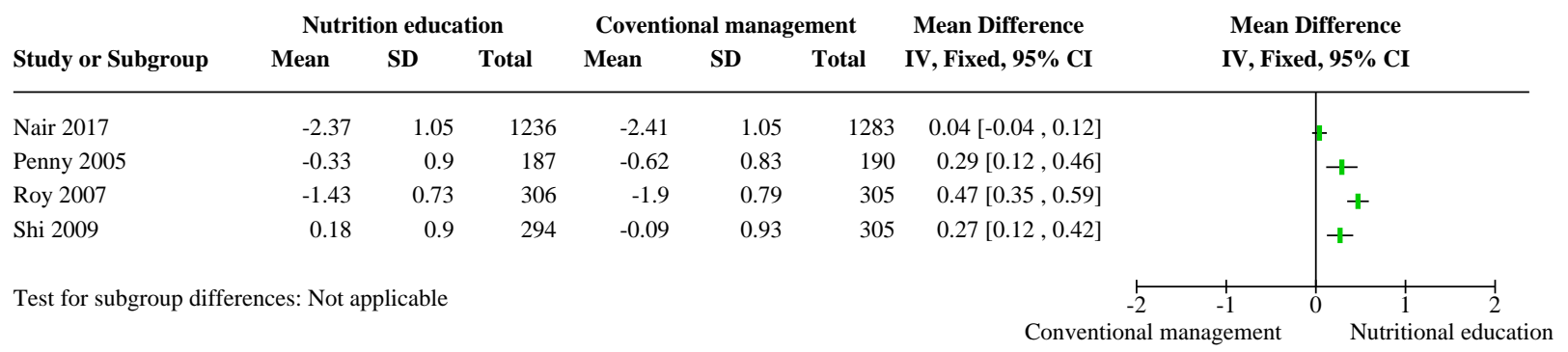

Similar findings were found when analyses included studies in which the intervention was carried out after the first six months of life with higher WAZ at 12 months (MD $0.18,95 \% \mathrm{Cl} 0.07$ to $0.29 ; \mathrm{P}=$ $0.001 ; 2$ studies; 1078 infants; $\left.I^{2}=55 \%\right)$.

\section{Height for age}

For studies in which nutrition education was carried out during the first six months of life, infants in the nutrition education group had higher HAZ at 12 months (MD $0.17,95 \% \mathrm{Cl} 0.06$ to $0.27 ; \mathrm{P}=0.002 ; 4$ studies; 1473 infants; $I^{2}=12 \%$ ) and heterogeneity at 18 months was considerable $\left(I^{2}=79 \%\right)$. These findings were similar to those of the initial analyses (Analysis 1.6; Figure 5: Analysis 1.7 Figure 6).

For the two studies in which the intervention was carried out after the first six months of life, meta-analysis reveals considerable heterogeneity and inconsistency in the magnitude of effects across studies $\left(I^{2}=81 \%\right)$.

For the two studies in which the intervention was carried out antenatally, infants in the intervention group had higher HAZ at 18 months, which barely achieved statistical significance (MD 0.08 , $95 \% \mathrm{Cl} 0$ to $0.16 ; \mathrm{P}=0.04 ; 2$ studies; 3226 infants; $I^{2}=0 \%$ ).

\section{Weight for height}

For studies in which nutrition education was carried out during the first six months of life, meta-analyses revealed that nutrition education did not have an effect on the WHZ at 12 months (MD $-0.03,95 \% \mathrm{Cl}-0.18$ to $0.12 ; \mathrm{P}=0.34 ; 2$ studies; 684 infants; $\mathrm{I}^{2}=0 \%$, but infants in the intervention group had higher WHZ at 18 months (MD 0.20, 95\% Cl 0.09 to $0.32 ; \mathrm{P}=0.0007 ; 2$ studies; 976 infants; $I^{2}$ $=64 \%)$.

For the two studies in which the intervention was carried out after the first six months of life, the intervention group had higher WHZ at 12 months (MD $0.14,95 \% \mathrm{Cl} 0.01$ to $0.26 ; \mathrm{P}=0.03 ; 2$ studies; 1078 infants; $\left.\left.\right|^{2}=0 \%\right)$.

For the two studies in which the intervention was carried out antenatally, meta-analyses revealed that nutrition education did not have an effect on the $\mathrm{WHZ}$ at 18 months (MD 0.03, 95\% Cl -0.04 to $0.10 ; P=0.42 ; 2$ studies; 3175 infants; $\left.\left.\right|^{2}=64 \%\right)$.

Although conclusions drawn from these analyses were similar to those of the initial analyses (Analysis 1.9; Analysis 1.10), worth noting is the change in direction of effects on the WHZ at 12 months for studies whereby the nutrition education was done in the first six months of life, as well as the lack of statistically significant effects in the antenatal studies that reported WHZ at 18 months. This may indicate a potential impact of timing of delivery of the intervention on WHZ.

\section{Exclusive breastfeeding at six months}

Meta-analysis of the two studies in which nutrition education was carried out during the first six months of life reveals considerable heterogeneity in effects of nutrition education on exclusive breastfeeding rates at six months $\left(1^{2}=92 \%\right)$, which was similar to that in the initial analysis (Analysis 1.14; Figure 9).

Figure 9. Forest plot of comparison: 1 Nutrition education versus conventional management, outcome: 1.14 Exclusive breastfeeding at 6 months of age.

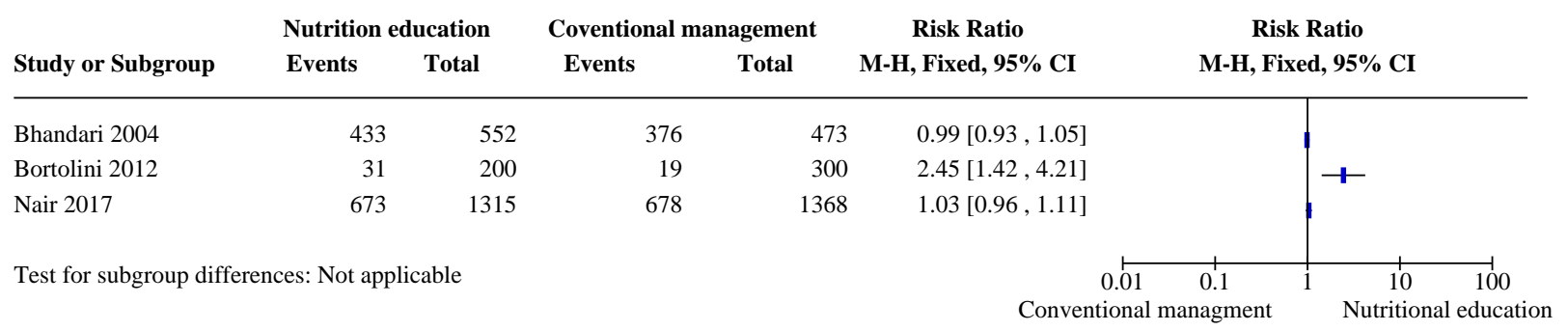




\section{Death before one year of age}

Meta-analysis of the two studies in which nutrition education was carried out during the first six months of life reveals that nutrition education did not have an effect on the risk of dying before one year of age due to imprecision ( $\mathrm{RR} 0.98,95 \% \mathrm{Cl} 0.32$ to $3.01 ; \mathrm{P}=0.97 ; 2$ studies; 622 infants; $\left.I^{2}=0 \%\right)$, which was similar to that in the initial analysis (Analysis 1.13 Figure 7 ).

\section{Duration of intervention}

We divided the studies into two groups, in which nutrition education was delivered for 12 months (Muhoozi 2018; Bhadari 2001; Bhandari 2004; Bortolini 2012; Olaya 2013; Roy 2007; Shi 2009), or nutrition education was delivered for longer than 12 months (Nair 2017; Nikiema 2017; Penny 2005; Vazir 2013). Subgroup analyses for this aspect were possible only for the following analyses.

\section{Weight for age}

For studies in which nutrition education was carried out for 12 months, meta-analysis did not show an effect on the change in weight from six to 12 months of age due to imprecision and substantial heterogeneity (MD $0.03,95 \% \mathrm{Cl}-0.03$ to $0.08 ; \mathrm{P}=0.35$; 3 studies; 1834 infants; $\left.\right|^{2}=74 \%$ ), but infants in the nutrition education group had higher WAZ at 12 months (MD 0.13, 95\% $\mathrm{Cl} 0.05$ to $0.21 ; \mathrm{P}=0.001 ; 4$ studies; 1762 infants; $\left.\mathrm{I}^{2}=55 \%\right)$ and heterogeneity at 18 months was considerable $\left(1^{2}=77 \%\right)$.

For studies in which nutrition education was carried out for longer than 12 months, infants in the nutrition education group had higher WAZ at 12 months (MD $0.21,95 \% \mathrm{Cl} 0.03$ to $0.38 ; \mathrm{P}=0.02 ; 2$ studies; 789 infants; $I^{2}=0 \%$ ) and heterogeneity at 18 months was considerable $\left(I^{2}=84 \%\right)$. These findings were similar to those of the initial analyses (Analysis 1.4, Figure 4: Analysis 1.5 Figure 8).

\section{Height for age}

For studies in which nutrition education was carried out for 12 months, infants in the nutrition education group showed a greater increase in height from six to 12 months (MD $0.21,95 \% \mathrm{Cl} 0.08$ to $0.34 ; \mathrm{P}=0.001 ; 3$ studies; 1834 infants; $\mathrm{I}^{2}=76 \%$ ) and in $\mathrm{HAZ}$ at 12 months (MD $0.11,95 \% \mathrm{Cl} 0.02$ to $0.20 ; \mathrm{P}=0.001 ; 4$ studies; 1762 infants; $\mathrm{I}^{2}=46 \%$ ) and at 18 months (MD $0.19,95 \% \mathrm{Cl} 0.08$ to $0.3 ; \mathrm{P}=$ $0.0006 ; 2$ studies; 1210 infants; $\left.I^{2}=14 \%\right)$.

For studies in which nutrition education was carried out for longer than 12 months, infants in the nutrition education group had higher $\mathrm{HAZ}$ at 12 months (MD $0.13,95 \% \mathrm{Cl} 0.02$ to $0.24 ; \mathrm{P}=0.02 ; 3$ studies; 1858 infants; $\left.\right|^{2}=67 \%$ ) and heterogeneity at 18 months was considerable $\left(I^{2}=80 \%\right)$. These findings were similar to those of the initial analyses (Analysis 1.6; Figure 5: Analysis 1.7 Figure 6).

\section{Weight for height}

For studies in which nutrition education was carried out for 12 months, meta-analyses reveal that nutrition education did not have an effect on the WHZ at 12 months (MD $0.07,95 \% \mathrm{Cl}-0.03$ to 0.17 ; $\mathrm{P}=$ $0.27 ; 3$ studies; 1295 infants; $\left.\right|^{2}=23 \%$ ) but infants in the intervention group had higher WHZ at 18 months (MD $0.41,95 \% \mathrm{Cl} 0.31$ to 0.52 ; $\mathrm{P}<0.0001 ; 2$ studies; 1210 infants; $\left.\left.\right|^{2}=69 \%\right)$.

For studies in which nutrition education was carried out for longer than 12 months, meta-analyses reveal that nutrition education did not have an effect on the WHZ at 18 months (MD 0.04, 95\% Cl-0.03 to $0.11 ; P=0.23 ; 3$ studies; 3552 infants; $\left.I^{2}=40 \%\right)$. The conclusions from these analyses are similar to those of the initial analyses (Analysis 1.9; Analysis 1.10).

\section{Exclusive breastfeeding at six months}

Meta-analysis of the two studies in which nutrition education was carried out for 12 months show considerable heterogeneity in effects of nutrition education on exclusive breastfeeding rates at six months $\left(I^{2}=92 \%\right)$, which is similar to findings of the initial analysis (Analysis 1.14; Figure 9).

\section{Death before one year of age}

Meta-analysis of the two studies in which nutrition education was carried out for 12 months shows that nutrition education did not have an effect on the risk of dying before one year of age due to imprecision (RR $0.72,95 \% \mathrm{Cl} 0.14$ to $3.62 ; \mathrm{P}=0.69 ; 2$ studies; 821 infants; $\left.\left.\right|^{2}=0 \%\right)$. For studies carried out for longer than 12 months, similar findings were found $(\mathrm{RR} 0.69,95 \% \mathrm{Cl} 0.43$ to $1.11 ; \mathrm{P}=0.12 ; 2$ studies; 3413 infants; $\left.I^{2}=0 \%\right)$. These findings are similar to those of the initial analysis (Analysis 1.13 Figure 7).

\section{Delivery of the intervention}

We decided to investigate the impact of how nutrition education was delivered in terms of the setting (one-to-one session during a home or clinic visit; group session; or combination of group and one-to-one), as well as the person delivering the nutrition education (trained professional versus community worker).

\section{Setting}

\section{Weight for age}

For studies in which nutrition education was carried out in oneto-one settings, meta-analysis found that nutrition education did not have an effect on the change in weight from six to 12 months (MD $0.04,95 \% \mathrm{Cl}-0.02$ to $0.11 ; \mathrm{P}=0.19 ; 2$ studies; 1437 infants; $\mathrm{I}^{2}=$ $0 \%$ ) but infants in the nutrition education group had higher WAZ at 12 months (MD 0.20, 95\% Cl 0.07 to $0.33 ; \mathrm{P}=0.002 ; 3$ studies; 874 infants; $\left.\left.\right|^{2}=0 \%\right)$.

Similar findings were found upon analysis of studies in which the intervention was carried out in a group setting with WAZ at 12 months (MD 0.18, 95\% Cl 0.07 to $0.29 ; \mathrm{P}=0.001 ; 2$ studies; 1078 infants; $\left.\right|^{2}=55 \%$ ).

For studies in which nutrition education was carried out in both one-to-one and group settings, meta-analysis shows considerable heterogeneity for WAZ at 18 months $\left(I^{2}=86 \%\right)$. These findings were similar to those of the initial analyses (Analysis 1.4; Figure 4: Analysis 1.5; Figure 8).

\section{Height for age}

For studies in which nutrition education was carried out in one-toone settings, considerable heterogeneity was evident in the effects of nutrition education on change in height from six to 12 months $\left(I^{2}=78 \%\right)$ and in $\mathrm{HAZ}$ at 18 months $\left(1^{2}=84 \%\right)$, but infants in the nutrition education group had higher HAZ at 12 months (MD 0.13 , $95 \% \mathrm{Cl} 0.03$ to $0.24 ; \mathrm{P}=0.001 ; 4$ studies; 1943 infants; $\left.I^{2}=51 \%\right)$.

For the two studies in which the intervention was delivered in a group setting, meta-analysis reveals considerable heterogeneity 
and inconsistency in the magnitude of effects across studies $\left(I^{2}=\right.$ $81 \%)$.

For studies in which nutrition education was carried out in both one-to-one and group settings, infants in the nutrition education group had higher HAZ at 18 months (MD $0.10,95 \% \mathrm{Cl} 0.02$ to 0.17 ; P $=0,01 ; 2$ studies; 3160 infants; $\left.I^{2}=0 \%\right)$. These findings were similar to those of the initial analyses (Analysis 1.6; Figure 5: Analysis 1.7 Figure 6).

\section{Weight for height}

For studies in which nutrition education was carried out in one-toone settings, meta-analyses reveal no effect on WHZ at 12 months (MD $0.02,95 \% \mathrm{Cl}-0.11$ to $0.15 ; \mathrm{P}=0.78 ; 2$ studies; 1154 infants; $1^{2}=0 \%$ ) but infants in the intervention group had higher WHZ at 18 months (MD $0.13,95 \% \mathrm{Cl} 0.01$ to $0.25 ; \mathrm{P}=0.03 ; 2$ studies; 1042 infants; $\left.I^{2}=0 \%\right)$.

For the two studies in which intervention was delivered in group settings, the intervention group had higher WHZ at 12 months (MD $0.14,95 \% \mathrm{Cl} 0.01$ to $0.26 ; \mathrm{P}=0.03 ; 2$ studies; 1078 infants; $\mathrm{I}^{2}=0 \%$ ).

For studies in which nutrition education was carried out in both one-to-one and group settings, meta-analyses reveal considerable heterogeneity in effects on $\mathrm{WHZ}$ at 18 months $\left(I^{2}=90 \%\right)$.

\section{Exclusive breastfeeding at six months}

Meta-analysis of the two studies in which nutrition education was delivered in a one-to-one setting shows considerable heterogeneity in effects of nutrition education on exclusive breastfeeding rates at six months $\left(I^{2}=92 \%\right)$, which was similar to findings of the initial analysis (Analysis 1.14; Figure 9).

\section{Death before one year of age}

Meta-analysis of the two studies in which nutrition education was carried out in a one-to-one setting did not show an effect on the risk of dying before one year of age due to imprecision (RR $0.98,95 \%$ $\mathrm{Cl} 0.33$ to $3.01 ; \mathrm{P}=0.97 ; 2$ studies; 622 infants; $\mathrm{I}^{2}=0 \%$ ), which was similar to findings of the initial analysis (Analysis 1.13 Figure 7).

\section{Person delivering the intervention}

\section{Weight for age}

For studies in which nutrition education was carried out by a trained professional, substantial heterogeneity is evident in the effects of nutrition education on change in weight from six to 12 months $\left(I^{2}=74 \%\right)$ but infants in the nutrition education group had higher WAZ at 12 months (MD 0.14, 95\% $\mathrm{Cl} 0.06$ to 0.22 ; $\mathrm{P}=0.0006$; 5 studies; 2139 infants; $I^{2}=44 \%$ ) and at 18 months (MD 0.37, 95\% $\mathrm{Cl} 0.29$ to $0.45 ; \mathrm{P}<0.0001 ; 3$ studies; 1587 infants; $\left.\mathrm{I}^{2}=62 \%\right)$. These findings were similar to those of initial analyses (Analysis 1.4 Figure 4: Analysis 1.5 Figure 8).

\section{Height for age}

For studies in which nutrition education was carried out by a trained professional, infants in the nutrition education group showed a greater increase in height from six to 12 months (MD 0.21, $95 \% \mathrm{Cl} 0.08$ to $0.34 ; \mathrm{P}=0.001 ; 3$ studies; 1834 infants; $\left.\right|^{2}=76 \%$ ) and in HAZ at 12 months (MD 0.10, 95\% $\mathrm{Cl} 0.02$ to $0.17 ; \mathrm{P}=0.01 ; 6$ studies; 3208 infants; $I^{2}=48 \%$ ) and at 18 months (MD $0.22,95 \% \mathrm{Cl} 0.13$ to
0.30; $\mathrm{P}<0.0001 ; 4$ studies; 2252 infants; $\left.\mathrm{I}^{2}=61 \%\right)$. These findings were similar to those of the initial analyses (Analysis 1.6; Figure 5: Analysis 1.7 Figure 6).

\section{Weight for height}

For studies in which nutrition education was carried out by a professional, considerable heterogeneity is evident for WHZ at 18 months $\left(I^{2}=81 \%\right)$. Conclusions from these analyses were similar to those of the initial analyses (Analysis 1.9; Analysis 1.10).

\section{Exclusive breastfeeding at six months}

Meta-analysis of the two studies in which nutrition education was carried out by a trained professional shows considerable heterogeneity in effects of nutrition education on exclusive breastfeeding rates at six months $\left(1^{2}=92 \%\right)$, which was similar to findings of the initial analysis (Analysis 1.14; Figure 9).

\section{Death before one year of age}

Meta-analysis of the two studies in which nutrition education was carried out by a trained professional did not show an effect on the risk of dying before one year of age (RR $0.72,95 \% \mathrm{Cl} 0.14$ to 3.62; $\mathrm{P}=0.69 ; 2$ studies; 821 infants; $\mathrm{I}^{2}=0 \%$ ). For studies carried out by a community worker, similar findings were found (RR $0.69,95 \% \mathrm{Cl}$ 0.43 to $1.11 ; P=0.12 ; 2$ studies; 3413 infants; $\left.I^{2}=0 \%\right)$. These findings are similar to findings of the initial analysis (Analysis 1.13 Figure 7 ).

\section{Sensitivity analyses}

\section{Unit of analysis issues}

A total of 12 cluster-randomised controlled trials are included in this review (Muhoozi 2018; Bhandari 2004; Ferreira 2019; Morandi 2019; Nair 2017; Nikiema 2017; Penny 2005; Rafieya-Kopaei 2019; Roy 2007; Saleem 2014; Shi 2009; Vazir 2013). Muhoozi 2018 Bhandari 2004 Ferreira 2019 Nair 2017 Nikiema 2017 Penny 2005 Shi 2009, and Vazir 2013 mainly used random-effects analyses to account for the effects of clustering. It is unclear if clustering was taken into account in Morandi 2019 Rafieya-Kopaei 2019 Roy 2007, and Saleem 2014.

We did not use a summary measurement from each cluster and we did not use the cluster as the unit of analysis, as this would have considerably and unnecessarily reduced the power of the studies (Higgins 2019). Instead, we carried out 'approximate analyses' to obtain 'effective sample sizes' (Higgins 2019). The intracluster correlation coefficient (ICC) does vary depending on the geographical area, as well as on the size of clusters used. External estimates of the ICC from similar studies done in developing countries range from 0.01 in Shi 2009 to 0.05 in Handa 2018. Hence, we used the ICC of 0.05 to reduce the unit of analysis error as much as possible by reducing the 'effective sample size' (Table 1).

We carried out repeat analyses for outcome measures involving cluster-randomised trials.

\section{Weight for age}

Meta-analysis still demonstrate that nutrition education did not have an effect on the change in weight from six to 12 months (MD - $0.01,95 \% \mathrm{Cl}-0.09$ to $0.07 ; 4$ studies; $\mathrm{I}^{2}=44 \%$ ) (Analysis 2.1 ). 
However, the direction of effect has changed from that seen in the initial analysis (Analysis 1.1).

Simlar to initial analyses (Analysis 1.4 Figure 4: Analysis 1.5; Figure $8)$, infants in the nutrition education group had higher WAZ at 12 months (MD $0.19,95 \% \mathrm{Cl} 0.10$ to $0.28 ; 6$ studies; $I^{2}=0 \%$ ) (Analysis 2.3) and considerable heterogeneity at 18 months $\left(\mathrm{I}^{2}=\right.$ 86\%) (Analysis 2.4).

\section{Height for age}

After approximate analyses were done to account for the unit of analysis error for the clustering effect, meta-analyses revealed that nutrition education did not have an effect on the change in height from six to 12 months (MD $-0.02,95 \% \mathrm{Cl}-0.20$ to $0.17 ; 4$ studies; $I^{2}=$ 45\%) (Analysis 2.2). Results show a change in both the magnitude and the direction of effect as compared to the initial analyses (Analysis 1.2).

Similar to the initial analyses (Analysis 1.6; Figure 5: Analysis 1.7 Figure 6), infants in the nutrition education group had higher $\mathrm{HAZ}$ at 12 months (MD $0.18,95 \% \mathrm{Cl} 0.08$ to $0.28 ; 7$ studies; $\left.\right|^{2}=0 \%$ ) (Analysis 2.5 ) and at 18 months (MD $0.17,95 \% \mathrm{Cl} 0.08$ to $0.26 ; 5$ studies; $\mathrm{I}^{2}=$ 21\%) (Analysis 2.6).

\section{Weight for height}

Similar to the initial analyses (Analysis 1.9), the meta-analysis still demonstrates that nutrition education did not have an effect on the WHZ at 12 months (MD $0.11,95 \% \mathrm{Cl}-0.02$ to $0.23 ; 5$ studies; $I^{2}=0 \%$ ) (Analysis 2.7). After approximate analyses, there was considerable heterogeneity in the WHZ at 18 months $\left(I^{2}=84 \%\right.$ ) (Analysis 2.8). A change in the magnitude of effect led to the lack of effect seen as compared to the initial analyses (Analysis 1.10).

\section{Death before one year of age}

Similar to the initial analysis (Analysis 1.13 Figure 7), the metaanalysis still demonstrates that nutrition education did not have an effect on the risk of dying before one year of age (RR $0.70,95 \% \mathrm{Cl}$ 0.37 to $1.29 ; 3$ studies; $\left.\right|^{2}=0 \%$ ) (Analysis 2.9).

\section{Exclusive breastfeeding at six months}

Similar to the initial analysis (Analysis 1.14; Figure 9), there was still considerable heterogeneity about effects of nutrition education on exclusive breastfeeding rates at six months $\left(1^{2}=79 \%\right.$ ) (Analysis 2.10).

\section{Heterogeneity assessment}

Seven analyses showed moderate or considerable heterogeneity $\left(I^{2}>50 \%\right.$ ) (Analysis 1.1; Analysis 1.2; Analysis 1.5; Analysis 1.7; Analysis 1.10; Analysis 1.12; Analysis 1.14). After accounting for the clustering effect via approximate analyses, only three analyses showed moderate of considerable heterogeneity (Analysis 2.4; Analysis 2.8; Analysis 2.10). Reasons for this are unclear, and it could not be explained even after subgroup analyses were performed as detailed above.

WAZ (Analysis 1.4; Analysis 2.3) and HAZ (Analysis 1.6; Analysis 2.5) at 12 months, respectively, for Penny 2005 were presented as graphs, and values were calculated via scales in Adobe Acrobat software. This may account for the high standard deviation seen for Penny 2005 in the corresponding analyses (Analysis 1.4; Analysis
1.6; Analysis 2.3; Analysis 2.5). Results remained the same even after Penny 2005 was removed.

\section{DISCUSSION}

\section{Summary of main results}

Low- to moderate-certainty evidence suggests that nutrition education targeted at improving feeding practices related to weaning improves weight and height in the first two years of life. However, these results must be interpreted with caution due to substantial heterogeneity in the results, which may be due in part to differences in study design (cluster versus non-cluster randomised controlled trial (RCT)) and in delivery of nutrition education in terms of timing of initiation, duration, setting (oneto-one, group, or combination of both), and the professional experience required to deliver the nutrition education. Limited data are available to conclude which of these factors plays a bigger role in the effectiveness of nutrition education in improving growth parameters during the first two years of life. Improvement in growth parameters is seen as between 0.12 and 0.16 standard deviation in $z$ scores. This is of unclear clinical significance, as it accounts for a small improvement in weight and height in grams and centimetres, respectively. It is also unclear how this small improvement in growth parameters during the first two years of life impacts longterm growth and health. Further long-term studies are needed to see if this small short-term improvement in growth parameters persists, translating into a bigger difference in growth over the long term.

Besides this, all studies included in the meta-analysis were carried out in low-income countries and reported mean $z$ scores of growth parameters below 0 at baseline, indicating some degree of malnutrition. Hence, these findings could not be extrapolated to obesity/overnutrition or to countries of high income. The impact of nutrition education on long-term growth is unclear, with only one study reporting the outcome measure with mixed results.

We did not find evidence that nutrition education reduces the prevalence of anaemia or iron deficiency anaemia in infants. Two studies included interventions that focused on increasing the intake of iron-rich and/or meat-based weaning foods, but their combined results reveal that nutrition education did not have an effect on anaemia. Most of the studies included interventions that promoted exclusive breastfeeding until six months of age. The effect of nutrition education on exclusive breastfeeding rates at six months remains unclear based on the meta-analysis of current studies. Only two studies investigated effects of nutrition education on neurodevelopmental outcomes and reported no effect on cognitive or motor scores. We did not find any studies that investigated effects of this intervention on long-term, school-age developmental outcomes. Data on death before the first birthday were available from four studies and showed that nutrition education did not have an effect on death in the first year of life. Other secondary outcomes considered in this review (parent and infant quality of life, risk of atopy, food neophobia) were not reported by any of the included studies.

\section{Overall completeness and applicability of evidence}

All studies included in the meta-analyses in this systematic review were based in low- and middle-income countries and used education packages aimed at reducing the burden of 
undernutrition. In high-income countries and increasingly in certain populations in low- and middle-income countries, the target of nutrition education is likely to be the opposite i.e. prevention of overnutrition and amelioration of childhood overweight and obesity. We found several such studies, which were set in countries such as Australia, the USA, and the UK, but their results could not be combined in any meta-analyses due to variations in inclusion criteria and in reported outcomes (see Fildes 2015; Koehler 2007; Morandi 2019; Palacios 2019; Watt 2009 and Excluded studies).

We included studies that provided nutrition education as the only intervention, and we excluded studies that combined education with food supplementation. In addition, we looked at studies in all settings, irrespective of food security in the population. Food security was not described as a potential problem of malnutrition in the included studies, although it is likely that nutrition education alone may not be as effective in settings where food scarcity is an underlying cause of malnutrition.

The World Health Organization defines the problem of the double burden of malnutrition as the coexistence of undernutrition along with overweight and obesity, or diet-related non-communicable diseases (NCDs), within individuals, households, and populations, and across the life course (WHO 2017a), and has identified "doubleduty actions" (i.e. interventions, programmes, and policies that have the ability to simultaneously reduce the risk or burden of both undernutrition and overweight, obesity, or diet-related NCDs) (WHO 2017b). Promotion of appropriate early and complementary feeding in infants is included in the list of potential candidate interventions capable of achieving double duty. This review demonstrates that nutrition education may be an effective tool for improving growth and nutrition (as measured by weight and height in the first two years of life) with evidence of low to moderate certainty due to differences in study design and in the delivery of nutrition education. Evidence is insufficient to conclude which aspect of the delivery of nutrition education plays a bigger role in improving growth parameters. Although the clinical significance of the observed improvement in growth parameters is likely to be small, its impact on long-term growth is unclear. Lack of evidence makes it difficult to decide whether such interventions would be effective in reducing the burden of childhood overweight and obesity or undernutrition in settings where food scarcity is a major problem.

\section{Quality of the evidence}

We used the GRADE approach to assess the certainty of evidence for the following outcomes: weight-for-age z score (WAZ) at 12 months, height-for-age $z$ score (HAZ) at 12 and 18 months, prevalence of anaemia at 12 months of age, and death before one year of age (Summary of findings 1). Evidence from RCTs was mainly of low to moderate certainty at best - downgraded due to risk of bias (attrition bias imbalance in baseline demographics) and unexplained heterogeneity.

\section{Potential biases in the review process}

Our main concern with the review process is the possibility that findings are subject to publication and other reporting biases. We attempted to minimise this threat by screening the reference lists of included trials and related reviews and searching for proceedings of major international conferences to identify trial reports that are not published or in preparation. Manually imputing data from the published graph in Penny 2005 may have introduced a moderate risk of bias. Sensitivity analyses completed by removing the study data of Penny 2005 did not alter the overall findings of this review.

The precision of some of the analyses may be overestimated, as 'approximate analyses' were used to account for clustering, rather than using a summary measurement from each cluster and using the cluster as the unit of analysis. This is because the latter method would unnecessarily reduce the power of the included study. We noted moderate to considerable heterogeneity and inconsistencies in the included studies in some of the analyses, even after clustering effects were accounted for. Subgroup analyses exploring different aspects of delivery of nutrition education were carried out to investigate the heterogeneity.

The wide confidence intervals with large standard deviations for $z$ scores of growth parameters reported in some of the included studies may indicate heterogeneity of weight and height of infants recruited in the study ranging from undernutrition to overnutrition. Hence, this may explain some of the heterogeneity seen in the analyses and the small improvement noted in growth parameters.

\section{Agreements and disagreements with other studies or reviews}

Another recent Cochrane systematic review examined educational interventions for improving primary caregiver complementary feeding practices for children age two years and younger (Arikpo 2018). This extensive review focused on age at introduction of complementary foods, exclusive breastfeeding for four months, and hygiene practices. Review authors also reported on effects of the intervention on growth parameters. They reported on effects of the intervention on duration of breastfeeding and found that combining data from three studies showed a trend towards a higher rate of exclusive breastfeeding for four months or longer in the intervention group (risk ratio (RR) 1.58, 95\% confidence interval (CI) 0.77 to 3.22) compared to the control group. We chose to investigate the duration of breastfeeding as per the World Health Organization (WHO) recommendation (exclusive breastfeeding up to six months of age) and found no effects of the intervention in a meta-analysis of data from three studies. When assessing growth parameters, we did not include absolute values of anthropometric parameters such as weight or height at any time point, as in Arikpo 2018, because the studies were conducted in heterogeneous populations. Arikpo 2018 did not find any effect of the intervention on weight or height at 6,12 , or 18 months of age. Review authors also reported that nutrition education did not have an effect on the outcomes of stunting (height-for-age $z$ score (HAZ) $\leq-2$ standard deviations (SD)), wasting (weight-for-height $z$ score $(W H Z) \leq-2 S D$ ), and underweight (weight-for-age $z$ score (WAZ) $\leq-2 \mathrm{SD}$ ). Growth parameters were the primary outcomes for our review. We did not dichotomise the growth measures but instead analysed them (WAZ, HAZ, and WHZ) as continuous variables. Use of growth parameters as continuous variables rather than as dichotomous variables provides more information and a better overview of the impact of nutrition education on growth. We found that the children of those who received nutrition education had higher HAZ at 18 months of age and higher WAZ and HAZ at 12 months of age. Similar to other reviews, such as Imdad 2011, our analyses demonstrate that significant improvements in growth parameters may be achieved with appropriate nutrition education. However, the clinical significance of the improvement noted in our 
review is small and may explain the findings of Arikpo 2018 that such improvement in growth parameters may not be sufficiently large to bring a statistically significant number of children out of the dichotomous brackets of wasting, stunting, or underweight without a large sample size. The long-term significance of the small improvement in growth parameters seen in our review in the first two years of life is also unclear.

Imdad 2011 is a systematic review of published randomised and quasi-randomised controlled trials conducted to assess the effectiveness of nutritional counselling alone and of providing complementary foods with or without counselling on mean change in weight and height outcomes. In their analyses, which included studies with nutritional counselling as the only intervention, review authors included eight studies and demonstrated that educating mothers about complementary feeding improved weight gain (weighted mean difference 0.30 SD, $95 \% \mathrm{Cl} 0.05$ to 0.54 ) and height gain (weighted mean difference $0.21 \mathrm{SD}, 95 \% \mathrm{Cl} 0.01$ to 0.41 ). These results are in keeping with our findings, although we excluded some of the studies included in these meta-analyses: Guldan 2000 and Kilaru 2005, due to incomplete randomisation, and Santos 2001, as the intervention was delivered to healthcare providers and not directly to families and was not focused on weaning. In addition, both Kilaru 2005 and Santos 2001 reported changes in absolute weight or height only, and hence the outcomes were not suitable for inclusion in this review. In addition to these exclusions, this review is up-to-date with inclusion of studies published since 2011. Similar findings were reported by Dewey 2008, which conducted an extensive review of studies related to a variety of complementary feeding support strategies but did not perform formal metaanalyses of available data.

Lassi 2013 is a systematic review of randomised and nonrandomised trials conducted to assess the effectiveness of education for complementary feeding and of providing complementary foods for the growth and morbidity of children below two years of age in developing countries. Review authors found that education on complementary feeding alone improved HAZ (standard mean difference $0.23,95 \% \mathrm{Cl} 0.09$ to 0.36 ) and WAZ (standard mean difference $0.16,95 \% \mathrm{Cl} 0.05$ to 0.27 ). The impact on height and weight gain was reported to be uncertain. Again, these findings are similar to those reported by our review. However, Lassi 2013 did not specify the age at which growth parameters were measured. Review authors included Guldan 2000, Kilaru 2005, and Santos 2001, which were excluded from our review for the reasons stated previously. Zaman 2008 was not included in our review as the intervention comprised training of healthcare professionals rather than nutrition counselling targeted at families.

We found only four studies that reported exclusive breastfeeding up to six months of age as an outcome. The combined results of three of these studies did not show any effect of nutrition education. McFadden 2017 reviewed 100 trials to examine the effectiveness of different modes of offering supportive interventions to improve breastfeeding rates and included stopping exclusive breastfeeding before six months postpartum as an outcome. Upon combining data from 46 studies including 18,591 women, review authors found that women in the intervention groups were less likely to have stopped exclusive breastfeeding before six months (average RR $0.88,95 \% \mathrm{Cl} 0.85$ to 0.92 ; moderate-certainty evidence). The interventions in these studies were focused on supporting breastfeeding, and many were started during the antenatal period.
Education that is focused more on weaning and is provided later in infancy may not have the same effect in increasing rates of exclusive breastfeeding, and we suspect that this and smaller sample sizes are the reasons why the studies included in our review do not show any effect.

In this review, we have focused on studies with nutrition education as the only intervention and have included only randomised controlled trials and cluster-randomised controlled trials that reported our pre-specified outcomes. We have systematically reviewed studies in both high- and low- and middle-income country settings, as our purpose was to assess the efficacy of nutrition education as a double-duty intervention (WHO 2017b). None of the studies set in high-income countries and no studies that aimed to use nutrition education to target childhood obesity were included in the meta-analyses, as reported outcomes were not in keeping with the outcomes of this review. This highlights the research gap and the need for good quality randomised trials conducted to assess the effectiveness of nutrition education as an instrument to prevent or reduce childhood obesity. These trials should be undertaken in appropriate settings both in high-income settings and in appropriately targeted populations in low- and middleincome countries because there is a subgroup of populations in low- and middle-income countries that is at increasing risk of overnutrition and its concomitant health risks.

\section{AUTHORS' CONCLUSIONS}

\section{Implications for practice}

In 2014, there were over 42 million overweight or obese children and 156 million stunted children worldwide. The WHO has identified double-duty actions that have the potential to reduce the risks or burden of undernutrition and of overweight and obesity, which include actions to optimise early nutrition and promotion of appropriate early and complementary feeding in infants. This review demonstrates that nutrition education delivered to families of infants (between 0 and 12 months of age) may reduce undernutrition as evidenced by low- to moderate-certainty evidence for improvement in weight and height during the first two years of life. Based on the studies reviewed, the clinical significance of the improvement in growth parameters is small and must be interpreted with caution due to inconsistencies among the studies, which may be due in part to differences in study design and in delivery of nutrition education. Limited data at present do not allow us to conclude which of these factors plays a bigger role in the effectiveness of nutrition education in improving growth parameters during the first two years of life. Evidence is insufficient to support that such educational interventions would ameliorate the risks of childhood overnutrition and would prevent overweight and obesity among young children.

Possibly due to the small numbers of available studies and participants, this review also does not provide evidence that nutrition education can improve rates of exclusive breastfeeding or reduce the risk of iron deficiency anaemia in infancy. These results should be interpreted with caution due to the small number of studies included in these analyses and to incomplete reporting of these outcomes. 


\section{Implications for research}

Findings of this review suggest that nutrition education on appropriate weaning/complementary feeding practices in infancy may be an effective tool for reducing the risks of childhood undernutrition, particularly in low- and middle-income countries. Although only a small improvement in growth parameters is seen during the first two years of life, it is unclear whether these improvements may continue into later life, leading to a bigger difference in growth parameters long term. Hence, studies are needed to investigate the impact of early nutrition education on long-term growth. Good quality evidence is insufficient to support the hypothesis that educational interventions could reduce risks of overweight and obesity in children. Randomised controlled trials of nutrition education interventions targeting populations at high risk of overnutrition both in high-income countries and in appropriately selected populations in low- and middle-income countries are required to test the true "double-duty" efficacy of this intervention. Comparison with a parallel group selected by adequate randomisation is crucial for investigating this, as such a trial design will ensure that the study measures effects of the intervention without confounding due to other ongoing health programmes, changes in health or marketing regulations, or natural changes in population demographics. These studies must be conducted in appropriate settings and must include populations in high- and low- and middle-income countries.

It is also important to determine core outcomes for such trials, so that effects of nutrition education on the same clinically relevant outcomes can be studied in different settings. This would allow for future meta-analyses and systematic reviews and would enable comparability between studies. Such outcomes should include some long-term effects such as risk of non-communicable disease in later life and measures of infant and parental quality of life. Systematic reviews and meta-analyses investigating effects of nutrition education on growth must ensure that growth data from studies targeting undernutrition and those addressing childhood obesity are combined into predefined separate analyses, as the intended effects of one group of studies are likely to be opposite the intended effects of the others despite common goals of combating the double burden of malnutrition. Effects on other outcomes such as reduction in anaemia, neurodevelopment, and parent and infant quality of life measures would be amenable to a single metaanalysis each, as interventions would be targeted to achieve the same effect.

Further studies are also warranted to investigate whether appropriately targeted nutrition education can reduce the risk of micronutrient deficiencies such as iron deficiency anaemia.

\section{ACK N O WLEDGEMENTS}

We would like to thank Cochrane Neonatal for help with the literature review. We would also like to thank $\mathrm{Dr}$ Vazir and $\mathrm{Dr}$ Palacios for providing further information regarding their studies.

The methods section of this review is based on a standard template used by Cochrane Neonatal. 


\section{R E F E R E N C E S}

\section{References to studies included in this review}

Bhadari 2001 \{published data only\}

Bhandari N, Bahl R, Nayyar B, Khokhar P, Rohde JE, Bhan MK. Food supplementation with encouragement to feed it to infants from 4 to 12 months of age has a small impact on weight gain. Journal of Nutrition 2001;131(7):1946-51. [DOI: 10.1093/ jn/131.7.1946] [PMID: 11435512]

\section{Bhandari 2004 \{published data only\}}

Bhandari N, Mazumder S, Bahl R, Martines J, Black RE, Bhan MK. An educational intervention to promote appropriate complementary feeding practices and physical growth in infants and young children in rural Haryana, India. Journal of Nutrition 2004;134(9):2342-8. [DOI: 10.1093/jn/131.7.1946] [PMID: 11435512]

\section{Bortolini 2012 \{published data only\}}

* Bortolini GA, Vitolo MR. The impact of systematic dietary counselling during the first year of life on prevalence rates of anemia and iron deficiency at 12-16 months. Jornal de Pediatria 2012;88(1):33-9. [DOI: 10.2223/JPED.2156] [PMID: 22159301]

Costa CS, Campagnolo PD, Lumey LH, Vitolo MR. Effect of maternal dietary counselling during the 1st year of life on glucose profile and insulin resistance at the age of 8 years: a randomised field trial. British Journal of Nutrition 2017;117:134-41.

Louzada ML, Campagnolo PD, Rauber F, Vitolo MR. Longterm effectiveness of maternal dietary counseling in a lowincome population: a randomized field trial. Pediatrics 2012;129(6):e1477-84

Vitolo MR, Bortolini GA, Feldens CA, Drachler ML. [Impacts of the 10 Steps to Healthy Feeding in Infants: a randomized field trial]. Cad Saude Publica 2005;21(5):1448-57.

\section{de Oliveira 2012 \{published data only\}}

de Oliveira LD, Giugliani ER, Santo LC, Nunes LM. Impact of a strategy to prevent the introduction of non-breast milk and complementary foods during the first 6 months of life: a randomized clinical trial with adolescent mothers and grandmothers. Early Human Development 2012;88(6):357-61. [DOI: 10.1016/j.earlhumdev.2011.09.010] [PMID: 22001312]

\section{Ferreira 2019 \{published data only\}}

Ferreira VR, Sangalli CN, Leffa PS, Rauber F, Vitolo MR. The impact of a primary health care intervention on infant feeding practices: a cluster randomised controlled trial in Brazil. Journal of Human Nutrition and Dietetics 2019;32(1):21-30. [DOI: 10.1111/jhn.12595] [PMID: 30182376]

\section{Fildes 2015 \{published data only\}}

Fildes A, Lopes C, Moreira P, Moschonis G, Oliveira A, Mavrogianni $C$, et al. An exploratory trial of parental advice for increasing vegetable acceptance in infancy. British Journal of Nutrition 2015;114(2):328-36. [DOI: 10.1017/ S0007114515001695] [PMID: 26063588]
Koehler 2007 \{published data only\}

Koehler S, Sichert-Hellert W, Kersting M. Measuring the effects of nutritional counseling on total infant diet in a randomized controlled intervention trial. Journal of Pediatric Gastroenterology and Nutrition 2007;45(1):106-13. [DOI: 10.1097/MPG.0b013e3180331e2a] [PMID: 17592372]

\section{Morandi 2019 \{published data only\}}

Morandi A, Tommasi M, Soffiati F, Destro F, Grando F, Simonetti $G$, et al. Prevention of obesity in toddlers (PROBIT): a randomised clinical trial of responsive feeding promotion from birth to 24 months. International Journal of Obesity (London) 2019;43(10):1961-6. [DOI: 10.1038/s41366-019-0406-0] [PMID: 31270429]

\section{Muhoozi 2018 \{published data only\}}

Atukunda P, Muhoozi GKM, Westerberg AC, Iversen PO. Nutrition, hygiene and stimulation education for impoverished mothers in rural Uganda: effect on maternal depression symptoms and their associations to child development outcomes. Nutrients 2019;11(7):1561. [DOI: 10.3390/ nu11071561] [PMID: 31373314]

Atukunda P, Muhoozi GKM, van den Broek TJ, Kort R, Diep LM, Kaaya AN, et al. Child development, growth and microbiota: follow-up of a randomized education trial in Uganda. Journal of Global Health 2019;9(1):010431. [DOI: 10.7189/jogh-09-010431]

Muhoozi GKM, Atukunda P, Diep LM, Mwadime R, Kaaya AN, Skaare $A B$, et al. Nutrition, hygiene, and stimulation education to improve growth, cognitive, language, and motor development among infants in Uganda: a cluster-randomized trial. Maternal \& Child Nutrition 2018;14(2):e12527. [DOI: $10.1111 / \mathrm{mcn} .12527]$

\section{Murthy 2019 \{published data only\}}

Murthy N, Chandrasekharan S, Prakash MP, Kaonga NN, Peter J, Ganju A, et al. The impact of an mHealth voice message service (mMitra) on infant care knowledge, and practices among low-income women in India: findings from a pseudorandomized controlled trial. Maternal and Child Health Journal 2019;23:1658-69. [DOI: 10.1007/s10995-019-02805-5] [PMID: 31584144]

Nair 2017 \{published data only\}

* Nirmala N, Tripathy P, Sachdev HS, Pradhan H, Bhattacharyya S, Gope R, et al. Effect of participatory women's groups and counselling through home visits on children's linear growth in rural eastern India (CARING trial): a cluster-randomised controlled trial. Lancet Global Health 2017;5(10):e1004-16. [DOI: 10.1016/S2214-109X(17)30339-X] [PMID: 28911749 ]

\section{Nikiema 2017 \{published and unpublished data\}}

Nikiema L, Huybregts L, Martin-Prevel Y, Donnen P, Lanou H, Grosemans J, et al. Effectiveness of facility-based personalized maternal nutrition counselling in improving child growth and morbidity up to 18 months: a cluster-randomized controlled 
trial in rural Burkina Faso. PloS One 2017;12(5):e0177839. [DOI: 10.1371/journal.pone.0177839] [PMID: 28542391]

Olaya 2013 \{published data only\}

Olaya G, Fernanda Buitrago M, Fewtrell M. Randomised trial testing new complementary feeding guidelines: effects on food consumption and growth at 6 years of age. Journal of Pediatric Gastroenterology and Nutrition 2018;66(Suppl 2):1160. [DOI: 10.1097/MPG.0000000000002005]

* Olaya GA, Lawson M, Fewtrell MS. Efficacy and safety of new complementary feeding guidelines with an emphasis on red meat consumption: a randomized trial in Bogota, Colombia. American Journal of Clinical Nutrition 2013;98(4):983-93. [DOI: 10.3945/ajcn.112.053595] [PMID: 23945724]

\section{Palacios 2019 \{published data only\}}

Gibby CLK, Palacios C, Campos M, Graulau RE, Banna J. Acceptability of a text message-based intervention for obesity prevention in infants from Hawai'i and Puerto Rico WIC. BMC Pregnancy and Childbirth 2019;19(1):291. [DOI: 10.1186/ s12884-019-2446-9] [PMID: 31409286]

* Palacios C, Campos M, Gibby C, Meléndez M, Lee JE, Banna J. Effect of a multi-site trial using short message service (SMS) on infant feeding practices and weight gain in low-income minorities. Journal of the American College of Nutrition 2018;37(7):605-13.

\section{Penny 2005 \{published data only\}}

Penny ME, Creed-Kanashiro HM, Robert RC, Narro MR, Caulfield LE, Black RE. Effectiveness of an educational intervention delivered through the health services to improve nutrition in young children: a cluster-randomised controlled trial. Lancet 2005;365(9474):1863-72. [DOI: 10.1016/ S0140-6736(05)66426-4] [PMID: 15924983]

\section{Rafieya-Kopaei 2019 \{published data only\}}

IRCT20180901040919N1. The Impact of framing mothers' education messages on complementary feeding children. who.int/trialsearch/Trial2.aspx?TrialID=IRCT20180901040919N1 (first received 26 May 2018).

* Rafieyan-Kopaei Z, Fathian-Dastgerdi Z, Tarrahi MJ, ZamaniAlavijeh F. Effectiveness of message-framing intervention on complementary feeding related behaviors among mothers with infants aged 4-8 months: a 3-arm randomized controlled trial. Italian Journal of Pediatrics 2019;45(1):158. [DOI: 10.1186/ s13052-019-0749-0] [PMID: 31801605]

\section{Roy 2007 \{published data only\}}

Roy SK, Jolly SP, Shafique S, Fuchs GJ, Mahmud Z, Chakraborty B, et al. Prevention of malnutrition among young children in rural Bangladesh by a food-health-care educational intervention: a randomized, controlled trial. Food and Nutrition Bulletin 2007;28(4):375-83. [DOI: 10.1177/156482650702800401] [PMID: 18274163]

\section{Saleem 2014 \{published data only\}}

Saleem A, Mahmud S, Baig-Ansari N, Zaidi A. Impact of maternal education about complementary feeding on their infants' nutritional outcomes in low- and middle-income households: a community-based randomized interventional study in Karachi, Pakistan. Journal of Health Population Nutrition 2014;32(4):623-33. [PMID: 25895196]

Shi 2009 \{published data only\}

* Shi L, Zhang J, Wang Y, Caulfield LE, Guyer B. Effectiveness of an educational intervention on complementary feeding practices and growth in rural China: a cluster randomised controlled trial. Public Health Nutrition 2009;13(4):556-65. [DOI: 10.1017/S1368980009991364] [PMID: 19706219]

Zhang J, Shi L, Chen DF, Wang J, Wang Y. Effectiveness of an educational intervention to improve child feeding practices and growth in rural China: updated results at 18 months of age. Maternal and Child Nutrition 2013;9(1):118-29. [DOI: 10.1111/ j.1740-8709.2012.00447.x] [PMID: 23020102]

\section{Vazir 2013 \{published data only\}}

Vazir S, Engle P, Balakrishna N, Griffiths PL, Johnson SL, CreedKanashiro $\mathrm{H}$, et al. Cluster-randomized trial on complementary and responsive feeding education to caregivers found improved dietary intake, growth and development among rural Indian toddlers. Maternal and Child Nutrition 2013;9(1):99-117. [DOI: 10.1111/j.1740-8709.2012.00413.x] [PMID: 22625182]

Watt 2009 \{published data only\}

Watt RG, Tull KI, Hardy R, Wiggins M, Kelly Y, Molloy B, et al. Effectiveness of a social support intervention on infant feeding practices: randomised controlled trial. Journal of Epidemiology of Community Health 2009;63(2):156-62. [DOI: 10.1136/jech.2008.077115] [PMID: 19141661]

\section{References to studies excluded from this review}

\section{Aboud 2008 \{published data only\}}

Aboud FE, Moore AC, Akhter S. Effectiveness of a communitybased responsive feeding programme in rural Bangladesh: a cluster randomized field trial. Maternal and Child Nutrition 2008;4(4):275-86. [DOI: 10.1111/j.1740-8709.2008.00146.x] [PMID: 18811792]

\section{Ahmad 2019 \{published data only\}}

Ahmad A, Madanijah S, Dwiriani CM, Kolopaking R. Nutrition education using food monitoring card and multi-nutrient biscuit interventions improving nutritional and iron status in undernourished children aged 6-23 months: a cluster randomized control trial in Aceh, Indonesia. Annals of Nutrition \& Metabolism 2019;75(3):316. [DOI: 10.1159/000501751]

\section{Brown 1992 \{published data only\}}

Brown LV, Zeitlin MF, Peterson KE, Chowdhury AMR, Rogers BL, Weld $\mathrm{LH}$, et al. Evaluation of the impact of weaning food messages on infant feeding practices and child growth in rural Bangladesh. American Journal of Clinical Nutrition 1992;56(6):994-1003. [DOI: 10.1093/ajcn/56.6.994] [PMID: 1442668]

\section{Carmichael 2019 \{published data only\}}

* Carmichael SL, Mehta K, Srikantiah S, Mahapatra T, Chaudhuri I, Balakrishnan R, et al. Use of mobile technology by frontline health workers to promote reproductive, maternal, 
newborn and child health and nutrition: a cluster randomized controlled trial in Bihar, India. Journal of Global Health 2019;9(2):0204249. [DOI: 10.7189/jogh.09.020424]

NCT03406221. Use of mobile technology by community-based health workers to promote maternal and child health in Bihar, India. clinicaltrials.gov/show/nct03406221 (first received 23 January 2018).

\section{Cofie 2012 \{published data only\}}

Cofie AN. An integrated education intervention to improve infant and young child nutrition and growth in Ghana [Doctoral thesis]. Montreal (CA): McGill Univeristy, 2012.

\section{Cohen 1994 \{published data only\}}

Cohen RJ, Brown KH, Canahuati J, Rivera LL, Dewey KG. Effects of age of introduction of complementary foods on infant breast milk intake, total energy intake, and growth: a randomised intervention study in Honduras. Lancet 1994;344(8918):288-93. [PMID: 7914260]

\section{Cohen 1995 \{published data only\}}

Cohen RJ, Brown KH, Canahuati J, Rivera LL, Dewey KC. Determinants of growth from birth to 12 months among breastfed Honduran infants in relation to age of introduction of complementary foods. Pediatrics 1995;96(3):504-10. [PMID: 7651785]

\section{Cupples 2010 \{published data only\}}

Cupples ME, Stewart MC, Percy A, Hepper P, Murphy C, Halliday HL. An RCT of peer-mentoring for first-time mothers in socially disadvantaged areas (the MOMENTS study). Archives of Disease in Childhood 2011;96(3):252-8. [DOI: 10.1136/ adc.2009.167387] [PMID: 20522466]

\section{Daniels 2013 \{published data only\}}

Daniels LA, Mallan KM, Nicholson JM, Battistutta D, Magarey A. Outcomes of an early feeding practices intervention to prevent childhood obesity. Pediatrics 2013;132(1):e109-18. [DOI: 10.1542/peds.2012-2882] [PMID: 23753098]

\section{Daniels 2015 \{published data only\}}

Daniels LA, Mallan KM, Nicholson JM, Thorpe K, Nambiar S, Mauch CE, et al. An early feeding practices intervention for obesity prevention. Pediatrics 2015;136(1):e40-9. [DOI: 10.1542/ peds.2014-4108] [PMID: 26055848]

\section{Dewey 1998 \{published data only\}}

Dewey KG, Cohen RJ, Rivera LL, Brown KH. Effects of age of introduction of complementary foods on iron status of breast-fed infants in Honduras. American Journal of Clinical Nutrition 1998;67(5):878-84. [DOI: 10.1093/ajcn/67.5.878] [PMID: 9583845]

\section{Erickson 2018 \{published data only\}}

Erickson LW, Taylor RW, Haszard JJ, Fleming EA, Daniels L, Morison BJ, et al. Impact of a modified version of babyled weaning on infant food and nutrient intakes: the BLISS randomized controlled trial. Nutrients 2018;10(6):740. [DOI: 10.3390/nu10060740] [PMID: 29880769]

\section{Fahmida 2015 \{published data only\}}

Fahmida U, Kolopaking R, Santika O, Sriani S, Umar J, Htet MK, et al. Effectiveness in improving knowledge, practices, and intakes of "key problem nutrients" of a complementary feeding intervention developed by using linear programming: experience in Lombok, Indonesia. American Journal of Clinical Nutrition 2015;101(3):455-61. [DOI: 10.3945/ajcn.114.087775] [PMID: 25733629]

\section{Frongillo 2017 \{published data only\}}

Frongillo EA, Nguyen PH, Saha KK, Sanghvi T, Afsana K, Hague R, et al. Large-scale behavior-change initiative for infant and young child feeding advanced language and motor development in a cluster-randomized program evaluation in Bangladesh. Journal of Nutrition 2017;147(2):256-63. [DOI: 10.3945/jn.116.240861] [PMID: 28031374]

Gross 2016 \{published data only\}

Gross RS, Mendelsohn AL, Gross MB, Scheinmann R, Messito MJ. Randomized controlled trial of a primary care-based child obesity prevention intervention on infant feeding practices. Journal of Pediatrics 2016;174:172-7. [DOI: 10.1016/ j.jpeds.2016.03.060] [PMID: 27113376]

Guldan 2000 \{published data only\} Guidan GS, Fan HC, Ma X, Ni ZZ, Xiang X, Tang MZ. Culturally appropriate nutrition education improves infant feeding and growth in rural Sichuan, China. Journal of Nutrition 2000;130(5):1204-11. [DOI: 10.1093/jn/130.5.1204] [PMID: 10801920]

\section{Guptill 1982 \{published data only\}}

Guptill KS, Esrey SA, Oni GA, Brown KH. Evaluation of a faceto-face weaning food intervention in Kwara state, Nigeria: knowledge, trial, and adoption of a home-prepared weaning food. Social Science \& Medicine 1993;36(5):665-72. [PMID: 8456336]

\section{Jonsdottir 2012 \{published data only\}}

Jonsdottir $\mathrm{OH}$, Thorsdottir I, Hibberd PL, Fewtrell MS, Wells JC, et al. Timing of the introduction of complementary foods in infancy: a randomized controlled trial. Pediatrics 2012;130(6):1038-45. [DOI: 10.1542/peds.2011-3838] [PMID: 23147979]

\section{Kang 2017 \{published data only\}}

Kang Y, Kim S, Sinamo S, Christian P. Effectiveness of a community-based nutrition programme to improve child growth in rural Ethiopia: a cluster randomized trial. Maternal \& Child Nutrition 2017;13(1). [DOI: 10.1111/mcn.12349] [PMID: 27549570 ]

\section{Kapil 1995 \{published data only\}}

Kapil U, Verma D, Sachdev HP, Nayar D, Shah AD, Gnanasekaran N. Use of milk based commercial weaning foods amongst scheduled caste communities in Haryana. Indian Paediatrics 1995;32(8):905-8. [PMID: 8635836]

\section{Kilaru 2005 \{published data only\}}

Kilaru A, Griffiths PL, Ganapathy S, Ghosh S. Communitybased nutrition education for improving infant growth in 
rural Karnataka. Indian Pediatrics 2005;42(5):425-32. [PMID: 15923688]

\section{Kim 2018 \{published data only\}}

Kim SS, Nguyen PH, Tran LM, Sanghvi T, Mahmud Z, Haque MR, et al. Large-scale social and behavior change communication interventions have sustained impacts on infant and young child feeding knowledge and practices: results of a 2-year follow-up study in Bangladesh. Journal of Nutrition 2018;148(10):1605-14. [DOI: 10.1093/jn/nxy147] [PMID: 30169665]

Kim 2019 \{published data only\}

Kim SS, Nguyen PH, Yohannes Y, Abebe Y, Tharaney M, Drummond $\mathrm{E}$, et al. Behavior change interventions delivered through interpersonal communication, agricultural activities, community mobilization, and mass media increase complementary feeding practices and reduce child stunting in Ethiopia. Journal of Nutrition 2019;149:1470-81. [DOI: 10.1093/ jn/nxz087] [PMID: 31165869]

\section{Krebs 2006 \{published data only\}}

Krebs NF, Westcott JE, Butler N, Robinson C, Bell M, Hambidge KM. Meat as a first complementary food for breastfed infants: feasibility and impact on zinc intake and status. Journal of Pediatric Gastroenterology and Nutrition 2006;42(2):207-14. [DOI: 10.1097/01.mpg.0000189346.25172.fd] [PMID: 16456417]

\section{Krebs 2013 \{published data only\}}

Krebs NF, Sherlock LG, Westcott J, Culbertson D, Hambidge KM, Feazel LM, et al. Effects of different complementary feeding regimens on iron status and enteric microbiota in breastfed infants. Journal of Pediatrics 2013;163(2):416-23. [DOI: 10.1016/ j.jpeds.2013.01.024] [PMID: 23452586]

\section{Lakkam 2014 \{published data only\}}

Lakkam M, Wager S, Wise PH, Wein LM. Quantifying and exploiting the age dependence in the effect of supplementary food for child undernutrition. PLoS One 2014;9(6):e99632-42. [DOI: 10.1371/journal.pone.0099632] [PMID: 24967745]

\section{Maingi 2018 \{published data only\}}

Maingi M, Kimiywe J, Iron-Segev S. Effectiveness of baby friendly community initiative (BFCl) on complementary feeding in Koibatek, Kenya: a randomized control study. BMC Public Health 2018;18(1):600. [DOI: 10.1186/s12889-018-5519-1] [PMID: 29739374]

\section{Makrides 2002 \{published data only\}}

Makrides M, Hawkes JS, Neumann MA, Gibson RA. Nutritional effect of including egg yolk in the weaning diet of breast-fed and formula-fed infants: a randomized controlled trial. American Journal of Clinical Nutrition 2002;75(6):1084-92. [DOI: 10.1093/ ajcn/75.6.1084] [PMID: 12036817]

\section{Manjang 2018 \{published data only\}}

Manjang B, Hemming K, Bradley C, Ensink J, Martin JT, Sowe J, et al. Promoting hygienic weaning food handling practices through a community-based programme: intervention implementation and baseline characteristics for a cluster randomised controlled trial in rural Gambia. BMJ Open 2018;8(8):e017573. [DOI: 10.1136/bmjopen-2017-017573] [PMID: 30082338]

\section{Martinez 2018 \{published data only\}}

Martinez B, Cardona S, Rodas P, Lubina M, Gonzalez A, Farley Webb M, et al. Developmental outcomes of an individualised complementary feeding intervention for stunted children: a substudy from a larger randomised controlled trial in Guatemala. BMJ Paediatrics Open 2018;2:e000314. [DOI: 10.1136/bmjpo-2018-000314]

\section{Morison 2018 \{published data only\}}

Morison BJ, Heath AM, Haszard JJ, Hein K, Fleming EA, Daniels $L$, et al. Impact of a modified version of baby-led weaning on dietary variety and food preferences in infants. Nutrients 2018;10(8):1092. [DOI: 10.3390/nu10081092] [PMID: 30111722]

\section{Moursi 2003 \{published data only\}}

Moursi M, Mbemba F, Treche S. Does the consumption of amylase-containing gruels impact on the energy intake and growth of Congolese infants? Public Health Nutrition 2003;6(3):249-57. [DOI: 10.1079/PHN2002428] [PMID: 12740074]

\section{Navarro 2013 \{published data only\}}

Navarro JI, Sigulem DM, Ferraro AA, Polanco JJ, Barros AJ. The double task of preventing malnutrition and overweight: a quasi-experimental community-based trial. BMC Public Health 2013;13:212. [DOI: 10.1186/1471-2458-13-212] [PMID: 23496939]

\section{Negash 2014 \{published data only\}}

Negash C, Belachew T, Henry CJ, Kebebu A, Abegaz K, Whiting SJ. Nutrition education and introduction of broad bean-based complementary food improves knowledge and dietary practices of caregivers and nutritional status of their young children in Hula, Ethiopia. Food and Nutrition Bulletin 2014;35(4):480-6. [DOI: 10.1177/156482651403500409] [PMID: 25639132]

\section{Newman 2014 \{published data only\}}

Newman JE, Garces A, Mazariegos M, Michael Hambidge K, Manasyan A, Tshefu A, et al. Theory-driven process evaluation of a complementary feeding trial in four countries. Health Education Research 2014;29(2):297-305. [DOI: 10.1093/her/ cyt115] [PMID: 24399265]

\section{Owais 2017 \{published data only\}}

Owais A, Schwartz B, Kleinbaum DG, Suchdev PS, Farugue AS, Das SK, et al. A nutrition education program in rural Bangladesh was associated with improved feeding practices but not with child growth. Journal of Nutrition 2017;147(5):948-54. [DOI: 10.3945/jn.116.243956] [PMID: 28298543]

\section{Palwala 2009 \{published data only\}}

Palwala M, Sharma S, Udipi SA, Ghugre PS, Kothari G, Sawardekar P. Nutritional quality of diets fed to young children in urban slums can be improved by intensive nutrition education. Food and Nutrition Bulletin 2009;30(4):317-26. [DOI: 10.1177/156482650903000402] [PMID: 20496621] 
Paul 2010 \{published data only\}

Paul IM, Savage JS, Anzman SL, Beiler JS, Marini ME, Stokes JL, et al. Preventing obesity during infancy: a pilot study. Obesity Journal 2011;19(2):353-61. [DOI: 10.1038/oby.2010.182] [PMID: 20725058]

\section{Reinbott 2018 \{published data only\}}

Reinbott A, Schelling A, Jordan I, Krawinkel MB. Effectiveness of a nutrition education linked to agricultural interventions to improve infant and young child feeding practices, perceptions, and nutritional status in Cambodia. Maternal and Child Nutrition 2018;14(Suppl 2):(no pagination). [DOI: 10.1111/mcn.12587]

\section{Roy 2005 \{published data only\}}

Roy SK, Fuchs GJ, Mahmud Z, Ara G, Islam S, Shafique S, et al. Intensive nutrition education with or without supplementary feeding improves the nutritional status of moderatelymalnourished children in Bangladesh. Journal of Health, Population, and Nutrition 2005;23(4):320-30. [PMID: 16599102]

\section{Ruel 1992 \{published data only\}}

Ruel MT, Habicht JP. Growth charts only marginally improved maternal learning from nutrition education and growth monitoring in Lesotho. Journal of Nutrition 1992;122(9):1772-80. [DOI: 10.1093/jn/122.9.1772] [PMID: 1380982]

\section{Santos 2001 \{published data only\}}

Santos I, Victora CG, Martines J, Goncalves H, Gigante DP, Valle NJ, et al. Nutrition counseling increases weight gain among Brazilian children. Journal of Nutrition 2001;131(11):2866-73. [DOI: 10.1093/jn/131.11.2866] [PMID: 11694610]

\section{Seetha 2018 \{published data only\}}

Seetha A, Tsusaka TW, Munthali TW, Musukwa M, Mwangwela A, Kalumikiza Z, et al. How immediate and significant is the outcome of training on diversified diets, hygiene and food safety? An effort to mitigate child undernutrition in rural Malawi. Public Health Nutrition 2018;21(6):1156-66. [DOI: 10.1017/S1368980017003652] [PMID: 29338801]

\section{Seyyedi 2020 \{published data only\}}

IRCT20190705044103N1. Smartphone-based maternal education directed at complementary feeding among malnourished children below 3 years of age in Urmia, Iran CNO - CN-01969102. who.int/trialsearch/Trial2.aspx? TrialID=IRCT20190705044103N1 (first received 14 July 2018).

* Seyyedi N, Rahimi B, Eslamlou HRF, Afshar HL, Spreco A, Timpka T. Smartphone-based maternal education for the complementary feeding of undernourished children under 3 years of age in food-secure communities: randomised controlled trial in Urmia, Iran. Nutrients 2020;12(2):587. [PMID: 32102310]

\section{Singh 2017 \{published data only\}}

Singh V, Ahmed S, Dreyfuss ML, Kiran U, Chaudhery DN, Srivastava VK, et al. An integrated nutrition and health program package on IYCN improves breastfeeding but not complementary feeding and nutritional status in rural northern
India: a quasi-experimental randomized longitudinal study. PloS One 2017;12(9):e0185030. [DOI: 10.1371/journal.pone.0185030]

Skau 2015 \{published data only\}

Skau JK, Touch B, Chhoun C, Chea M, Unni US, Makurat J, et al. Effects of animal source food and micronutrient fortification in complementary food products on body composition, iron status, and linear growth: a randomized trial in Cambodia. American Journal of Clinical Nutrition 2015;101(4):742-51. [DOI: 10.3945/ajcn.114.084889] [PMID: 25833972]

\section{Sutrisna 2019 \{published data only\}}

Sutrisna A, Mallipu A, Ariawan I. Emo-demo: combining science and innovation for community-based child feeding interventions in East Java Indonesia. Annals of Nutrition \& Metabolism 2019;75(3):173. [DOI: 10.1159/000501751]

\section{Tang 2014a \{published data only\}}

Tang M, Krebs NF. High protein intake from meat as complementary food increases growth but not adiposity in breast fed infants: a randomized trial. American Journal of Clinical Nutrition 2014;100(5):1322-8. [DOI: 10.3945/ ajcn.114.088807] [PMID: 25332329]

\section{Tang 2014b \{published data only\}}

Tang M, Sheng XY, Krebs NF, Hambidge KM. Meat as complementary food for older breastfed infants and toddlers: a randomized, controlled trial in rural China. Food and Nutrition Bulletin 2014;35(4 Suppl):S188-92. [DOI: 10.1177/15648265140354S304] [PMID: 25639137]

\section{Tariku 2015 \{published data only\}}

Tariku B, Whiting SJ, Mulualem D, Singh P. Application of the health belief model to teach complementary feeding messages in Ethiopia. Ecology of Food and Nutrition 2015;54(5):572-82. [DOI: 10.1080/03670244.2015.1049344] [PMID: 26075935]

\section{Taylor 2017 \{published data only\}}

Daniels L, Taylor RW, Williams SM, Gibson RS, Fleming EA, Wheeler BJ, et al. Impact of a modified version of babyled weaning on iron intake and status: a randomised controlled trial. BMJ Open 2018;8(6):e019036. [DOI: 10.1136/ bmjopen-2017-019036] [PMID: 29950456]

Daniels L, Taylor RW, Williams SM, Gibson RS, Samman S, Wheeler BJ, et al. Modified version of baby-led weaning does not result in lower zinc intake or status in infants: a randomized controlled trial. Journal of the Academy of Nutrition and Dietetics 2018;118(6):1006-16. [DOI: 10.1016/j.jand.2018.02.005] [PMID: 29803269]

Taylor RW, Williams SM, Fangupo LJ, Wheeler BJ, Taylor BJ, Daniels $L$, et al. Effect of a baby-led approach to complementary feeding on infant growth and overweight: a randomized clinical trial. JAMA Pediatrics 2017;171(9):838-46. [DOI: 10.1001/ jamapediatrics.2017.1284] [PMID: 28692728]

Williams Erickson L, Taylor RW, Haszard JJ, Fleming EA, Daniels L, Morison BJ, et al. Impact of a modified version of baby-led weaning on infant food and nutrient intakes: the BLISS randomized controlled trial. Nutrients 2018;10(6). [DOI: 10.3390/nu10060740] [PMID: 29880769] 
Yousafzai 2014 \{published data only\}

Yousafzai AK, Rasheed MA, Rizvi A, Armstrong R, Bhutta ZA. Effect of integrated responsive stimulation and nutrition interventions in the Lady Health Worker programme in Pakistan on child development, growth, and health outcomes: a cluster-randomised factorial effectiveness trial. Lancet 2014;384(9950):1282-93. [DOI: 10.1016/S0140-6736(14)60455-4] [PMID: 24947106]

\section{Zaman 2008 \{published data only\}}

Zaman S, Ashraf R N, Martines J. Training in complementary feeding counselling of healthcare workers and its influence on maternal behaviours and child growth: a cluster-randomized controlled trial in Lahore, Pakistan. Journal of Health, Population, and Nutrition 2008;26(2):210-22.

\section{References to ongoing studies}

\section{Billah 2017 \{published data only\}}

Billah SM, Ferdous TE, Karim MA, Dibley MJ, Raihana S, Moinuddin $\mathrm{M}$, et al. A community-based cluster randomised controlled trial to evaluate the effectiveness of different bundles of nutrition-specific interventions in improving mean length-for-age $z$ score among children at 24 months of age in rural Bangladesh: study protocol. BMC Public Health 2017;17(1):375. [DOI: 10.1186/s12889-017-4281-0]

NCT02768181. Evaluate bundling of nutrition interventions. clinicaltrials.gov/ct2/show/NCT02768181 (first received 11 May 2016).

\section{CTRI/2018/01/011275 \{published data only\}}

CTRI/2018/01/011275. A study to assess the effectiveness of structured complementary feeding instructions on anthropometric and morbidity status of infants and the level of knowledge of mothers of infants at a tertiary referral hospital, Tamilnadu, India. who.int/trialsearch/Trial2.aspx? TrialID=CTRI/2018/01/011275 (first received 31 January 2018).

\section{Gupta 2018 \{published data only\}}

CTRI/2018/03/012512. A community based trial to study the effectiveness of a culturally appropriate nutrition educational intervention delivered through health services to improve growth and feeding of 6 months to 1 year old infants in Chandigarh. who.int/trialsearch/Trial2.aspx? TrialID=CTRI/2018/03/012512 (first received 3 December 2018)

\section{Helle 2017 \{published data only\}}

ISRCTN13601567. Early food for future health: a randomized controlled trial evaluating the effect of an eHealth intervention aiming to promote healthy food habits from early childhood. http://www.isrctn.com/ISRCTN13601567 (first received 15 February 2016).

\section{Horodynski 2013 \{published data only\}}

Horodynski M. Healthy babies through infant-centered feeding. Journal of Nutrition Education and Behavior 2013;45:S84.

Horodynski MA, Olson B, Baker S, Brophy-Herb H, Auld G, Van Egeren $\mathrm{L}$, et al. Healthy babies through infant-centered feeding protocol: an intervention targeting early childhood obesity in vulnerable populations. BMC Public Health 2011;11:868.

Ingalls 2019 \{published data only\}

Ingalls A, Rosenstock S, Foy Cuddy R, Neault N, Yessilth S, Goklish N, et al. Family Spirit Nurture (FSN) - a randomized controlled trial to prevent early childhood obesity in American Indian populations: trial rationale and study protocol. $B M C$ Obesity 2019;6:18.

NCT03101943. Preventing early childhood obesity, part 1: family spirit nurture, 3-9 months. clinicaltrials.gov/show/nct03101943 (first received 5 April 2017).

NCT03334266. Preventing early childhood obesity, part 2: family spirit nurture, prenatal - 18 months. clinicaltrials.gov/ct2/show/ nct03334266 (first received 7 November 2017).

\section{ISRCTN10892553 \{published data only\}ISRCTN10892553}

ISRCTN10892553. Delivering a contextualized package of care for child development (0-12 months) and maternal mental health in the camps for forcibly displaced Myanmar nationals in Bangladesh. who.int/trialsearch/Trial2.aspx? TrialID=ISRCTN10892553 (first received 15 May 2019).

\section{ISRCTN98898991 \{published data only\}ISRCTN98898991}

ISRCTN98898991. Healthy future: a community health worker program to improve maternal, newborn and child health in rural China. who.int/trialsearch/Trial2.aspx? TrialID=ISRCTN98898991 (first received 26 March 2019).

NCTNCT03597061 \{published data only\}

NCTNCT03597061. Healthy start to feeding intervention. https:// clinicaltrials.gov/ct2/show/NCT03597061 (first received 24 July 2018).

\section{Wasser 2017 \{published data only\}}

Wasser HM, Thompson AL, Suchindran CM, Hodges EA, Goldman BD, Perrin EM, et al. Family-based obesity prevention for infants: design of the "Mothers \& Others" randomized trial. Contemporary Clinical Trials 2017;60:24-33. [DOI: 10.1016/ j.cct.2017.06.002] [PMID: 28600160]

\section{Additional references}

\section{AAP 2012}

American Academy of Pediatrics (AAP). Breastfeeding and the use of human milk. Pediatrics 2012;129(3):e827-41.

\section{Agostoni 2008}

Agostoni C, Decsi T, Fewtrell M, Goulet O, Kolacek S, Koletzko B, et al. Complementary feeding: a commentary by the ESPGHAN Committee on Nutrition. Journal of Pediatric Gastroenterology and Nutrition 2008;46(1):99-110. [DOI: 10.1097/01.mpg.0000304464.60788.bd] [PMID: 18162844]

\section{Ajzen 1980}

Ajzen I, Fishbein M. Understanding Attitudes and Predicting Social Behaviour. Upper Saddle River, NJ (USA): Prentice Hall, 1980. 


\section{Arden 2010}

Arden MA. Conflicting influences on UK mothers' decisions to introduce solid foods to their infants. Maternal \& Child Nutrition 2010;6(2):159-73. [DOI: 10.1111/j.1740-8709.2009.00194.x] [PMID: 20624212]

\section{Arikpo 2018}

Arikpo D, Edet ES, Chibuzor MT, Odey F, Caldwell DM. Educational interventions for improving primary caregiver complementary feeding practices for children aged 24 months and under. Cochrane Database of Systematic Reviews 2018, Issue 5. Art. No: CD011768. [DOI: 10.1002/14651858.CD011768.pub2]

\section{Bandura 2004}

Bandura A. Health promotion by social cognitive means. Health Education \& Behavior 2004;31(2):143-64. [DOI: 10.1177/1090198104263660] [PMID: 15090118]

\section{Baughcum 2001}

Baughcum AE, Powers SW, Johnson SB, Chamberlin LA, Deeks CM, Jain A, et al. Maternal feeding practices and beliefs and their relationships to overweight in early childhood. Journal of Developmental and Behavioral Pediatrics 2001;22(6):391-408. [PMID: 11773804]

\section{Black 2000}

Black M, Matula K. Essentials of Bayley Scales of Infant Development II Assessment. Illustrated edition. London (UK): Wiley, 2000.

\section{Black 2013}

Black RE, Victora CG, Walker SP, Bhutta ZA, Christian P, de Onis $M$, et al. Maternal and child undernutrition and overweight in low-income and middle-income countries. Lancet 2013;382(9890):427-51. [DOI: 10.1016/S0140-6736(13)60937-X] [PMID: 23746772]

\section{Bowling 2004}

Bowling A. Measuring Health. Illustrated edition. London (UK): McGraw-Hill Education, 2004.

\section{Caroli 2012}

Caroli M, Mele RM, Tomaselli MA, Cammisa M, Longo F, Attolini E. Complementary feeding patterns in Europe with a special focus on Italy. Nutrition, Metabolism, and Cardiovascular Diseases 2012;22(10):813-8. [DOI: 10.1016/j.numecd.2012.07.007] [PMID: 22898449]

\section{Cassells 2014}

Cassells E, Magarey A, Daniels L, Mallan K. The influence of maternal infant feeding practices and beliefs on the expression of food neophobia in toddlers. Appetite 2014;82:36-42. [DOI: 10.1016/j.appet.2014.07.001] [PMID: 25014743]

\section{Contento 2010}

Contento R. Nutrition Education: Linking Theory, Research, and Practice. 2nd edition. London (UK): Jones \& Bartlett Learning, 2010.

\section{Dewey 2008}

Dewey KG, Adu-Afarwuah S. Systematic review of the efficacy and effectiveness of complementary feeding interventions in developing countries. Maternal \& Child Nutrition 2008;4 Suppl 1:24-85. [DOI: 10.1111/j.1740-8709.2007.00124.x] [PMID: 18289157]

\section{Gage 2012}

Gage H, Williams P, Von Rosen-Von Hoewel J, Laitinen K, Jakobik V, Martin-Bautista E, et al. Influences on infant feeding decisions of first-time mothers in five European countries. European Journal of Clinical Nutrition 2012;66(8):914-9. [DOI: 10.1038/ejcn.2012.56] [PMID: 22692025]

\section{GRADEpro GDT [Computer program]}

McMaster University (developed by Evidence Prime) GRADEpro GDT. Version accessed 14 July 2017. Hamilton (ON): McMaster University (developed by Evidence Prime). Available at gradepro.org.

\section{Grotevant 1989}

Grotevant H, Carlson Cl. Family Assessment: A Guide to Methods and Measures. London (UK): Guilford Press, 1989.

\section{Handa 2018}

Handa S, de Hoop T, Mitchell M, Seidenfeld D. ICC values in international development: evidence across many domains in subSaharan Africa. https:// editorialexpress.com/cgi-bin/conference/download.cgi? db_name=CSAE2018\&paper_id=1162, 2018 (accessed 9 January 2019).

\section{Hawkins 2009}

Hawkins S, Cole TJ, Law C. An ecological systems approach to examining risk factors for early childhood overweight: findings from the UK Millennium Cohort Study. Journal of Epidemiology and Community Health 2009;63(2):147-55. [DOI: 10.1136/ jech.2008.077917] [PMID: 18801795]

\section{Higgins 2019}

Higgins JPT, Thomas J, Chandler J, Cumpston M, Li T, Page MJ, et al (editors). Cochrane Handbook for Systematic Reviews of Interventions Version 6.0 (updated July 2019). Cochrane, 2019. Available from www.training.cochrane.org/handbook.

\section{Hoare 2002}

Hoare K, Wright CM, Wilson P, Weaver LT. Disseminating weaning messages: an intervention trial. British Journal of Community Nursing 2002;7(4):196-200. [DOI: 10.12968/bjcn.2002.7.4.10225] [PMID: 11979198]

\section{Hoffman 2003}

Hoffman DR, Birch EE, Castaneda YS, Fawcett SL, Wheaton DH, Birch DG, et al. Visual function in breast-fed term infants weaned to formula with or without long-chain polyunsaturates at 4 to 6 months: a randomized clinical trial. Journal of Pediatrics 2003;142(6):669-77. [DOI: 10.1067/mpd.2003.213] [PMID: 12838196] 


\section{Hopkins 2007}

Hopkins D, Emmett P, Steer C, Rogers I, Noble S, Emond A. Infant feeding in the second 6 months of life related to iron status: an observational study. Archives of Disease in Childhood 2007;92(10):850-4. [DOI: 10.1136/adc.2006.114074] [PMID: 17537759]

\section{Imdad 2011}

Imdad A, Yakoob MY, Bhutta ZA. Impact of maternal education about complementary feeding and provision of complementary foods on child growth in developing countries. BMC Public Health 2011;11 Suppl 3:S25. [DOI: 10.1186/1471-2458-11-S3S25] [PMID: 21501443]

\section{Kramer 2002}

Kramer M, Kakuma R, WHO. The optimal duration of exclusive breastfeeding: a systematic review. www.who.int/nutrition/publications/ optimal_duration_of_exc_bfeeding_review_eng.pdf accessed 12/01/2016.

\section{Lassi 2013}

Lassi Z, Das J, Zahid G, Imdad A, Bhutta Z. Impact of education and provision of complementary feeding on growth and morbidity in children less than 2 years of age in developing countries: a systematic review. BMC Public Health 2013;13(Suppl 3):S13. [DOI: 10.1186/1471-2458-13-S3-S13] [PMID: 24564534]

\section{Luepker 1996}

Luepker RV, Perry CL, McKinlay SM, Nader PR, Parcel GS, Stone EJ, et al. Outcomes of a field trial to improve children's dietary patterns and physical activity. The Child and Adolescent Trial for Cardiovascular Health. CATCH Collaborative Group. JAMA 1996;275(10):768-76. [PMID: 8598593]

\section{McFadden 2017}

McFadden A, Gavine A, Renfrew MJ, Wade A, Buchanan P, Taylor JL, et al. Support for healthy breastfeeding mothers with healthy term babies. Cochrane Database of Systematic Reviews 2017, Issue 2. Art. No: CD001141. [DOI: 10.1002/14651858.CD001141.pub5]

\section{Moore 2012}

Moore AP, Milligan P, Rivas C, Goff LM. Sources of weaning advice, comparisons between formal and informal advice, and associations with weaning timing in a survey of UK firsttime mothers. Public Health Nutrition 2012;15(9):1661-9. [DOI: 10.1017/S1368980012002868] [PMID: 22632545]

\section{Morgan 2004}

Morgan J, Taylor A, Fewtrell M. Meat consumption is positively associated with psychomotor outcome in children up to 24 months of age. Journal of Pediatric Gastroenterology and Nutrition 2004;39(5):493-8. [PMID: 15572888]

\section{Musher-Eizenman 2007}

Musher-Eizenman D, Holub S. Comprehensive Feeding Practices Questionnaire: validation of a new measure of parental feeding practices. Journal of Pediatric Psychology 2007;32(8):960-72. [DOI: 10.1093/jpepsy/jsm037] [PMID: 17535817]

\section{Redsell 2010}

Redsell SA, Atkinson P, Nathan D, Siriwardena AN, Swift JA, Glazebrook C. Parents' beliefs about appropriate infant size, growth and feeding behaviour: implications for the prevention of childhood obesity. BMC Public Health 2010;10:711. [DOI: 10.1186/1471-2458-10-711] [PMID: 21087482]

\section{RevMan 2014 [Computer program]}

Nordic Cochrane Centre, Cochrane Review Manager 5 (RevMan 5). Version 5.3. Copenhagen: Nordic Cochrane Centre, Cochrane, 2014.

\section{Schünemann 2013}

Schünemann H, Brożek J, Guyatt G, Oxman A, editor(s). Handbook for Grading the Quality of Evidence and the Strength of Recommendations Using the GRADE Approach (updated October 2013). GRADE Working Group, 2013. Available from gdt.gradepro.org/app/handbook/handbook.html.

\section{UNICEF 2005}

UNICEF. Nutrition: Complementary Feeding. www.unicef.org/ nutrition/index_24826.html (accessed 1 December 2016).

\section{Vitolo 2005}

Vitolo MR, Bortolini GA, Feldens CA, Drachler Mde L. Impacts of the 10 Steps to Healthy Feeding in Infants: a randomized field trial [Impactos da implementacao dos dez passos da alimentacao saudavel para criancas: ensaio de campo randomizado.]. Cadernos de Saude Publica 2005;21(5):1448-57. [DOI: /S0102-311X2005000500018] [PMID: 16158151]

\section{Weaver 2001}

Weaver L, Michaelsen KF. A good start in life: breast is best, but complementary foods should not be worse. Nutrition 2001;17(6):481-3. [PMID: 11399410]

\section{Wechsler 1974}

Wechsler D. Manual for the Wechsler Intelligence Scale for Children. Revised edition. New York, NY (USA): Psychological Corporation, 1974.

\section{WHO 1988}

World Health Organization, UNICEF. Weaning: from breast milk to family food, a guide for health and community workers. apps.who.int/iris/handle/10665/39335 (accessed 1 December 2016).

\section{WHO 2011}

WHO. Serum ferritin concentrations for the assessment of iron status and iron deficiency in populations. www.who.int/vmnis/ indicators/serum_ferritin.pdf (accessed 1 December 2016).

\section{WHO 2017a}

WHO. Double burden of malnutrition. www.who.int/nutrition/ double-burden-malnutrition/en/ (accessed 1 December 2016).

\section{WHO 2017b}

WHO. Double-duty actions for nutrition. www.who.int/iris/ bitstream/handle/10665/255414/WHO-NMH-NHD-17.2eng.pdf;jsessionid=00C32AA9EA6D57D8F37A4AFE55CA758C? sequence $=1$ (accessed 1 December 2016). 


\section{World Bank 2015}

World Bank. New Country Classifications. data.worldbank.org/ news/new-country-classifications-2015 (accessed 1 December 2016).

\section{References to other published versions of this review \\ Elfzzani 2016}

Elfzzani Z, Ojha S, Dorling J. Education of family members to support weaning to solids and nutrition in later infancy in termborn infants. Cochrane Database of Systematic Reviews 2016, Issue 6. Art. No: CD012241. [DOI: 10.1002/14651858.CD012241]

* Indicates the major publication for the study

CHARACTERISTICS OF STUDIES

Characteristics of included studies [ordered by study ID]

Bhadari 2001

\begin{tabular}{ll} 
Study characteristics & RCT \\
\hline Methods & Study setting: urban slum in New Delhi, India \\
Participants & Inclusion criteria: all pregnant women and infants $<4$ months of age \\
& Exclusion criteria: likely to emigrate; congenital malformation \\
& A total of 210 infants enrolled, of whom 104 (42 males) were in the nutritional counselling group and \\
& 106 (39 males) were in the no intervention group. The study had 2 other arms
\end{tabular}

Interventions Intervention group: the nutritional counselling group received 30 to 45 minutes of counselling monthly by trained nutritionists but received no food supplements

Control group: no intervention groups were contacted at 6, 9, and 12 months for anthropometry and dietary recalls. No other visits were made nor advice given

Weight gain between 6 and 12 months of age
Increase in length between 6 and 12 months of age
Death by 12 months of age

Identification For this review, we have included the nutritional counselling (intervention) and no intervention (control) groups only

Imputing of SD for change in weight and length between 6 and 12 months:

Mean change in weight and length between 6 and 12 months of age was calculated by subtracting mean weight/length at 26 weeks' gestation from mean weight/length at 52 weeks' gestation for both groups, as given in Tables 3 and 4

The SD for these changes was determined by imputation of the SD for changes from the baseline method given in Chapter 16.1.3.2 of the Cochrane Handbook for Systematic Reviews of Interventions. First, the correlation of coefficient was calculated by taking the average of correlation coefficients for changes between 26 and 38 weeks' gestation and 38 and 52 weeks' gestation using the data given in Table 3. This average correlation coefficient was then used to impute the SD for the change between 26 and 52 weeks' gestation

\section{Risk of bias}


Bhadari 2001 (Continued)

\begin{tabular}{|c|c|c|}
\hline Bias & Authors' judgement & Support for judgement \\
\hline $\begin{array}{l}\text { Random sequence genera- } \\
\text { tion (selection bias) }\end{array}$ & Unclear risk & $\begin{array}{l}\text { Quote: "children were stratified by weight for height status ( } \leq 80 \% \text { and }>80 \% \\
\text { of the National Center for Health Statistics median for that age) and random- } \\
\text { ly assigned to one of the four study groups", but methods of sequence genera- } \\
\text { tion and randomisation are not given }\end{array}$ \\
\hline $\begin{array}{l}\text { Allocation concealment } \\
\text { (selection bias) }\end{array}$ & Unclear risk & $\begin{array}{l}\text { No information was provided; unable to judge whether allocation conceal- } \\
\text { ment was adequate }\end{array}$ \\
\hline $\begin{array}{l}\text { Blinding of participants } \\
\text { and personnel (perfor- } \\
\text { mance bias) } \\
\text { All outcomes }\end{array}$ & Low risk & $\begin{array}{l}\text { No information was provided; however, the intervention is not amenable to } \\
\text { blinding of participants and personnel, and outcome measures relevant to this } \\
\text { review are unlikely to be affected by lack of blinding }\end{array}$ \\
\hline $\begin{array}{l}\text { Blinding of outcome as- } \\
\text { sessment (detection bias) } \\
\text { All outcomes }\end{array}$ & Unclear risk & No information was provided \\
\hline $\begin{array}{l}\text { Incomplete outcome data } \\
\text { (attrition bias) } \\
\text { All outcomes }\end{array}$ & Low risk & $\begin{array}{l}\text { A total of } 210 \text { infants were randomised to the } 2 \text { groups included in this review. } \\
\text { At } 26 \text { weeks' follow-up, data on } 195(92.9 \%) \text { were available, and at } 52 \text { weeks' } \\
\text { follow-up, data on } 190(90.5 \%) \text { were available }\end{array}$ \\
\hline $\begin{array}{l}\text { Selective reporting (re- } \\
\text { porting bias) }\end{array}$ & Low risk & $\begin{array}{l}\text { Although the study protocol is not available, all proposed outcome measures } \\
\text { were reported }\end{array}$ \\
\hline Other bias & High risk & $\begin{array}{l}\text { At baseline, energy intake from non-breast milk foods, percentage of literate } \\
\text { fathers, and father's income per year appear to be higher among the no inter- } \\
\text { vention group when compared to the nutritional counselling group }\end{array}$ \\
\hline
\end{tabular}

\section{Bhandari 2004}

\section{Study characteristics}

\begin{tabular}{|c|c|}
\hline Methods & Cluster-RCT \\
\hline \multirow[t]{4}{*}{ Participants } & Study setting: rural communities in the state of Haryana, India \\
\hline & $\begin{array}{l}\text { Inclusion criteria: infants born between October } 1999 \text { and June } 2000 \text { if they were "local residents and } \\
\text { informed written consent was obtained" }\end{array}$ \\
\hline & Exclusion criteria: none given \\
\hline & $\begin{array}{l}8 \text { cluster including a total of } 1025 \text { infants enrolled, of whom } 552(288(52.2 \%) \text { males) infants in } 4 \text { clus- } \\
\text { ters were in the nutritional counselling group and } 473(253(53.5 \%) \text { males) in } 4 \text { clusters were in the no } \\
\text { intervention group }\end{array}$ \\
\hline \multirow[t]{2}{*}{ Interventions } & $\begin{array}{l}\text { Intervention group: locally relevant nutritional messages were developed by formative research; mes- } \\
\text { sages were discussed in monthly home visits up to } 12 \text { months and in 3-month visits up to } 2 \text { years }\end{array}$ \\
\hline & $\begin{array}{l}\text { Control group received routine services, which included advice on initiation of complementary feeding } \\
\text { at } 4 \text { to } 6 \text { months, types of foods to be fed, and frequency of feeding, but the focus was on family plan- } \\
\text { ning and immunisation }\end{array}$ \\
\hline
\end{tabular}

Outcomes

$$
\begin{aligned}
& \text { Weight gain between } 6 \text { and } 12 \text { months of age } \\
& \text { Increase in length between } 6 \text { and } 12 \text { months of age }
\end{aligned}
$$


Bhandari 2004 (Continued)

Prevalence of exclusive breastfeeding at 6 months

Identification

Notes

The intervention was continued until the child was 2 years of age. For this review, we have extracted

data only up to the first year of life

\section{Risk of bias}

\section{Bias Authors' judgement Support for judgement}

Random sequence genera- Low risk tion (selection bias)

Allocation concealment Low risk
(selection bias)

Blinding of participants Low risk and personnel (performance bias)

All outcomes

Blinding of outcome as- Low risk
sessment (detection bias) All outcomes
Quote: "generated 4 single-digit random numbers using a random numbers table; the first listed community in a pair was allocated to the intervention group if the random number was 0-4 and the second if it was 5-9"

A statistician not involved with the study performed the randomisation (i.e. there was central allocation using random number tables)

The intervention is not amenable to blinding of participants or of personnel delivering the intervention; however, outcomes included in this review are unlikely to be affected by lack of blinding

There was an attempt to blind personnel who collected outcome data

Quote: "mothers and infants were visited at home by workers who were not involved in the delivery of the intervention at 3, 6, 9, 12, 15, and 18 months of age"

Also, outcomes included in this review are unlikely to be affected by lack of blinding

Incomplete outcome data High risk (attrition bias)

All outcomes

The number of infants followed up at 12 months is not reported. However, attrition at both 9 months and 18 months was $>10 \%$. At 9 months, $451(81.2 \%)$ in the intervention group and $403(85.2 \%)$ in the control group were followed up. The numbers followed up were further reduced at 18 months: $435(78.8 \%)$ in intervention group and 394 (83.3\%) in control group. There also appears to be imbalance in the reasons for loss to follow-up. There were $26(4.7 \%)$ deaths, 13 $(2.4 \%)$ refusals, and $78(14.1 \%)$ in the intervention group as reasons for loss to follow-up as compared to $12(2.5 \%), 5(1.1 \%)$, and $62(13.1 \%)$, respectively, in the control group

\begin{tabular}{|c|c|c|}
\hline $\begin{array}{l}\text { Selective reporting (re- } \\
\text { porting bias) }\end{array}$ & Low risk & $\begin{array}{l}\text { Although the study protocol is not available, all proposed outcome measures } \\
\text { were reported }\end{array}$ \\
\hline
\end{tabular}

Other bias Low risk

\section{Bortolini 2012}

\section{Study characteristics}

\begin{tabular}{ll}
\hline Methods & RCT \\
\hline Participants & Study setting: Sao Leopoldo, state of Rio Grande do Sul, Brazil
\end{tabular}


Inclusion criteria: all infants born in the Brazilian National Health Service wards of the Hospital Centenario between October 2001 and June 2002 at birth weight $\geq 2500$ grams and at gestational age $\geq 37$ weeks

Exclusion criteria: HIV-positive mothers, congenital malformations, newborns admitted to intensive care units, multiple delivery, infants with serum haemoglobin levels $<110 \mathrm{~g} / \mathrm{L}$ at 6 months of age

Initially 500 infants were enrolled (200 in intervention group and 300 in control group), of whom 197 and 272 received the allocated treatment. A total of 397 infants were followed up, of whom 163 (93 $(57.1 \%)$ males) were in the nutritional counselling group and 234 (130 (55.5\%) males) were in the no intervention group

Interventions Intervention group: nutritional messages based on "Ten Steps for Healthy Feeding in Children Younger Than Two Years"

Counselling by 10 home visits: first 10 days of birth, monthly up to 6 months, and at 8,10 , and 12 months

Control group: families were visited at 6 and 12 months for collection of anthropometric, dietary, and socio-demographic data

Prevalence of exclusive breastfeeding at 6 months
Prevalence of anaemia (serum haemoglobin $<110 \mathrm{~g} / \mathrm{L}$ ) at the age of 12 months

Identification

Notes Some information was extracted from other publications of the same study (Vitolo 2005 and Costa
2017). Google translation was used to translate the article from Portuguese to English

\section{Risk of bias}

\section{Bias}

Random sequence genera- Unclear risk tion (selection bias)

\section{Authors' judgement Support for judgement}

Quote (Costa 2017): "mothers who agreed to participate were sequentially listed on the basis of their time of delivery, grouped in blocks of five, and their names separated in opaque, sealed envelopes. Two mothers from each block were randomly assigned to the intervention group, and the remaining three mothers were allocated to the control group"

However, the method of randomisation is not given in any of the publications

\begin{tabular}{|c|c|c|}
\hline $\begin{array}{l}\text { Allocation concealment } \\
\text { (selection bias) }\end{array}$ & Low risk & As above \\
\hline $\begin{array}{l}\text { Blinding of participants } \\
\text { and personnel (perfor- } \\
\text { mance bias) } \\
\text { All outcomes }\end{array}$ & High risk & $\begin{array}{l}\text { The intervention is not amenable to blinding of participants or of personnel } \\
\text { delivering the intervention. One outcome considered in this review (serum } \\
\text { haemoglobin level) is unlikely to be affected by lack of blinding, but the other } \\
\text { (prevalence of exclusive breastfeeding) is highly likely to be affected by knowl- } \\
\text { edge of treatment allocation }\end{array}$ \\
\hline
\end{tabular}

\begin{tabular}{|c|c|c|}
\hline $\begin{array}{l}\text { Blinding of outcome as- } \\
\text { sessment (detection bias) }\end{array}$ & High risk & This report indicates that outcome assessors were blind \\
\hline All outcomes & & $\begin{array}{l}\text { Quote: "interviewers who were not involved in the intervention process and } \\
\text { who were blind to which group children belonged conducted home visits at } 6 \\
\text { and } 12 \text { months in order to collect data on the study variables" }\end{array}$ \\
\hline
\end{tabular}

However, the statement in Vitolo 2005 suggests that interviewers were not blind to treatment allocation 
Bortolini 2012 (Continued)

Incomplete outcome data Low risk (attrition bias)

All outcomes
$397(79.4 \%)$ of the 500 randomised infants were included in the final analysis. A similar percentage of infants were lost to follow-up in both intervention (37 $(19 \%))$ and control groups (66 (22\%))
Selective reporting (re- Low risk porting bias)
The protocol for this study is available: some outcomes, such as effectiveness of a nutrition advice programme for occurrence of diarrhoea, respiratory problems, use of dental caries, and hospitalisation, were not reported. However, all proposed outcomes relevant to this review have been reported

Other bias Low risk

de Oliveira 2012

\section{Study characteristics}

\begin{tabular}{ll}
\hline Methods & RCT \\
\hline Participants & $\begin{array}{l}\text { Study setting: Hospital de Clínicas de Porto Alegre (Brazil), a public general university hospital where } \\
\text { about } 3000 \text { to } 4000 \text { births take place annually } \\
\text { Inclusion criteria: adolescent mothers (younger than } 20 \text { years) living with their mothers or not, living in } \\
\text { the city of Porto Alegre, with healthy non-twin newborn infants with birth weight } \geq 2500 \text { g, in the room- } \\
\text { ing-in ward in Hospital de Clínicas de Porto Alegre, who had started breastfeeding }\end{array}$ \\
& $\begin{array}{l}\text { Exclusion criteria: pairs that had to be separated due to problems related to the mother or the baby, } \\
\text { adolescent mothers who lived with their newborn's paternal grandmother }\end{array}$ \\
& $\begin{array}{l}323 \text { mothers and infants were recruited: } 163 \text { (76 (47\%) males) in the intervention group and } 160 \text { ( } 88 \\
\text { (55\%) males) in the control group }\end{array}$ \\
Intervention group: counselling sessions in the maternity ward and at mother's home in the first 6 \\
months. Session included advice on breastfeeding as per WHO guidelines (in the first 4 months) and \\
complementary feeding as per "Brazillian Nutririon Guidelines for Children Younger Than Two Years \\
Old" from 4 months of age \\
Control group: routine care
\end{tabular}

Outcomes Duration of exclusive breastfeeding

Identification

$\begin{array}{ll}\text { Notes } & \text { Three other publications from the same study were identified from the study registration at clinical- } \\ \text { trials.gov, but outcomes of interest were not reported. Review authors contacted the authors of this } \\ \text { study but did not receive a response }\end{array}$

\section{Risk of bias}

\begin{tabular}{lll}
\hline Bias & Authors' judgement & Support for judgement \\
\hline $\begin{array}{l}\text { Random sequence genera- } \\
\text { tion (selection bias) }\end{array}$ & Low risk & $\begin{array}{l}\text { Participants were assigned to study groups by block random allocation } \\
\text { in groups of } 2 . \text { Two spheres of similar texture and size, } 1 \text { bearing the word } \\
\text { "Yes" (assignment to intervention group) and the other bearing the word } \\
\text { "No" (assignment to control group), were drawn from a dark bag, and partici- } \\
\text { pants were allocated to study groups accordingly }\end{array}$
\end{tabular}

\begin{tabular}{|c|c|c|}
\hline $\begin{array}{l}\text { Allocation concealment } \\
\text { (selection bias) }\end{array}$ & Low risk & $\begin{array}{l}\text { Participants were assigned to study groups by block random allocation } \\
\text { in groups of } 2 \text {. Two spheres of similar texture and size, } 1 \text { bearing the word }\end{array}$ \\
\hline
\end{tabular}

Education of family members to support weaning to solids and nutrition in later infancy in term-born infants (Review) 
de Oliveira 2012 (Continued)

"Yes" (assignment to intervention group) and the other bearing the word "No" (assignment to control group), were drawn from a dark bag, and participants were allocated to study groups accordingly

\begin{tabular}{|c|c|c|}
\hline $\begin{array}{l}\text { Blinding of participants } \\
\text { and personnel (perfor- } \\
\text { mance bias) }\end{array}$ & High risk & $\begin{array}{l}\text { The intervention is not amenable to blinding of participants or of personnel } \\
\text { delivering the intervention. The main outcome of duration of exclusive breast- } \\
\text { feeding is likely to be affected by bias }\end{array}$ \\
\hline
\end{tabular}

All outcomes

$\begin{array}{lll}\begin{array}{l}\text { Blinding of outcome as- } \\ \text { sessment (detection bias) }\end{array} \quad \text { Low risk } & \begin{array}{l}\text { Interviewers who delivered the questionnaire for data collection were blinded } \\ \text { to the group to which the mothers belonged }\end{array}\end{array}$

All outcomes

Incomplete outcome data High risk

(attrition bias)

All outcomes

Selective reporting (re- Low risk porting bias)

Other bias
High risk
$257(79.6 \%)$ of the 323 randomised mothers were included in the final analysis. However, the dropout rate appears to be higher in the control group - 35 mothers (21.9\%) - as compared to the intervention group - 28 mothers (17.5\%)

All outcome measures proposed were reported based on clinicaltrials.gov (NCT00910377)

There appear to be more males ( $55 \%$ vs $47 \%$ ), breastfeeding duration longer than 6 months appears lower among previous children (44\% vs 59\%), and breastfeeding duration for the adolescent mother appears lower (12.9 vs 17.7 months) in the control group, which may introduce bias to the analysis

Ferreira 2019

\section{Study characteristics}

Methods Cluster-RCT

Participants

Study setting: the trial is conducted in Porto Alegre, South of Brazil, which comprises 1.4 million inhabitants. The trial included health centres that are part of the National Health Care System in Brazil, which provides free health care. Families enrolled in these services are predominantly of low-income status

Inclusion criteria: pregnant women in the last trimester were identified and were invited to participate and were enrolled in the study as potential mothers to receive dietary counselling provided by health workers. Births from May 2008 to February 2009 were included in the study

Exclusion criteria (for cluster): $\leq 100$ infant patient visits in 2006, staff sharing between clinics or participation in other contemporaneous community-based dietary programmes

Exclusion criteria (for participants): women reporting a positive HIV test were excluded because of concerns of HIV transmission via breastfeeding

A total of 617 infants were enrolled, of whom 317 (168 males) were in the intervention group and 300 (157 males) in the no intervention group. There was no difference in baseline demographics

Interventions

Intervention group: a standardised training session was conducted by an experienced nutritionist for the healthcare team to outline the "Ten Steps" recommendations and strategies and to incorporate these into follow-up consultations. Health workers received 2 printed materials, as developed by the main researcher, which were delivered to mothers during follow-up consultations

Control group: routine care with no material provided to the healthcare worker

Outcomes

Any breastfeeding at 6 to 9 months 
Ferreira 2019 (Continued)

Identification
Sponsorship source: Ministry of Health (No. 577/200) and Fundacao de Amparo a Pesquisa do Rio Grande do Sul (PPSUS/2006/1537-7)

Author's name: V.R. Ferreira

Institution: Universidade Federal de Ciencias

Email: vivianrodrigues_17@hotmail

Address: Universidade Federal de Cienciasda Saude de Porto Alegre (UFCSPA), Nucleo de Pesquisa em Nutricao, Sarmento Leite 245, Porto Alegre 90050-340, RS, Brasil

\title{
Notes
}

\section{Risk of bias}

\begin{tabular}{lll}
\hline Bias & Authors' judgement & Support for judgement \\
\hline $\begin{array}{l}\text { Random sequence genera- } \\
\text { tion (selection bias) }\end{array}$ & Low risk & $\begin{array}{l}\text { Quote: "Following a stratified randomisation scheme, health centres were } \\
\text { block-randomised by district, with one health centre per district allocated to } \\
\text { the intervention and another to the control group" }\end{array}$ \\
& $\begin{array}{l}\text { It is unclear from this statement how the sequence was generated, although it } \\
\text { would be fair to assume that it was computer generated }\end{array}$
\end{tabular}

\begin{tabular}{|c|c|c|}
\hline $\begin{array}{l}\text { Allocation concealment } \\
\text { (selection bias) }\end{array}$ & Low risk & $\begin{array}{l}\text { Quote: "Of the } 31 \text { eligible health centres, } 16 \text { were initially selected via a wit- } \\
\text { nessed drawing, by the principal investigator, by labelled markers from an } \\
\text { opaque container" }\end{array}$ \\
\hline
\end{tabular}

Blinding of participants High risk Blinding is not possible for this intervention. Outcome of reported breastfeedand personnel (perforing can be influenced by awareness of treatment allocation mance bias)

All outcomes

\section{Blinding of outcome as- High risk} sessment (detection bias) All outcomes

\begin{abstract}
Quote: "Trained field workers, who were not involved in the intervention and who were unaware of group allocation, conducted maternal interviews using questionnaires at baseline (in pregnancy), during home visits at 6 months (range 5-9 months) and at 12 months (range 11- 15 months)"

However, outcome of reported breastfeeding can be influenced by awareness of treatment allocation
\end{abstract}

\begin{tabular}{|c|c|c|}
\hline $\begin{array}{l}\text { Incomplete outcome data } \\
\text { (attrition bias) } \\
\text { All outcomes }\end{array}$ & High risk & $\begin{array}{l}545 \text { of } 715(76 \%) \text { infants completed the study. } 79 \% \text { vs } 74 \% \text { of infants in the in- } \\
\text { tervention vs control group completed the study with reason 'not found' in } \\
12.7 \% \text { and } 9.2 \% \text { in intervention and control groups, respectively }\end{array}$ \\
\hline $\begin{array}{l}\text { Selective reporting (re- } \\
\text { porting bias) }\end{array}$ & Low risk & All proposed outcomes were reported \\
\hline Other bias & Low risk & There was no difference in baseline demographics \\
\hline
\end{tabular}

\section{Fildes 2015}

\section{Study characteristics}

Methods Multi-centre, individually randomised (ratio: 1:1), parallel-group study design


Fildes 2015 (Continued)

Participants
Study setting: UK, Greece, and Portugal between February 2011 and July 2012

Inclusion criteria: random sub-sample of participants in a large study exploring children's fruit and vegetable acceptance during weaning was selected to participate in the study before initiation of complementary feeding. In the large study, 327 women in the final trimester of their pregnancy and mothers of infants younger than 6 months of age were eligible to participate if they were older than 18 years of age at recruitment and were sufficiently proficient in each country's respective native language to understand the study materials, and if their infant was born after 37 weeks' gestation, without diagnosed feeding problems

For this study, 146 mothers and infants were recruited: 75 (33 out of 68 (49\%) males) in the intervention group and 71 (40 (57\%) males) in the control group
Intervention group: counselling sessions either at home or at the paediatrician's office up to 4 weeks before initiation of complementary feedings. Session included advice on introduction of vegetables and the technique of exposure feeding for weaning and on vegetable intake and preference

Control group: usual care without any specific guidance, instructions, or information on weaning with vegetables

\begin{tabular}{|c|c|c|}
\hline Outcomes & \multicolumn{2}{|c|}{ Taste test with intake (g) of the novel vegetable as the primary outcome } \\
\hline \multicolumn{3}{|l|}{ Identification } \\
\hline \multicolumn{3}{|l|}{ Notes } \\
\hline \multicolumn{3}{|l|}{ Risk of bias } \\
\hline Bias & Authors' judgement & Support for judgement \\
\hline $\begin{array}{l}\text { Random sequence genera- } \\
\text { tion (selection bias) }\end{array}$ & Low risk & $\begin{array}{l}\text { Women in the final trimester of their pregnancy and mothers of infants } \\
\text { younger than } 6 \text { months of age }\end{array}$ \\
\hline $\begin{array}{l}\text { Allocation concealment } \\
\text { (selection bias) }\end{array}$ & Low risk & $\begin{array}{l}\text { Women in the final trimester of their pregnancy and mothers of infants } \\
\text { younger than } 6 \text { months of age }\end{array}$ \\
\hline $\begin{array}{l}\text { Blinding of participants } \\
\text { and personnel (perfor- } \\
\text { mance bias) } \\
\text { All outcomes }\end{array}$ & High risk & $\begin{array}{l}\text { Because of the nature of the intervention, parents in the intervention arm and } \\
\text { researchers delivering the intervention were not blind. The same researcher } \\
\text { who delivered the intervention also delivered the taste test }\end{array}$ \\
\hline $\begin{array}{l}\text { Blinding of outcome as- } \\
\text { sessment (detection bias) } \\
\text { All outcomes }\end{array}$ & High risk & $\begin{array}{l}\text { The researcher present at the taste test was the same individual who delivered } \\
\text { the intervention and therefore was not able to be blinded to the condition }\end{array}$ \\
\hline $\begin{array}{l}\text { Incomplete outcome data } \\
\text { (attrition bias) } \\
\text { All outcomes }\end{array}$ & Low risk & $139(95 \%)$ infants completed the study \\
\hline $\begin{array}{l}\text { Selective reporting (re- } \\
\text { porting bias) }\end{array}$ & Low risk & All proposed outcomes were reported \\
\hline Other bias & High risk & $\begin{array}{l}\text { A random sub-sample of participants in a large study was used in this study. It } \\
\text { is unclear how the sub-sample of participants was selected as this may intro- } \\
\text { duce bias to the study }\end{array}$ \\
\hline
\end{tabular}


Koehler 2007

\section{Study characteristics}

\begin{tabular}{ll}
\hline Methods & RCT \\
\hline Participants & $\begin{array}{l}\text { Study setting: Dortmund, Germany, including members of a nationwide compulsory health insurance } \\
\text { company (NOVITAS Vereinigte BKK, Duisburg, Germany) who reported the birth of a baby } \\
\text { Inclusion criteria: mother speaking German and available by telephone, as well as healthy term (> 37 } \\
\text { weeks of pregnancy) infant with birth weight }>2500 \mathrm{~g}\end{array}$ \\
$\begin{array}{ll}183 \text { mothers and infants were recruited: } 142 \text { (68 (48\%) males) in the intervention group and } 41 \text { (22 } \\
\text { (54\%) males) in the control group }\end{array}$ \\
\hline $\begin{array}{l}\text { Intervention group: nutrition counselling sessions via telephone hotline } 3 \text { times per week for } 2 \text { hours } \\
\text { each time (Group 1), written information (Group 2), and personal telephone counselling (Group 3) }\end{array}$ \\
\hline Control group: no counselling \\
\hline Outcomes & Food-based and meal-based dietary scores to evaluate infant's diet \\
\hline Notes & \\
\hline
\end{tabular}

\section{Risk of bias}

\begin{tabular}{|c|c|c|}
\hline Bias & Authors' judgement & Support for judgement \\
\hline $\begin{array}{l}\text { Random sequence genera- } \\
\text { tion (selection bias) }\end{array}$ & Unclear risk & This was not mentioned in the article \\
\hline $\begin{array}{l}\text { Allocation concealment } \\
\text { (selection bias) }\end{array}$ & Unclear risk & This was not mentioned in the article \\
\hline $\begin{array}{l}\text { Blinding of participants } \\
\text { and personnel (perfor- } \\
\text { mance bias) } \\
\text { All outcomes }\end{array}$ & High risk & $\begin{array}{l}\text { Because of the nature of the intervention, parents in the intervention arm } \\
\text { were not blinded }\end{array}$ \\
\hline $\begin{array}{l}\text { Blinding of outcome as- } \\
\text { sessment (detection bias) } \\
\text { All outcomes }\end{array}$ & High risk & $\begin{array}{l}\text { Outcome assessment depended upon maternal recall of infant's diet, whereby } \\
\text { the mother was not blinded to the intervention given }\end{array}$ \\
\hline $\begin{array}{l}\text { Incomplete outcome data } \\
\text { (attrition bias) } \\
\text { All outcomes }\end{array}$ & Low risk & All recruited infants completed the study \\
\hline $\begin{array}{l}\text { Selective reporting (re- } \\
\text { porting bias) }\end{array}$ & Low risk & All proposed outcomes were reported \\
\hline Other bias & High risk & $\begin{array}{l}\text { Only } 37 \% \text { and } 54 \% \text { of potential users used the telephone hotline and personal } \\
\text { telephone counselling, respectively }\end{array}$ \\
\hline
\end{tabular}

\section{Study characteristics}

Education of family members to support weaning to solids and nutrition in later infancy in term-born infants (Review)

Copyright $\odot 2020$ The Cochrane Collaboration. Published by John Wiley \& Sons, Ltd. 
Morandi 2019 (Continued)
Methods
Cluster-RCT

Participants

Study setting: primary paediatricians in the Veneto region (northeastern Italy) registered in their district list of primary care practitioners interested in research projects

Inclusion criteria: healthy full-term newborns whose parents or guardians had given their informed consent at the time of the first routine visit who were followed until the age of 2 years

Exclusion criteria: preterm or post-term birth or any congenital disorder, disease, or syndrome

562 infants were recruited: 295 (48\% males) in the intervention group and 267 (50\% males) in the control group. There is no baseline difference between groups of infants

Intervention group: parents were provided with standardised oral and written nutrition education con-
cerning protective practices at all routine visits scheduled during the children's first 2 years of life (at
$1,3,6,12$, and 24 months of age). Encouraged behaviours were breastfeeding, feeding on demand, re-
sponsive feeding, timely complementary feeding, giving portions based on the child's appetite, alter-
nating protein sources correctly, and playing active games with the child
Control group: routine care and follow-up

Outcomes $\quad$ Change in weight and length between 6 and 12 months
Exclusive breastfeeding at 3 months

Identification

Notes

\section{Risk of bias}

Bias Authors' judgement Support for judgement

Random sequence genera- Low risk tion (selection bias)

Quote: "Twenty-two accepted and were randomly assigned 1:1 to the intervention or control arm using the random selection function of Microsoft Excel. The eleven 'intervention paediatricians' were asked to recruit at least 30 consecutive newborns during the first six months of the study"

\begin{tabular}{ll}
\hline $\begin{array}{l}\text { Allocation concealment } \\
\text { (selection bias) }\end{array}$ & High risk \\
& $\begin{array}{l}\text { Although paediatricians were randomly allocated to the intervention or con- } \\
\text { trol arm, they were aware of their patient's treatment allocation while recruit- } \\
\text { ing the } 30 \text { patients from their practice }\end{array}$
\end{tabular}

\begin{tabular}{ll}
\hline $\begin{array}{l}\text { Blinding of participants } \\
\begin{array}{l}\text { and personnel (perfor- } \\
\text { mance bias) }\end{array}\end{array}$ & $\begin{array}{l}\text { The intervention is not amenable to blinding of participants and personnel, } \\
\text { but outcome measures relevant to this review are unlikely to be affected by } \\
\text { All outcomes }\end{array}$ \\
\hline
\end{tabular}

\begin{tabular}{lll}
\hline $\begin{array}{l}\text { Blinding of outcome as- } \\
\text { sessment (detection bias) } \\
\text { All outcomes }\end{array}$ & Low risk & $\begin{array}{l}\text { The intervention is not amenable to blinding of participants and personnel, } \\
\text { but outcome measures relevant to this review are unlikely to be affected by } \\
\text { lack of blinding }\end{array}$ \\
\hline $\begin{array}{l}\text { Incomplete outcome data } \\
\begin{array}{l}\text { (attrition bias) } \\
\text { All outcomes }\end{array}\end{array}$ & Low risk & $\begin{array}{l}468 \text { of } 562(83 \%) \text { infants completed the study. There was no major difference } \\
\text { in dropout rates across both groups }(81 \% \text { vs } 85 \% \text { in control vs intervention } \\
\text { group) }\end{array}$
\end{tabular}

\begin{tabular}{ll}
\hline $\begin{array}{l}\text { Selective reporting (re- } \\
\text { porting bias) }\end{array}$ & Low risk \\
\end{tabular}


Morandi 2019 (Continued)

Other bias High risk Mother's professional category was higher in control group as compared to the intervention group at baseline

\section{Study characteristics}

\begin{tabular}{ll}
\hline Methods & Cluster-RCT \\
\hline Participants & $\begin{array}{l}\text { Study setting: the study was conducted in Kabale and Kisoro districts in southwestern Uganda because } \\
\text { of the high prevalence of stunting (UBOS - Uganda Demographic and Health Survey, 2011). Town cen- } \\
\text { tres were excluded to minimise differences in socio-economic status and feeding practices. People liv- } \\
\text { ing in the study area are predominantly small-scale farmers. Both districts are densely populated and } \\
\text { are made up of several sub-counties, each consisting of } 18 \text { to } 25 \text { villages } \\
\text { Inclusion criteria: children between } 6 \text { and } 8 \text { months of age } \\
\text { Exclusion criteria: households with a child having a congenital malformation, a physical disorder that } \\
\text { would influence assessments and/or nutrient intake, and/or a diagnosis of mental or brain illness, as } \\
\text { reported by the mother or by a health worker } \\
\text { A total of } 511 \text { infants were enrolled, of whom } 263 \text { (139 males) were in the nutritional counselling group } \\
\text { and } 248 \text { (123 males) were in the no intervention group. There were no apparent differences between in- } \\
\text { tervention and control groups at baseline }\end{array}$
\end{tabular}

Interventions Intervention group: nutrition education was delivered via 3 group meetings over a period of 6 months to 26 groups of mothers ( 4 to 12 mothers per group). It was delivered by a trained education team and included 2 behaviour change techniques: Providing information and prompt practice (i.e. demonstrations of preparing food and stimulating children)

Control group: routine care

Outcomes

Weight-for-age z score at 12 months

Height-for-age z score at 12 months

Weight-for-height $z$ score at 12 months

Head circumference $z$ score at 12 months

Bayley Scales of Infant and Toddler Development III scales (cognitive) at 12 to 16 months

Identification Sponsorship source: study is funded by the Throne Holst Foundation and the University of Oslo

Author's name: Per O. Iversen

Institution: University of Oslo

Email: p.o.iversen@medisin.uio.no

Address: Department of Nutrition, Institute of Basic Medical Sciences, University of Oslo, P.O. Box 1046, Blindern, 0317 Oslo, Norway

Notes

\section{Risk of bias}

\section{Bias}

Authors' judgement Support for judgement 
Muhoozi 2018 (Continued)

Random sequence genera- Low risk Quote. "By use of computer-generated random numbers, villages whose astion (selection bias) signed number matched with the random numbers were selected"

Allocation concealment Low risk (selection bias)
Although investigators were not blinded of the numbers given to each village as the villages were listed alphabetically and were numbered in ascending order, use of computer-generated random numbers to select the village will reduce allocation concealment bias

$\begin{array}{ll}\begin{array}{l}\text { Blinding of participants } \\ \text { and personnel (perfor- }\end{array} & \text { Low risk } \\ \begin{array}{l}\text { mance bias) } \\ \text { All outcomes }\end{array} & \begin{array}{l}\text { The intervention is not amenable to blinding of participants or of personnel } \\ \text { delivering the intervention; however, outcomes (growth and development) in- } \\ \text { cluded in this review are unlikely to be affected by lack of blinding of partici- } \\ \text { pants }\end{array}\end{array}$

Blinding of outcome as- Low risk sessment (detection bias)

All outcomes

Growth and development outcome assessors were blinded to the allocation as stated in Muhoozi 2018. Outcome assessors for Atukunda 2019 outcomes (child development at 36 months) were blinded, but all other outcomes measured previously were not assessed by blinded assessors

Incomplete outcome data Unclear risk (attrition bias)

Attrition bias was unclear as proportionate sampling was used to obtain 10 All outcomes sub-counties ( 6 out of 19 in Kabale, and 4 out of 14 in Kisoro) to participate in the study. Researchers used a 3-stage procedure to obtain households for the study. Hence, only a sub-sample of a population that has received the intervention participated in the study and had outcome measures obtained. This is an appropriate method for a large-scale community study, However, risk of attrition bias is unclear. The follow-up study (Atukunda 2019) included only patients from January to May 2014. This may be fully representative of the whole recruited sample, as this represents only $30 \%$ of the original sample size

\begin{tabular}{ll}
\hline $\begin{array}{l}\text { Selective reporting (re- } \\
\text { porting bias) }\end{array}$ & Low risk
\end{tabular}

Other bias Low risk

Murthy 2019

\section{Study characteristics}

\begin{tabular}{|c|c|}
\hline Methods & Pseudo-randomised controlled trial \\
\hline \multirow[t]{4}{*}{ Participants } & $\begin{array}{l}\text { Study setting: } 2 \text { municipal wards (F North and M East) in the urban slum areas of Mumbai (India) were } \\
\text { purposely selected due to their large slum area, high population proportion classified as low-income, } \\
\text { and no prior exposure to mMitra. Each ward is typically served by } 1 \text { maternity home and } 5 \text { or } 6 \text { health } \\
\text { posts that provide pregnancy and infant health services. Each ward appoints roughly } 100 \text { communi- } \\
\text { ty health workers who make home visits, register pregnant women, and motivate them to seek health } \\
\text { care for themselves and their children }\end{array}$ \\
\hline & Inclusion criteria: pregnant women speaking the Hindi or Marathi language were enrolled in the study \\
\hline & $\begin{array}{l}\text { Exclusion criteria: women without access to a mobile phone at home or not likely to be in Mumbai for } 4 \\
\text { to } 5 \text { months during the pregnancy and post-delivery periods }\end{array}$ \\
\hline & $\begin{array}{l}\text { A total of } 2016 \text { mothers enrolled, of whom } 1516 \text { were in the intervention group and } 500 \text { were in the no } \\
\text { intervention group }\end{array}$ \\
\hline Interventions & $\begin{array}{l}\text { Intervention group: the mMitra package consisted of } 145 \text { voice messages designed to be shared from } \\
\text { when a woman was } 6 \text { weeks pregnant until the infant reached } 1 \text { year of age. Messages were delivered } 2 \\
\text { times per week during pregnancy; they were clustered at } 1 \text { message per day immediately postpartum }\end{array}$ \\
\hline
\end{tabular}


Murthy 2019 (Continued)

for 7 days, and then were reduced in frequency back to 2 messages per week from the second week of infancy. mMitra also provided a free call-back service within 2 days after the original call was received, in case women wanted to hear the messages again. No text messages were delivered through this programme unlike in other programmes

Control group: no information was given

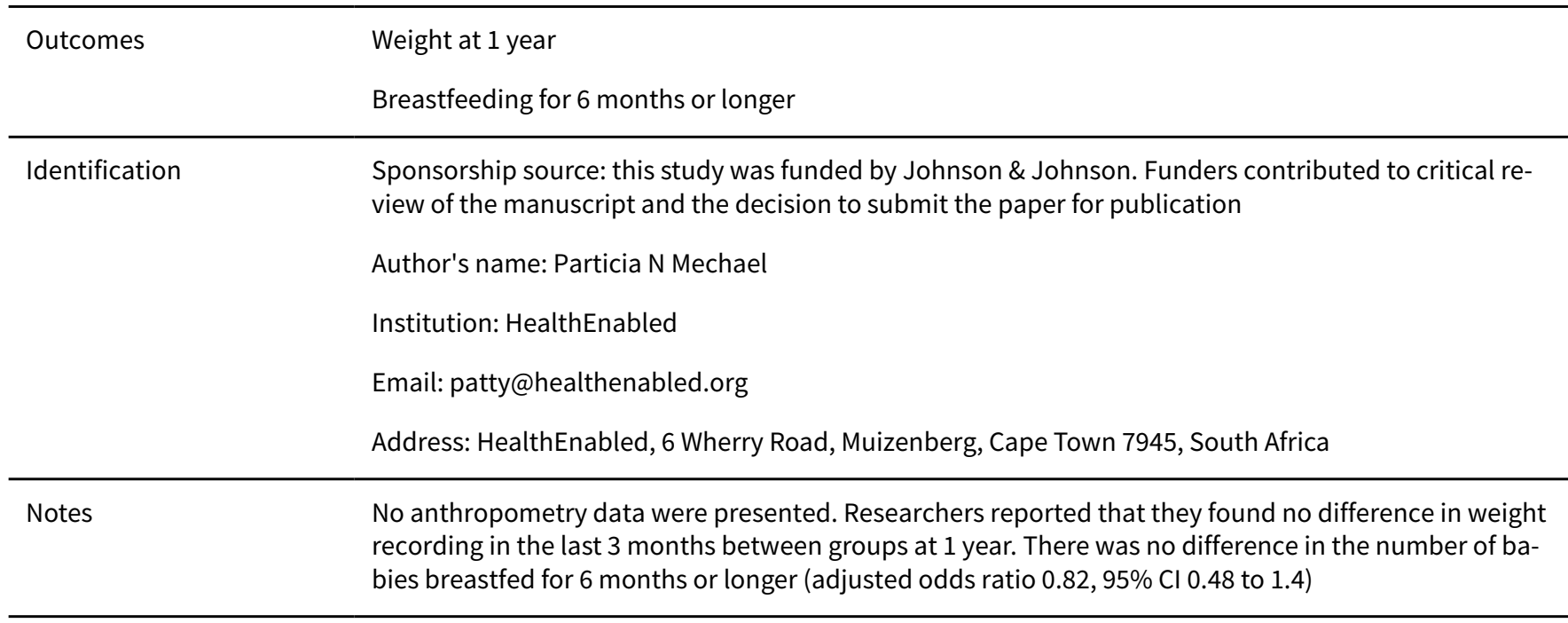

\section{Risk of bias}

\begin{tabular}{|c|c|c|}
\hline Bias & Authors' judgement & Support for judgement \\
\hline $\begin{array}{l}\text { Random sequence genera- } \\
\text { tion (selection bias) }\end{array}$ & High risk & $\begin{array}{l}\text { Quote: "For every four women enrolled consecutively, the first three were as- } \\
\text { signed to the intervention group and the last woman was assigned to the con- } \\
\text { trol group" }\end{array}$ \\
\hline $\begin{array}{l}\text { Allocation concealment } \\
\text { (selection bias) }\end{array}$ & High risk & $\begin{array}{l}\text { Quote: "Pregnant women were identified and enrolled into the study by re- } \\
\text { search team members. They were systematically assigned to either the inter- } \\
\text { vention or control group" }\end{array}$ \\
\hline $\begin{array}{l}\text { Blinding of participants } \\
\text { and personnel (perfor- } \\
\text { mance bias) } \\
\text { All outcomes }\end{array}$ & Low risk & $\begin{array}{l}\text { Although blinding is not possible due to the nature of the intervention, this is } \\
\text { unlikely to affect the objective measure of the outcome of interest (growth) }\end{array}$ \\
\hline $\begin{array}{l}\text { Blinding of outcome as- } \\
\text { sessment (detection bias) } \\
\text { All outcomes }\end{array}$ & Low risk & $\begin{array}{l}\text { Although blinding is not possible due to the nature of the intervention, this is } \\
\text { unlikely to affect the objective measure of the outcome of interest (growth) }\end{array}$ \\
\hline $\begin{array}{l}\text { Incomplete outcome data } \\
\text { (attrition bias) } \\
\text { All outcomes }\end{array}$ & High risk & $\begin{array}{l}\text { Quote: "1038 of the } 1516 \text { women originally enrolled in the intervention group } \\
\text { (69\%) and } 379 \text { of the } 500 \text { women originally enrolled in the control group }(76 \%) \\
\text { were successfully followed from baseline (Time } 1 \text { ) up through when their in- } \\
\text { fants were } 1 \text { year of age (Time } 3) " \\
\text { Quote: "There was greater loss to follow-up in the intervention group as com- } \\
\text { pared to the control group ( }=70,6.7 \% \text { vs } n=12,3.1 \%) "\end{array}$ \\
\hline $\begin{array}{l}\text { Selective reporting (re- } \\
\text { porting bias) }\end{array}$ & High risk & $\begin{array}{l}\text { No anthropometry data were presented although this is } 1 \text { of the study's } 3 \text { main } \\
\text { outcome measures }\end{array}$ \\
\hline Other bias & High risk & $\begin{array}{l}\text { Quote: "More women in the intervention group were employed }(P=0.01) \text {.and } \\
\text { owned a mobile phone }(P=0.0001) \text {. They were more likely to listen to the radio }\end{array}$ \\
\hline
\end{tabular}


Quote: "This study was funded by Johnson \& Johnson. The funders contributed to critical review of the manuscript and the decision to submit the paper for publication"

Nair 2017

\section{Study characteristics}

\begin{tabular}{|c|c|}
\hline Methods & Cluster-RCT \\
\hline \multirow[t]{4}{*}{ Participants } & $\begin{array}{l}\text { Study setting: West Singhbhum and Kendujhar - } 2 \text { adjoining rural districts of Jharkhand and Odisha in } \\
\text { eastern India }\end{array}$ \\
\hline & $\begin{array}{l}\text { Inclusion criteria: individual participants were pregnant women identified and recruited in study clus- } \\
\text { ters and their children }\end{array}$ \\
\hline & $\begin{array}{l}\text { Exclusion criteria: stillbirths and neonatal deaths, infants whose mothers died, those with congenital } \\
\text { abnormalities, multiple births, and mother and infant pairs who migrated out of the study area perma- } \\
\text { nently during the trial period }\end{array}$ \\
\hline & 3001 infants from 120 geographical clusters were recruited in the study \\
\hline Interventions & $\begin{array}{l}\text { Intervention group: community-based workers conduct a single home visit to each pregnant woman in } \\
\text { the third trimester of pregnancy for counselling on maternal nutrition, followed by monthly home visits } \\
\text { to all children younger than } 2 \text { years with counselling for growth promotion, and facilitate } 2 \text { to } 3 \text { partici- } \\
\text { patory meetings with local women's groups per month }\end{array}$ \\
\hline \multirow[t]{5}{*}{ Outcomes } & Change in height in the first 18 months of life \\
\hline & Height-for-age $z$ score at 18 months of age \\
\hline & Weight-for-age $z$ score at 18 months of age \\
\hline & Weight-for-height z score at 18 months of age \\
\hline & Exclusive breastfeeding at 6 months of age \\
\hline
\end{tabular}

Identification

\section{Notes}

\section{Risk of bias}

\begin{tabular}{lll}
\hline Bias & Authors' judgement & Support for judgement \\
\hline $\begin{array}{l}\text { Random sequence genera- } \\
\text { tion (selection bias) }\end{array}$ & Low risk & $\begin{array}{l}\text { Meeting participants put numbered balls corresponding to clusters in each } \\
\text { stratum in a local tombola (lottery device), then sequentially allocated each } \\
\text { ball (cluster) to the intervention or control arm }\end{array}$ \\
\hline $\begin{array}{l}\text { Allocation concealment } \\
\text { (selection bias) }\end{array}$ & High risk & $\begin{array}{l}\text { Due to the nature of the intervention, participants and the intervention team } \\
\text { were not masked to allocation }\end{array}$ \\
\hline $\begin{array}{l}\text { Blinding of participants } \\
\text { and personnel (perfor- } \\
\text { mance bias) }\end{array}$ & Low risk & $\begin{array}{l}\text { Although participants and personnel were not blinded due to the nature of the } \\
\text { intervention, the growth parameters obtained were an objective measure }\end{array}$
\end{tabular}


Nair 2017 (Continued)

All outcomes

\begin{tabular}{lll}
$\begin{array}{l}\text { Blinding of outcome as- } \\
\text { sessment (detection bias) } \\
\text { All outcomes }\end{array}$ & Low risk & The data collection team and the data manager were masked to allocation \\
\hline $\begin{array}{l}\text { Incomplete outcome data } \\
\text { (attrition bias) } \\
\text { All outcomes }\end{array}$ & Low risk & $\begin{array}{l}\text { The overall follow-up rate was similar across both intervention and control } \\
\text { groups at } 86 \% \text { and } 85 \%, \text { respectively }\end{array}$ \\
\hline $\begin{array}{l}\text { Selective reporting (re- } \\
\text { porting bias) }\end{array}$ & High risk & $\begin{array}{l}\text { There was diversion from protocol on outcomes reported as the number of } \\
\text { secondary outcomes was later reduced on the online trial registration form af- } \\
\text { ter feedback from the data monitoring committee. The following outcomes in } \\
\text { the published protocol were not reported change in weight from birth to } 18 \\
\text { months of age, and mean mid-upper arm circumference } z \text { score at } 18 \text { months } \\
\text { of age }\end{array}$
\end{tabular}

Other bias Low risk No difference in baseline demographics was reported between groups

Nikiema 2017

\section{Study characteristics}

\begin{tabular}{|c|c|}
\hline Methods & Cluster-RCT \\
\hline \multirow[t]{4}{*}{ Participants } & $\begin{array}{l}\text { Study setting: health district of Hounde, located } 250 \text { km west of Ouagadougou, Burkina Faso's capital } \\
\text { city }\end{array}$ \\
\hline & $\begin{array}{l}\text { Inclusion criteria: a cohort of pregnant women in their third trimester was prospectively recruited from } \\
\text { each cluster. Pregnant women were eligible for inclusion if they had no intention of leaving the study } \\
\text { area for the next } 2 \text { years and provided informed written consent. Eligible pregnant women were identi- } \\
\text { fied through antenatal consultations (women attending their third antenatal visit) and were included } \\
\text { until the desired sample size was reached at each health centre }\end{array}$ \\
\hline & $\begin{array}{l}\text { Exclusion criteria: only } 1 \text { infant from multiple pregnancy was included. Infants with major birth defects } \\
\text { were excluded }\end{array}$ \\
\hline & 2253 infants were recruited from 12 clusters of a primary healthcare catchment area \\
\hline
\end{tabular}

Height-for-age z score at 12 and 18 months of age, respectively
Weight-for-height z score at 12 and 18 months, respectively
Exclusive breastfeeding at 6 months of age

Identification

\section{Risk of bias}

Education of family members to support weaning to solids and nutrition in later infancy in term-born infants (Review) 
Nikiema 2017 (Continued)

\begin{tabular}{lll} 
Bias & Authors' judgement & Support for judgement \\
\hline $\begin{array}{l}\text { Random sequence genera- } \\
\text { tion (selection bias) }\end{array}$ & Low risk & $\begin{array}{l}\text { For each pair of health centres, } 2 \text { identical pieces of paper were numbered cor- } \\
\text { responding to each health centre and were put into a basket. A volunteer not } \\
\text { involved in the study was asked to choose a paper for the intervention centre }\end{array}$ \\
\hline $\begin{array}{l}\text { Allocation concealment } \\
\text { (selection bias) }\end{array}$ & Low risk & As above \\
\hline $\begin{array}{l}\text { Blinding of participants } \\
\text { and personnel (perfor- } \\
\text { mance bias) } \\
\text { All outcomes }\end{array}$ & High risk & $\begin{array}{l}\text { Participants and personnel were not blinded due to the nature of the interven- } \\
\text { tion. However, anthropometric assessments are unlikely to be affected by lack } \\
\text { of blinding. On the other hand, the other outcome considered in this review } \\
\text { (duration of exclusive breastfeeding) is dependent on parental report and may } \\
\text { be affected by lack of blinding }\end{array}$
\end{tabular}

\begin{tabular}{|c|c|c|}
\hline $\begin{array}{l}\text { Blinding of outcome as- } \\
\text { sessment (detection bias) } \\
\text { All outcomes }\end{array}$ & High risk & $\begin{array}{l}\text { Data collection was performed by trained field workers not involved in inter- } \\
\text { vention delivery who were not blind to the intervention. However, anthropo- } \\
\text { metric assessments are unlikely to be affected by lack of blinding. On the oth- } \\
\text { er hand, the other outcome considered in this review (duration of exclusive } \\
\text { breastfeeding) is dependent on parental report and may be affected by lack of } \\
\text { blinding }\end{array}$ \\
\hline
\end{tabular}
Incomplete outcome data High risk
(attrition bias)

All outcomes
Overall $67.5 \%$ children were lost to follow-up, with $68.6 \%$ and $66.3 \%$ in the intervention and control arms, respectively. No significant difference was reported between the 2 study arms in the distribution of children lost to follow-up. However, reasons for loss to follow-up were not reported

\begin{tabular}{lll}
\hline $\begin{array}{l}\text { Selective reporting (re- } \\
\text { porting bias) }\end{array}$ & Low risk & There was no deviation from the published protocol \\
\hline Other bias & Low risk & $\begin{array}{l}\text { No difference in baseline characteristics was noted in the intervention and } \\
\text { control arms, respectively }\end{array}$ \\
\hline
\end{tabular}

Olaya 2013

\section{Study characteristics}

\begin{tabular}{ll}
\hline Methods & RCT \\
\hline Participants & Study setting: Bogota, Colombia \\
Inclusion criteria: term-born infants with birth weight $>2.500 \mathrm{~g}$ who were exclusively breastfed at 4 \\
months of age and were still breastfeeding at 6 months of age \\
Exclusion criteria: infants with a haemoglobin concentration $<110 \mathrm{~g} / \mathrm{L}$ \\
A total of 85 infants were enrolled, of whom 42 (20 males) were in the new complementary feeding \\
guideline (nutritional counselling) group and 43 (21 males) were in the no intervention group
\end{tabular}


Olaya 2013 (Continued)

Control group: advice on breastfeeding and general recommendations on suitable complementary

foods including meat, food hygiene, and food preparation

WAZ, LAZ, WLZ, head circumference-for-age $z$ score at 12 months
Change in WAZ, LAZ, WLZ, head circumference $z$ score between 6 and 12 months of age
Prevalence of anaemia (haemoglobin $<110 \mathrm{~g} / \mathrm{L}$ ) and iron deficiency (serum ferritin $<12 \mathrm{micrograms} / \mathrm{L}$ )
at 12 months of age
Adverse events (narrative report)

Identification

Notes $\quad \begin{aligned} & \text { There was commercial support for the study: "Tommee Tipee (United Kingdom) donated the feeding } \\ & \text { spoons, cups, and beakers used in the study" }\end{aligned}$

\section{Risk of bias}

\begin{tabular}{|c|c|c|}
\hline Bias & Authors' judgement & Support for judgement \\
\hline $\begin{array}{l}\text { Random sequence genera- } \\
\text { tion (selection bias) }\end{array}$ & Low risk & $\begin{array}{l}\text { Quote: "Randomisation assignments were prepared by using randomised } \\
\text { blocks of permuted length by a member of the team who had contact with } \\
\text { study subjects" }\end{array}$ \\
\hline $\begin{array}{l}\text { Allocation concealment } \\
\text { (selection bias) }\end{array}$ & Low risk & Quote: "Stored in sealed opaque envelopes" \\
\hline $\begin{array}{l}\text { Blinding of participants } \\
\text { and personnel (perfor- } \\
\text { mance bias) } \\
\text { All outcomes }\end{array}$ & Low risk & $\begin{array}{l}\text { The intervention is not amenable to blinding of participants or personnel de- } \\
\text { livering the intervention. However, anthropometric and laboratory assess- } \\
\text { ments are unlikely to be affected by lack of blinding }\end{array}$ \\
\hline $\begin{array}{l}\text { Blinding of outcome as- } \\
\text { sessment (detection bias) } \\
\text { All outcomes }\end{array}$ & Low risk & $\begin{array}{l}\text { Quote: "It was not possible to blind researchers who collected anthropometric } \\
\text { and food-intake data, but laboratory measurements were blinded" }\end{array}$ \\
\hline $\begin{array}{l}\text { Incomplete outcome data } \\
\text { (attrition bias) } \\
\text { All outcomes }\end{array}$ & Low risk & $\begin{array}{l}\text { At } 12 \text { months' follow-up, attrition rate for anthropometric outcomes was 9.4\% } \\
\text { but attrition was higher for serum haemoglobin (14\%) and serum ferritin (33\%) }\end{array}$ \\
\hline $\begin{array}{l}\text { Selective reporting (re- } \\
\text { porting bias) }\end{array}$ & High risk & $\begin{array}{l}\text { Retrospectively registered in the ISRCTN registry (ISRCTN57733004) } \\
\text { Iron and zinc status, anthropometric parameters, and mothers' opinions are } \\
\text { reported, but motor development, energy and nutrient intakes, and serum } \\
\text { retinol are not reported in this paper }\end{array}$ \\
\hline Other bias & High risk & $\begin{array}{l}\text { Baseline differences in groups: "those in the control group were significant- } \\
\text { ly heavier with higher mid-upper arm circumferences, weight-for-age z score, } \\
\text { weight-for-length z score, and MUAC z score at baseline ( } 6 \text { months of age)" }\end{array}$ \\
\hline
\end{tabular}

Palacios 2019

\section{Study characteristics}

Methods RCT


Palacios 2019 (Continued)

Participants

Study setting: participants were recruited from 2 Women, Infants, and Children (WIC) clinics in Puerto Rico and from 4 WIC clinics in Hawaii, USA. WIC clinics were selected based on availability and accessibility to investigators, with the help of the WIC programme at each site.

Inclusion criteria: infants 0 to 2 months old; caregivers must be 18 years of age or older, owners of a mobile phone with unrestricted SMS capability, responsible for infant care, and willing to participate for the full study duration

Exclusion criteria: infants with special diets, infants with limited mobility, preterm birth ( $<37$ weeks), small or large for gestational age (birth weight $<10$ th or $>90$ th percentile), inability to consent to participate, unwillingness to be randomised, not being able to read

A total of 202 infants were enrolled, of whom 102 (51 males) were in the intervention group and 100 (52 males) were in the no intervention group. There was no difference in baseline demographics. There is no baseline group difference months. Intervention SMS was created based on the TransTheoretical Model (TTM) of health behaviour change and focused on reinforcing WIC messages on breastfeeding, preventing overfeeding, delaying introduction of solid foods, and delaying and reducing baby juice consumption. A total of 18 messages (1 per week for 4 months) were sent. All messages were written at a grade 5 level in Spanish for Puerto Rico or English for Hawaii. Each message was about 35 to 50 words long and was sent on different days and times of the week to help prevent participants from ignoring the messages over time

Control group: control SMS was related to general infant health issues related to sleeping, bathing, teething, travelling in a car, medications, handling baby, smoking, immunisation, and care of common illnesses

\begin{tabular}{ll}
\hline Outcomes & $\begin{array}{l}\text { Exclusive breastfeeding at } 6 \text { months } \\
\text { Weight at } 6 \text { months }\end{array}$
\end{tabular}

Identification Sponsorship source: National Institute of Minority Health and Health Disparities (NIMHD)

Author's name: Cristina Palacios

Institution: Florida International University

Email: cristina.palacios@fiu.edu

Address: Department of Dietetics and Nutrition, Robert Stempel College of Public Health \& Social Work, Florida International University, Miami, Florida 33199, USA

\section{Notes}

Exclusive breastfeeding data at 6 months were provided by the study author (CP). Data were not included in the meta-analysis as there was a high dropout of 6 and 0 infants in the intervention and control groups with exclusive breastfeeding data

Weight at 6 months old: no significant group differences were found in weight status at the end of the trial nor weight changes from visit 1 ( 0 to 2 months old) to visit 2 ( 4 to 6 months old). When stratified by site, there was a significant decrease in the proportion of infants classified as underweight during the initial visit compared to the follow-up visit in the intervention group in Puerto Rico. In Hawaii, a significant decrease in the proportion of infants with adequate weight and a significant increase in the proportion of infants with overweight or obesity in both control and intervention groups were noted

\section{Risk of bias}

Bias Authors' judgement Support for judgement

Random sequence genera- Low risk tion (selection bias)
Equal numbers of caregivers were randomised to the control arm (SMS about general infant's health issues) or to the intervention arm (SMS for improving feeding practices) using random block sizes $(2,4$, or 6$)$ with 26 total blocks. A 
Palacios 2019 (Continued)

computer-generated list of randomisation numbers and corresponding IDs was created by a biostatistician. Investigators were blind to the size of each block. Participants were allocated an ID sequentially as they were recruited, and this ID was matched with the randomised group

\begin{tabular}{lll}
\hline $\begin{array}{l}\text { Allocation concealment } \\
\text { (selection bias) }\end{array}$ & Low risk above \\
\hline
\end{tabular}

\begin{tabular}{|c|c|c|}
\hline $\begin{array}{l}\text { Blinding of participants } \\
\text { and personnel (perfor- }\end{array}$ & High risk & $\begin{array}{l}\text { Blinding is not possible for this intervention. The only included outcome - ex- } \\
\text { clusive breastfeeding at } 6 \text { months of age - is subject to bias }\end{array}$ \\
\hline
\end{tabular}

mance bias)

All outcomes

\begin{tabular}{|c|c|c|}
\hline $\begin{array}{l}\text { Blinding of outcome as- } \\
\text { sessment (detection bias) } \\
\text { All outcomes }\end{array}$ & High risk & As above \\
\hline $\begin{array}{l}\text { Incomplete outcome data } \\
\text { (attrition bias) }\end{array}$ & Low risk & $\begin{array}{l}170 \text { of } 202 \text { babies ( } 84.2 \%) \text { completed the study with no difference in dropout } \\
\text { rates across groups }\end{array}$ \\
\hline
\end{tabular}

\begin{tabular}{lll}
\hline $\begin{array}{l}\text { Selective reporting (re- } \\
\text { porting bias) }\end{array}$ & Low risk & All proposed outcomes were reported \\
\hline Other bias & Low risk & There was no difference in baseline demographics \\
\hline
\end{tabular}

Penny 2005

\section{Study characteristics}

\begin{tabular}{ll}
\hline Methods & Cluster-RCT \\
\hline Participants & Setting: peri-urban shanty town areas in Trujillo, Peru \\
& Inclusion criteria: between August 1999 and February 2000 , all newborn infants (aged 10 days or \\
& younger) who had no known congenital malformation or chronic condition that could affect growth \\
& 14 (7 pairs) clusters (health facilities) were randomised (1 pair was excluded because facilities were di- \\
rectly adjacent). Total of 377 infants were enrolled: 187 ( 87 (54\%) males) infants were enrolled in the in- \\
tervention group and $190(98(48 \%)$ males) in the control group
\end{tabular}

Interventions Intervention group: nutrition educational programme designed by formative research aimed at enhancing the quality and coverage of nutrition education

Control group: routine services, not specified in the report

\begin{tabular}{ll}
\hline Outcomes & WAZ, HAZ at 12, 15, and 18 months \\
& WHZ at 18 months \\
\hline Identification & $\begin{array}{l}\text { WAZ and HAZ (LAZ) at } 12 \text { and } 15 \text { months were presented as graphs, and values were calculated using } \\
\text { the scales provided in Adobe Acrobat software (Adobe Systems Software Ireland Ltd.). Standard errors } \\
\text { estimated from these measurements were converted to SDs via the RevMan v5.3 calculator }\end{array}$
\end{tabular}

\section{Risk of bias}

Education of family members to support weaning to solids and nutrition in later infancy in term-born infants (Review) 
Penny 2005 (Continued)

\begin{tabular}{lll} 
Bias & Authors' judgement & Support for judgement \\
\hline $\begin{array}{l}\text { Random sequence genera- } \\
\text { tion (selection bias) }\end{array}$ & Low risk & $\begin{array}{l}\text { Quote: "the investigator (MP) tossing a coin in the presence of the local health } \\
\text { authorities" }\end{array}$ \\
\hline $\begin{array}{l}\text { Allocation concealment } \\
\text { (selection bias) }\end{array}$ & Low risk & $\begin{array}{l}\text { Quote: "randomisation was done before formative research to avoid it acting } \\
\text { as an intervention" }\end{array}$ \\
Investigators used coin flipping as the means of randomisation. If used faith- \\
fully, this would effectively conceal each upcoming allocation
\end{tabular}

\begin{tabular}{|c|c|c|}
\hline $\begin{array}{l}\text { Blinding of participants } \\
\text { and personnel (perfor- }\end{array}$ & Low risk & $\begin{array}{l}\text { Quote: "Families were not told whether they were in the intervention or con- } \\
\text { trol group" }\end{array}$ \\
\hline
\end{tabular}

All outcomes

\begin{tabular}{|c|c|c|}
\hline $\begin{array}{l}\text { Blinding of outcome as- } \\
\text { sessment (detection bias) } \\
\text { All outcomes }\end{array}$ & Low risk & $\begin{array}{l}\text { Quote: "Data were collected by project field workers who were not involved in } \\
\text { the delivery of the intervention" }\end{array}$ \\
\hline $\begin{array}{l}\text { Incomplete outcome data } \\
\text { (attrition bias) } \\
\text { All outcomes }\end{array}$ & Low risk & $\begin{array}{l}\text { At } 18 \text { months' follow-up: in the intervention group } 171 / 187 \text { ( } 91.4 \%) \text { babies } \\
\text { were followed up, and in the control group } 167 / 190 \text { ( } 87.8 \%) \text { babies were fol- } \\
\text { lowed up Combined } 90 \% \text { of babies were followed up }\end{array}$ \\
\hline $\begin{array}{l}\text { Selective reporting (re- } \\
\text { porting bias) }\end{array}$ & Low risk & $\begin{array}{l}\text { Trial registration was not reported in the published paper. However, all pro- } \\
\text { posed outcomes have been reported }\end{array}$ \\
\hline Other bias & High risk & $\begin{array}{l}\text { Socio-economic differences were noted between families in intervention and } \\
\text { control groups (e.g. more educated mother in the intervention group (52\%) in } \\
\text { comparison to the control group (36\%)) }\end{array}$ \\
\hline
\end{tabular}

Rafieya-Kopaei 2019

\section{Study characteristics}

\begin{tabular}{ll}
\hline Methods & Cluster-RCT \\
\hline Participants & $\begin{array}{l}\text { Study setting: } 6 \text { public health centres located in downtown Isfahan (centre of Iran), which were similar } \\
\text { in terms of economic, social, and cultural conditions, were chosen }\end{array}$ \\
& Inclusion criteria: mothers with infants aged 4 months to 4 months and 29 days. Infants were single- \\
ton and exclusively breastfed and had a gestational age of 37 to 42 weeks and no disease or disorder. \\
In addition, there was no medical restriction to continue exclusive breastfeeding for up to 6 months of \\
age. Other inclusion criteria were literacy; having a Smartphone and telegram, an open-source global \\
messaging service, and Soroush - a national open-source messaging service; ability to work with these \\
apps; and consent to co-operate with the researcher \\
Exclusion criteria: as above \\
Total of 90 infants were enrolled: 60 (29 (48\%) males) infants were enrolled in the intervention group \\
and 30 (14 (47\%) males) in the control group. There was no difference in baseline demographics be- \\
tween groups \\
Intervention group: nutrition education was delivered via text messages in the form of gain framed \\
(Group 1) and loss framed (Group 2). Educational messages were based on the book printed by the Min- \\
istry of Health used at healthcare centres of Isfahan, instructions on complementary feeding by the \\
Ministry of Health, and guidelines on complementary feeding by the World Health Organization
\end{tabular}


Rafieya-Kopaei 2019 (Continued)

$$
\text { Control group: no text messages }
$$

$\begin{array}{ll}\text { Outcomes } & \text { Weight and head circumference at } 8 \text { months } \\ \text { Exclusive breastfeeding at } 6 \text { months }\end{array}$

Identification $\quad$ Sponsorship source: Isfahan University of Medical Sciences
Author's name: Fereshteh Zamani-Alavijeh
Institution: Isfahan University of Medical Sciences
Email: fe.zamani@gmail.com; fe.zamani@hlth.mui.ac.ir;
Address: Department of Health Education and Promotion, School of Health, Isfahan University of Med-
ical Sciences, Hezar Jarib Avenue, Isfahan 81676-36954, Iran
No data were available for inclusion in the meta-analysis
Growth: no significant difference was observed between intervention (gain- and loss-framed) groups
and the control group regarding growth status of children (weight and head circumference) and its
trend and $z$ score from birth to 8 months of age
Exclusive breastfeeding: frequency of exclusive breastfeeding until 6 months was significantly higher in
the loss-framed group ( $P=0.03$ )

\section{Risk of bias}

\section{Bias \\ Authors' judgement Support for judgement}

Random sequence genera- Low risk tion (selection bias)

Quote: "At first, six public health centers located in downtown Isfahan, which were similar in terms of economic, social and cultural conditions, were selected and randomly divided into three groups, including GF (Gain Frame) experimental group, LF (Loss Frame) experimental group, and CG (control group). In the next stage, 32 mothers were selected from each group (96 mothers in total) through simple random sampling"

Random sampling was reported to have been used but the method of sampling was not defined

\begin{tabular}{|c|c|c|}
\hline $\begin{array}{l}\text { Allocation concealment } \\
\text { (selection bias) }\end{array}$ & Low risk & $\begin{array}{l}\text { Quote: "Assignment carried out by a lottery performed by someone outside } \\
\text { the research team" }\end{array}$ \\
\hline $\begin{array}{l}\text { Blinding of participants } \\
\text { and personnel (perfor- } \\
\text { mance bias) } \\
\text { All outcomes }\end{array}$ & Low risk & $\begin{array}{l}\text { Quote: "Due to the nature of the intervention, the trainer (the first author) } \\
\text { was not blind to the allocation of groups to gain-framed and loss-framed cate- } \\
\text { gories. However, the participants and the statistics advisor (the third author) } \\
\text { were blind to allocations" }\end{array}$ \\
\hline
\end{tabular}

Blinding of outcome as- Low risk sessment (detection bias)

All outcomes

Due to the nature of the intervention, the trainer (the first author) was not blind to the allocation of groups to gain-framed and loss-framed categories. However, the participants and the statistics advisor (the third author) were blind to allocations." This should not affect objective measurement of growth parameters

Incomplete outcome data Low risk 90 of 96 infants (94\%) completed the study

(attrition bias)

All outcomes

\begin{tabular}{l}
$\begin{array}{l}\text { Selective reporting (re- Low risk } \\
\text { porting bias) }\end{array}$ \\
\hline
\end{tabular}


Rafieya-Kopaei 2019 (Continued)
Other bias
Low risk
There was no difference in baseline demographics

Roy 2007

\section{Study characteristics}

\begin{tabular}{|c|c|}
\hline Methods & Cluster-RCT \\
\hline \multirow[t]{3}{*}{ Participants } & $\begin{array}{l}\text { Setting: community nutrition centres where regular Bangladesh Integrated Nutrition Project (BNIP) ac- } \\
\text { tivities were available in } 4 \text { geographic regions of Bangladesh: northeastern Nikli in Dhaka Division, cen- } \\
\text { tral Sherpur in Rajshahi Division, Southeastern Chakaria in Chittagong Division, and southwestern Da- } \\
\text { cope in Khulna Division }\end{array}$ \\
\hline & Between June 2001 and July 2002 \\
\hline & $\begin{array}{l}\text { Inclusion criteria: children aged } 6 \text { to } 9 \text { months who were well nourished or mildly malnourished (weight } \\
\text { for age above } 75 \% \text { of the median National Centre for Health Statistics standard) Participants were se- } \\
\text { lected from } 121 \text { randomly selected community nutrition centres. } 611 \text { infants were enrolled, of whom } \\
306 \text { ( } 152(49.8 \%) \text { males) infants were in the nutritional counselling group and } 305 \text { ( } 174 \text { ( } 57.1 \%) \text { males) } \\
\text { in the control group }\end{array}$ \\
\hline
\end{tabular}

Interventions Intervention group: nutrition education via focus groups and behavioural change and communication materials such as flip charts

The intervention continued for 6 months, with educational messages once a week for the first 3 months and then once every 2 weeks for the next 3 months

Control: regular BINP services

\begin{tabular}{ll}
\hline Outcomes & WAZ at 12 and 18 months \\
& HAZ (LAZ) at 12 and 18 months \\
& WHZ (WLZ) at 12 and 18 months
\end{tabular}

Identification

Notes

\section{Risk of bias}

\section{Bias Authors' judgement Support for judgement}

Random sequence genera- Unclear risk No information was provided

tion (selection bias)

Allocation concealment $\quad$ Unclear risk $\quad$ No information was provided
(selection bias)

\begin{tabular}{ll}
\hline $\begin{array}{l}\text { Blinding of participants } \\
\text { and personnel (perfor- }\end{array}$ & Low risk \\
$\begin{array}{l}\text { mance bias) } \\
\text { All outcomes }\end{array}$ & $\begin{array}{l}\text { The intervention is not amenable to blinding of participants nor personnel de- } \\
\text { livering the intervention; however, outcomes included in this review are un- } \\
\text { likely to be affected by lack of blinding }\end{array}$ \\
& $\begin{array}{l}\text { Quote: "Families were not told whether they were in the intervention or con- } \\
\text { trol group" }\end{array}$
\end{tabular}

Blinding of outcome as- Unclear risk No information was provided
sessment (detection bias)

Education of family members to support weaning to solids and nutrition in later infancy in term-born infants (Review) 
Roy 2007 (Continued)

All outcomes

\begin{tabular}{lll}
$\begin{array}{l}\text { Incomplete outcome data } \\
\text { (attrition bias) } \\
\text { All outcomes }\end{array}$ & Low risk & $\begin{array}{l}\text { Follow-up at 18 months of age revealed 290/306 (94.7\%) in the intervention } \\
\text { group and 282/305 (92.5\%) in the control group }\end{array}$ \\
\hline $\begin{array}{l}\text { Selective reporting (re- } \\
\text { porting bias) }\end{array}$ & Low risk & $\begin{array}{l}\text { Study protocol is not available. However, all proposed outcomes have been re- } \\
\text { ported }\end{array}$ \\
\hline Other bias & Low risk &
\end{tabular}

\section{Saleem 2014}

\section{Study characteristics}

\begin{tabular}{ll}
\hline Methods & Cluster-RCT \\
\hline Participants & Setting: Bin Qasim Town, Karachi, Pakistan \\
& Between June 2001 and July 2002 \\
& Inclusion criteria: mothers of infants aged 10 to 20 weeks' gestation who were exclusively or partial- \\
ly breastfed but had not started or had recently started (<1 week before enrolment) complementary \\
feeding \\
Exclusion criteria: all infants with weight for age < 5th centile as per the WHO growth chart, history of \\
2 or more hospital admissions, serious congenital anomalies, other chronic conditions impairing feed \\
ing, or presence of acute illness and/or severe anaemia that required urgent hospital treatment \\
A total of 212 infants were recruited (118 in the intervention group and 94 in the control group), but \\
baseline data were reported on 110 infants and 84 infants in the 2 groups, respectively
\end{tabular}

Interventions Intervention group: 4 visits (baseline and then at 10 weekly intervals) with 10 key messages developed on WHO/UNICEF recommended practices: importance of breastfeeding continuation for 2 years, hygiene, complementary feeding initiation at 6 months, advice on promoting protein and iron-rich complementary foods

The intervention continued for 6 months with education messages provided once a week for the first 3 months and then once every 2 weeks for the next 3 months

Control: regular BINP services

\begin{tabular}{l} 
Wutcomes \\
Length \\
Mid-upper arm circumference \\
WAZ, HAZ, and WHZ at 10 weeks, 20 weeks, and 30 weeks after intervention \\
Age at which measurement was done was not standardised or reported \\
\hline Identification \\
\hline Notes \\
$\begin{array}{l}\text { Insufficient outcome data (age at which measurement was done) were reported for us to include the } \\
\text { study in the rew }\end{array}$
\end{tabular}

\section{Risk of bias}

Education of family members to support weaning to solids and nutrition in later infancy in term-born infants (Review) 
Saleem 2014 (Continued)

\section{Bias Authors' judgement Support for judgement}

Random sequence genera- Low risk 10 geographically distinct areas were randomly assigned via a random numtion (selection bias) bers table to educational intervention and control

Allocation concealment Unclear risk This was not described in the article

(selection bias)

Blinding of participants Unclear risk This was not described in the article
and personnel (perfor-
mance bias)
All outcomes

Blinding of outcome as- Unclear risk This was not described in the article
sessment (detection bias)

All outcomes

\begin{tabular}{|c|c|c|}
\hline $\begin{array}{l}\text { Incomplete outcome data } \\
\text { (attrition bias) } \\
\text { All outcomes }\end{array}$ & Low risk & $\begin{array}{l}170(80.2 \%) \text { infants were followed up until the end of the study, comprising } 95 \\
(80.5 \%) \text { and } 75(79.8 \%) \text { infants in intervention and control groups, respective- } \\
\text { ly, with similar proportions of infants dropped out for various reasons includ- } \\
\text { ing migrated ( } 20 \text { and } 15) \text {, refused length measurement ( } 2 \text { and } 3) \text {, and violated } \\
\text { study protocol ( } 1 \text { and } 1) \text { for intervention and control groups, respectively }\end{array}$ \\
\hline
\end{tabular}

\begin{tabular}{|c|c|c|}
\hline $\begin{array}{l}\text { Selective reporting (re- } \\
\text { porting bias) }\end{array}$ & Low risk & All proposed outcomes were reported \\
\hline Other bias & High risk & $\begin{array}{l}\text { Infants in the intervention group were younger at } 106.5 \pm 22.4 \text { days (mean } \pm \\
\text { standard deviation) as compared to } 113.7 \pm 24.5 \text { days in the control group, } \\
\text { with higher mid-upper arm circumference of } 12.5 \pm 0.9 \mathrm{~cm} \text { as compared to } 12.2 \\
\pm 1.1 \mathrm{~cm} \text { in the control group. A higher rate of illiteracy was noted in the con- } \\
\text { trol group }(67 \%) \text { vs the intervention group }(47 \%)\end{array}$ \\
\hline
\end{tabular}

Shi 2009

\section{Study characteristics}

\begin{tabular}{ll}
\hline Methods & Cluster-RCT \\
\hline Participants & Setting: Laishui County, Hebei Provence, northwest China \\
& Between April and September of 2006 \\
& Inclusion criteria: full term (gestational age > 37 weeks), singletons, without major birth defects, aged 2 \\
to 4 months at the time of the baseline survey & \\
& $\begin{array}{l}599 \text { infants enrolled from } 8 \text { clusters - } 294 \text { (142 (48\%) males) in the intervention group and 305 (162 } \\
\text { (53\%) males) in the control group }\end{array}$ \\
\hline Interventions & $\begin{array}{l}\text { and hygiene, childhood nutrition and growth, and responsive feeding style; (2) demonstrations of } \\
\text { preparing enhanced weaning food recipes, which were formulated using locally available, affordable, } \\
\text { acceptable, nutrient-dense foods; (3) booklets that contained infant feeding guidance and methods of } \\
\text { preparing recommended recipes; and (4) home visits every } 3 \text { months to identify possible feeding prob- } \\
\text { lems and to provide individual counselling } \\
\text { Control group: received a standard package of child health care from township hospitals, which includ- } \\
\text { ed breastfeeding counselling }\end{array}$
\end{tabular}

Education of family members to support weaning to solids and nutrition in later infancy in term-born infants (Review) 
Shi 2009 (Continued)

Weight change from 6 to 12 months
Length change from 6 to 12 months
WAZ, HAZ, and WHZ at 12,15 , and 18 months (in the Zhang 2013 paper)

Identification

Notes Standard deviation for changes in anthropometric measures from baseline were imputed via data provided in the paper; we used standard deviation for change (Bhandari 2001) Follow-up data to 18 months with outcomes reported as z scores were published subsequently (Zhang 2013)

Study was funded by Proctor and Gamble

\section{Risk of bias}

Bias Authors' judgement Support for judgement

Random sequence genera- Unclear risk tion (selection bias)

Quote: "the paired townships were listed alphabetically in blocks of two and assigned randomly to be intervention or control sites"

However, the method of randomisation is not clear

\begin{tabular}{|c|c|c|}
\hline $\begin{array}{l}\text { Allocation concealment } \\
\text { (selection bias) }\end{array}$ & Unclear risk & $\begin{array}{l}\text { Townships were listed alphabetically, but whether there was allocation con- } \\
\text { cealment or not cannot be judged, as the method of randomisation is not de- } \\
\text { scribed in sufficient detail }\end{array}$ \\
\hline
\end{tabular}
scribed in sufficient detail

\begin{tabular}{ll}
\hline $\begin{array}{l}\text { Blinding of participants } \\
\text { and personnel (perfor- }\end{array}$ & Low risk \\
$\begin{array}{l}\text { mance bias) } \\
\text { All outcomes }\end{array}$ & $\begin{array}{l}\text { blinding of participants nor personnel delivering the intervention; outcomes } \\
\text { included in this review are unlikely to be affected by lack of blinding }\end{array}$
\end{tabular}

\begin{tabular}{|c|c|c|}
\hline $\begin{array}{l}\text { Blinding of outcome as- } \\
\text { sessment (detection bias) } \\
\text { All outcomes }\end{array}$ & Unclear risk & No information was provided \\
\hline $\begin{array}{l}\text { Incomplete outcome data } \\
\text { (attrition bias) } \\
\text { All outcomes }\end{array}$ & High risk & $\begin{array}{l}\text { At } 12 \text { months' follow-up, the attrition rate was } 19.9 \% \text { in total ( } 12.9 \% \text { of infants } \\
\text { from the intervention group and } 23.3 \% \text { of infants from the control group were } \\
\text { missing) Reasons for loss to follow-up are explained. However, unknown rea- } \\
\text { son was higher in the control group at } 16(5.2 \%) \text { than in the intervention group } \\
\text { at } 3(1.0 \%) \text { infants }\end{array}$ \\
\hline $\begin{array}{l}\text { Selective reporting (re- } \\
\text { porting bias) }\end{array}$ & Low risk & $\begin{array}{l}\text { Study protocol is not available. However, all proposed outcomes have been re- } \\
\text { ported }\end{array}$ \\
\hline Other bias & High risk & $\begin{array}{l}\text { At baseline, there were some differences in parental occupation between the } 2 \\
\text { groups }\end{array}$ \\
\hline
\end{tabular}

Vazir 2013

\section{Study characteristics}

\begin{tabular}{ll}
\hline Methods & Cluster-RCT \\
\hline Participants & Setting: villages in Andhra Pradesh, India
\end{tabular}


Vazir 2013 (Continued)

Inclusion criteria: clusters with population size of at least 1000; all pregnant women in the third trimester of pregnancy in participating villages were enrolled and infants followed up from 3 to 12 months of age

210 pregnant women were enrolled in the nutrition education group and 202 in the control group. At baseline, there were 207 (100 (48\%) males) infants in the intervention group and 199 (117 (51\%) males) in the control group

Interventions

Intervention group: routine Integrated Child Development Services (ICDS) and 11 nutrition education messages based on sustained breastfeeding and complementary feeding twice or 4 times a month home visits over 12 months

Control group: routine ICDS services only

Change in weight and height between 6 and 12 months
WAZ and HAZ at 12 and 15 months
The paper reports weights at 6 and 12 months
On request, study authors provided data on change in weight between 6 and 12 months (mean, SD) and
on WAZ and HAZ at 12 and 15 months

Identification

Notes

Study had 2 intervention groups: nutrition education and nutrition education + responsive play. For this review, we have used data from control and nutrition education groups only

\section{Risk of bias}

\begin{tabular}{lll}
\hline Bias & Authors' judgement & Support for judgement \\
\hline $\begin{array}{l}\text { Random sequence genera- } \\
\text { tion (selection bias) }\end{array}$ & Low risk & $\begin{array}{l}\text { Quote: "the random allocation using a random number generator", using com- } \\
\text { puter software }\end{array}$ \\
\hline $\begin{array}{l}\text { Allocation concealment } \\
\text { (selection bias) }\end{array}$ & Low risk & $\begin{array}{l}\text { Quote: "allocation was undertaken by a researcher who was not familiar with } \\
\text { the villages or their characteristics" }\end{array}$ \\
\hline $\begin{array}{l}\text { Blinding of participants } \\
\text { and personnel (perfor- } \\
\text { mance bias) }\end{array}$ & Low risk & $\begin{array}{l}\text { No information was provided. However, the intervention is not amenable to } \\
\text { blinding of participants nor personnel delivering the intervention; outcomes } \\
\text { included in this review are unlikely to be affected by lack of blinding }\end{array}$ \\
\hline $\begin{array}{l}\text { Blinding of outcome as- } \\
\text { sessment (detection bias) } \\
\text { All outcomes }\end{array}$ & Low risk & $\begin{array}{l}\text { Quote: "the assessment teams were blinded to the intervention and had no in- } \\
\text { teraction with the village women" }\end{array}$ \\
\hline $\begin{array}{l}\text { Incomplete outcome data } \\
\text { (attrition bias) } \\
\begin{array}{l}\text { All outcomes } \\
\text { Selective reporting (re- }\end{array}\end{array}$ & Low risk \\
$\begin{array}{l}\text { porting bias) } \\
\text { Other bias }\end{array}$ & Low risk & $\begin{array}{l}\text { At 12 months, 375 (91.0\%) babies had growth parameters measured that were } \\
\text { included in this review }\end{array}$ \\
\hline
\end{tabular}


Watt 2009

\section{Study characteristics}

\begin{tabular}{ll}
\hline Methods & RCT \\
\hline Participants & Setting: inner London boroughs of Camden and Islington from December 2002 to February 2004 \\
Inclusion criteria: women with non-professional occupation who understands written and spoken Eng- \\
lish; resident in the area. Singleton babies born at > 37 weeks with birth weight above $2500 \mathrm{~g}$ \\
Exclusion criteria: women younger than 17 years old; infants with diagnosis of a serious medical condi- \\
tion or on special diets or over 12 weeks of age at recruitment \\
157 women were enrolled in the nutrition education group and 155 in the control group
\end{tabular}

Interventions Intervention group: monthly home visits by a group of trained local mothers starting when the baby was about 3 months old until the baby's first birthday to complement support and advice offered by health professionals

Control group: standard professional support of health visitors and general practitioners

\begin{tabular}{ll}
\hline Outcomes & Primary outcome \\
& Daily vitamin C intake from fruits as the primary outcome \\
& Other outcomes \\
Feeding habit & Dietary intake \\
Maternal knowledge & Weight and height of infants at 12 months and at 18 months \\
\hline
\end{tabular}

Identification

Notes

Data from the study were insufficient for inclusion in the meta-analysis as the study reported exclusive breastfeeding for less than 4 months and growth parameters at 3,12 , and 18 months only. Hence, change in growth parameters between 6 and 12 months of age could not be calculated

\section{Risk of bias}

\begin{tabular}{lll}
\hline Bias & Authors' judgement & Support for judgement \\
\hline $\begin{array}{l}\text { Random sequence genera- } \\
\text { tion (selection bias) }\end{array}$ & Low risk & $\begin{array}{l}\text { Quote: "A random allocation schedule was prepared in advance using random } \\
\text { digit computer tables" }\end{array}$ \\
\hline $\begin{array}{l}\text { Allocation concealment } \\
\text { (selection bias) }\end{array}$ & Low risk & $\begin{array}{l}\text { Quote: "Following recruitment, women were allocated a sequential identifica- } \\
\text { tion number and simple randomisation was used to allocate them to either in- } \\
\text { tervention or control group. The study administrator was responsible for the } \\
\text { randomisation process. As a result, those responsible for recruiting and as- } \\
\text { sessing outcomes were all masked to group assignment" }\end{array}$ \\
\hline $\begin{array}{l}\text { Blinding of participants } \\
\text { and personnel (perfor- } \\
\text { mance bias) }\end{array}$ & Low risk & $\begin{array}{l}\text { No information was provided; however, the intervention is not amenable to } \\
\text { blinding of participants nor personnel delivering the intervention. Outcomes } \\
\text { included in this review (growth parameters) are unlikely to be affected by lack } \\
\text { of blinding }\end{array}$ \\
\hline
\end{tabular}


Watt 2009 (Continued)

\begin{tabular}{|c|c|c|}
\hline $\begin{array}{l}\text { Blinding of outcome as- } \\
\text { sessment (detection bias) } \\
\text { All outcomes }\end{array}$ & Low risk & $\begin{array}{l}\text { For the purpose of the growth parameters, the article does not mention who } \\
\text { will carry out follow-up at } 12 \text { and } 18 \text { months of age to obtain the growth para- } \\
\text { meters. However, calibrated and standardised equipment is used }\end{array}$ \\
\hline
\end{tabular}

\begin{tabular}{|c|c|c|}
\hline $\begin{array}{l}\text { Incomplete outcome data } \\
\text { (attrition bias) } \\
\text { All outcomes }\end{array}$ & High risk & $\begin{array}{l}212(68 \%) \text { infants completed follow-up at } 18 \text { months; a large number of moth- } \\
\text { ers could not be contacted }\end{array}$ \\
\hline $\begin{array}{l}\text { Selective reporting (re- } \\
\text { porting bias) }\end{array}$ & Low risk & All proposed outcomes were reported \\
\hline
\end{tabular}

Other bias Low risk

CG: control group.

$\mathrm{Cl}$ : confidence interval.

GF: gain frame.

HAZ: height-for-age z score.

ICDS: Integrated Child Development Services.

LAZ: length-for-age z score.

LF: loss frame.

MUAC: mid-upper arm circumference.

RCT: randomised controlled trial.

SD: standard deviation.

SMS: short messaging service.

TTM: TransTheoretical Model.

UNICEF: United Nations Children's Fund.

WAZ: weight-for-age z score.

WHO: World Health Organization.

WHZ: weight-for-height z score.

WIC: Women, Infants, and Children programme.

WLZ: weight-for-length z score.

Characteristics of excluded studies [ordered by study ID]

\begin{tabular}{ll}
\hline Study & Reason for exclusion \\
\hline Aboud 2008 & Setting: rural Bangladesh \\
& $\begin{array}{l}\text { Cluster-randomised controlled trial of 6-session educational programme about responsive feeding } \\
\text { for mothers of 12- to 24-month-old children }\end{array}$ \\
& Demonstrated significant improvements in child self-feeding and weight gain in the intervention \\
& group \\
& Reason for exclusion: ineligible population - participants were > 1 year of age
\end{tabular}

Ahmad 2019 Recruited infants were older than 1 year of age

Brown 1992

Reason for exclusion: this study was not an RCT; participants may be $>12$ months old at baseline

Setting: rural Bangladesh

Families with weaning-age children were given nutrition education about weaning practices. Controls were selected from 5 other villages located 1 hour by foot away from the intervention sites

Children were 4 to 14 months old at recruitment and 9 to 18 months old at follow-up

Education of family members to support weaning to solids and nutrition in later infancy in term-born infants (Review) Copyright @ 2020 The Cochrane Collaboration. Published by John Wiley \& Sons, Ltd. 


\begin{tabular}{ll}
\hline Study & Reason for exclusion \\
\hline & $\begin{array}{l}\text { WAZ declined in both groups, but weight gain and final WAZ were significantly higher among chil- } \\
\text { dren in the intervention group when compared to those in the control group }\end{array}$ \\
\hline Carmichael 2019 & $\begin{array}{l}\text { This study was excluded as the intervention is an mHealth tool given to front-line healthcare work- } \\
\text { ers with general support for managing workload and better information. No nutrition education } \\
\text { was provided to participants }\end{array}$ \\
\hline
\end{tabular}

Cofie 2012

This study was excluded as participants were over 1 year of age at baseline

Study setting: rural Ghana

Cluster-randomised controlled trial ( 3 arms: integrated education (nutrition and agricultural education), nutrition education, and control)

Children were 6 to 24 months old at recruitment and were followed up for 9 months. This study had a very high dropout rate (43\%), and results do not show a difference in change in WAZ, HAZ, or WLZ between groups randomised to nutrition education when compared to the control group

Excluded as this study was conducted to determine the advantage of starting complementary feeding before 6 months

Set in Honduras, exclusively breastfeeding mothers were randomised to continued exclusive breastfeeding up to 6 months; introduction of complementary feeding at 4 months with ad libitum nursing from 4 to 6 months; or introduction of complementary breastfeeding at 4 months with maintenance of baseline nursing frequency from 4 to 6 months. Outcomes were assessed at 6 months, and there were no differences in weight or length gain

Cohen 1995

Randomised trial conducted to evaluate the impact of weaning at 4 vs 6 months. Researchers provided follow-up at the age of 12 months in the cohort of Cohen 1994

Cupples 2010

Reason for exclusion: ineligible intervention

Set in Northern Ireland, this is a randomised controlled trial of peer-to-peer mentoring during pregnancy and first year postpartum. Results show that the intervention did not improve infant development at 1 year of age

Daniels 2013

Reason for exclusion: included some preterm infants (cut-off for term gestation was $>35$ weeks); outcomes were reported at 22 months of age

Setting: Brisbane and Adelaide, Australia

Inclusion criteria: first-time mothers of healthy term infants ( $>35$ weeks' gestation), $\geq 2500$ grams birth weight; facility with written and spoken English; no documented or self-reported history of intravenous substance abuse, domestic violence, or eating disorder

A total of 698 infants were recruited - 346 (173 (50\%) males) in the control group and 352 (171 (49\%) males) in the intervention group

Intervention: 6 interactive group sessions of 1 to 1.5 hours delivered by trained facilitators and dieticians

9 months after the intervention, 307 (89\%) in the control group and 291 (83\%) in the intervention group were followed up

Anthropometric outcomes are reported for 18 months after baseline and demonstrate that fewer children in the intervention group were overweight or obese when compared to the control group 


\begin{tabular}{ll}
\hline Study & Reason for exclusion \\
\hline & $\begin{array}{l}\text { circumference } z \text { scores (control group mean (SD) } 0.72(1.01) \text {, intervention group mean } 0.67 \text { (0.67); P } \\
=0.62) \text { at } 5 \text { years of age were reported }\end{array}$ \\
\hline
\end{tabular}

Dewey 1998

This study was excluded as the intervention was time of weaning in exclusively breastfed infants, and no other nutrition education was provided in either group

Setting: Honduras

Randomised controlled trial of exclusive breastfeeding for 6 months vs exclusive breastfeeding for 4 months with breast milk + iron fortified foods from 4 months. This study included 164 full-term infants $\geq 2000 \mathrm{~g}$ at birth and showed that mean haemoglobin was significantly higher in the intervention group when compared to the control group, but the percentage of children with haemoglobin $<110 \mathrm{~g} / \mathrm{L}$ was the same in both groups

Erickson $2018 \quad$ Nutrition education was combined with other intervention(s)

Fahmida $2015 \quad$ This study was excluded as it was not an RCT

This quasi-experimental study was set in rural Indonesia and studied the effectiveness of optimised complementary feeding recommendations in 455 children aged 9 to 16 months at baseline. Results show increased intakes of calcium, iron, niacin, and zinc among children in the intervention group, although intakes were below the required ranges in both groups

Reason for exclusion: quasi-experimental (this study was conducted in 4 clusters, 1 of which was designated to the intervention group because it had been previously exposed to the study intervention at the pre-testing stage; the other 3 clusters were randomised); included infants were older than the target population for this review

Frongillo $2017 \quad$ Both control and intervention groups received nutrition education

Gross 2016

This is a report from an ongoing study - a randomised controlled trial of a child obesity prevention intervention (prenatal and postpartum individual nutrition/breastfeeding counselling) compared with standard care - scheduled to end in July 2019. In this paper, study authors report outcomes at 3 months of age demonstrating higher prevalence of exclusive breastfeeding on 24-hour diet recall in the intervention group compared to the control group

Reason for exclusion: the paper reported exclusive breastfeeding at 3 months, and the outcome for the review is exclusive breastfeeding at 6 months

Study authors were emailed to request breastfeeding outcomes at 6 months

Guldan 2000

Reason for exclusion: study authors stated that complete randomisation of townships selected was not possible

This study investigated effects of providing counselling and growth monitoring by trained nutrition educators in villages in the Sichuan province, China, to all pregnant women and women with infants up to 1 year old. It included 250 infants in the intervention group and 245 in the control group. After 1 year of the intervention, infants in the intervention group were heavier and longer at 12 months of age, and there was higher prevalence of breastfeeding and a lower rate of anaemia

Guptill 1982 This study was excluded from the review as it was not a randomised trial and outcomes measured are not relevant to the review

Conducted in Kawara State in southwestern Nigeria, this study evaluated nutrition education to improve daily dietary intake in children 4 to 24 months of age by introducing a fortified, home-prepared weaning food. Mothers were surveyed 2 to 8 weeks after the intervention to assess knowledge, trial, and adoption of the recipe. The evaluation demonstrated increased knowledge and trial of the recipe. Adoption rate was $20 \%$ at 2 to 6 weeks but declined to $9.8 \%$ by 7 to 8 weeks post intervention 


\begin{tabular}{ll}
\hline Study & Reason for exclusion \\
\hline Jonsdottir 2012 & Excluded as the intervention did not involve any nutrition education except the time of weaning \\
& $\begin{array}{l}\text { Based in Iceland, } 119 \text { mothers of exclusively breastfeeding, term-born, healthy infants were ran- } \\
\text { domly assigned to exclusively breastfeed up to } 6 \text { months or to introduce complementary feeding at } \\
\text { 4 months of age. Outcomes were reported at } 6 \text { months of age. There was no difference in growth. } \\
\text { Infants in the early complementary feeding group had higher serum ferritin levels at } 6 \text { months of } \\
\text { age, but there was no difference in serum haemoglobin levels }\end{array}$
\end{tabular}

\begin{tabular}{ll}
\hline Kang 2017 & Both control and intervention groups received nutrition education \\
\hline Kapil 1995 & $\begin{array}{l}\text { This study was excluded as it is a survey of breastfeeding and weaning practices conducted in } \\
\text { Haryana, India }\end{array}$ \\
\hline Kilaru 2005 & This was excluded as it is not a randomised controlled trial \\
& $\begin{array}{l}\text { Set in India, this study included } 138 \text { infants. The intervention consisted of trained research staff } \\
\text { providing nutrition education to primary caregivers. Results do not show any differences in weight } \\
\text { gain velocity between children in the intervention and control groups, but girls enrolled in the in- } \\
\text { tervention group had a weight velocity that was } 77 \text { ger month greater than that of non-interven- } \\
\text { tion girls }\end{array}$
\end{tabular}

\begin{tabular}{ll}
\hline Kim 2018 & This study was excluded as recruited infants were over 1 year of age \\
\hline Kim 2019 & This study was excluded as recruited infants were over 1 year of age \\
\hline Krebs 2006 & $\begin{array}{l}\text { This was a randomised controlled trial comparing weaning with pureed beef vs fortified cereal as } \\
\text { the first weaning food in exclusively breastfed infants. This study was excluded as there was no } \\
\text { control group and the intervention did not include any other educational component apart from } \\
\text { specifying the food item to be used as first food }\end{array}$
\end{tabular}

Krebs $2013 \quad$ Comparisons in this randomised trial were similar to Krebs 2006

Healthy, term infants were randomised to receive commercially available pureed meats, iron- and zinc-fortified infant cereals, or organic whole grain iron-only fortified infant cereals Infants received these consistently from 6 to 9 months of age. There was no control group (no intervention) in this study

\begin{tabular}{ll}
\hline Lakkam 2014 & This study was excluded due to ineligible study design - it provides an analysis of data obtained \\
from an observational study
\end{tabular}

Maingi $2018 \quad$ This study was excluded as recruited infants were over 1 year of age

Makrides $2002 \quad$ This study was excluded as the intervention was food supplementation with egg yolk

161 term-born, 6-month-old healthy infants were randomly allocated to receive no dietary intervention; regular eggs; or n-3 fatty acid enriched eggs (4 egg yolks per week between 6 and 12 months of age).

At 12 months, weight, length, and head circumference were not significantly different between groups

\begin{tabular}{ll}
\hline Manjang 2018 & This study was excluded as recruited infants were over 1 year of age \\
\hline Martinez 2018 & This study was excluded as recruited infants were over 1 year of age \\
\hline Morison 2018 & This study was excluded as nutrition education was combined with other intervention(s) \\
\hline Moursi 2003 & This study was excluded as the intervention was provision of flour with maize/soy-based amylase \\
\hline \hline
\end{tabular}

Education of family members to support weaning to solids and nutrition in later infancy in term-born infants (Review) 


\section{Study \\ Reason for exclusion}

Navarro 2013
This study was excluded because it is not an RCT

Set in the Dominican Republic, this paired-cluster quasi-experimental study included 266 mother-child dyads ( 26 communities) in the intervention group and 337 (27 communities) in the control group. The intervention was started before the third trimester of pregnancy and was delivered by trained community counsellors; it consisted of home visits and group meetings. Outcomes were measured at 18 months' follow-up, and there was $26 \%$ loss to follow-up in the intervention group and $22 \%$ in the control group

Weight-for-length z scores were reported at follow-up (nutrition education mean (SD) -0.46 (1.21); conventional management mean -0.66 (1.09); $\mathrm{P}=0.067$ )

Negash 2014

This study was excluded because children were over 1 year of age at baseline

Set in Ethiopia, 100 mother-infant dyads were randomly assigned to receive nutrition education or no intervention

The intervention consisted of nutrition education sessions twice a month for 6 months, where 8 specific messages were promoted and porridge preparation was demonstrated. The mean age of children was over 1 year of age at baseline. After 6 months of intervention, children in both groups had similar gains in weight and height

\begin{tabular}{ll}
\hline Newman 2014 & This is a secondary analysis - not a randomised controlled study \\
\hline Owais 2017 & This was not a randomised controlled study \\
\hline Palwala 2009 & This study was excluded as it is an observational study \\
& $\begin{array}{l}414 \text { mothers of } 6 \text { - to } 36 \text {-month-old children were provided } 3 \text { group educational sessions with week- } \\
\text { ly follow-up. Outcomes included analysis of diet and maternal knowledge }\end{array}$
\end{tabular}

Paul 2010

This study was excluded as the interventions were aimed at teaching parents about differences between hunger and other sources of infant distress, satiety cues, and soothing strategies

\section{Reinbott 2018}

This study was excluded as recruited infants were over 1 year of age
This study was excluded as the children were over 1 year of age at baseline

Set in Bangladesh, 282 children with moderate-degree malnutrition were randomised to intensive nutrition education, supplementary feeding, or conventional management. Nutrition education was provided to women in groups and included messages and demonstration of preparation of complementary foods. This study showed improved weight-for-age z scores after 3 months in both intervention groups when compared to the control group

\section{Ruel 1992} and use of growth charts, and the children were $<2$ years old at inclusion.

Mothers with children $<2$ years of age were sequentially assigned to be given growth charts or no growth charts. Mothers who were given growth charts received some nutrition education and growth monitoring information

Santos 2001

This study was an evaluation of the WHO Integrated Management of Childhood Illness strategy in Southern Brazil. Training was provided to 33 doctors based at 28 randomly selected health centres. A total of 424 children were recruited from these health centres. Results show improved growth (measured by weight and height gain or improvements in $z$ scores) between 2 points of observation, particularly in infants who were recruited after 1 year of age 


\begin{tabular}{|c|c|}
\hline Study & Reason for exclusion \\
\hline & $\begin{array}{l}\text { This study was excluded as participating infants were older (inclusion criteria }<18 \text { months of age), } \\
\text { the educational package was not focused on weaning, and outcomes were not in keeping with the } \\
\text { aims of this review }\end{array}$ \\
\hline Seetha 2018 & This study was excluded as recruited infants were over 1 year of age \\
\hline Seyyedi 2020 & This study was excluded as recruited infants were over 1 year of age \\
\hline Singh 2017 & This study was excluded as nutrition education was combined with other intervention(s) \\
\hline Skau 2015 & $\begin{array}{l}\text { This study was excluded as the intervention was a fortified food supplement. It is a comparison be- } \\
\text { tween rice-based complementary food products - } 1 \text { containing small fish with edible spiders, the } \\
\text { second with small fish and } 2 \text { fortified corn-soy blend products }\end{array}$ \\
\hline Sutrisna 2019 & This study was excluded as recruited infants were over 1 year of age \\
\hline Tang 2014a & $\begin{array}{l}\text { This study was excluded as the paper reports the secondary analysis of data Krebs 2013. In this ran- } \\
\text { domised study, there was no control group }\end{array}$ \\
\hline \multirow[t]{2}{*}{ Tang 2014b } & This study was excluded as the intervention was not suitable for inclusion in this review \\
\hline & $\begin{array}{l}\text { In this cluster-randomised study set in China, } 1471 \text { infants were randomly assigned to meat; multi- } \\
\text { ple-micronutrient fortified cereal; or locally produced, non-fortified cereal for } 12 \text { months. Between } \\
6 \text { and } 18 \text { months of age, infants in the meat group had a greater increase in height (measured as } \\
\text { change in height-for-age } z \text { score) }\end{array}$ \\
\hline \multirow[t]{2}{*}{ Tariku 2015} & $\begin{array}{l}\text { This study was excluded as infants were } 6 \text { to } 24 \text { months old at inclusion, and outcomes of the study } \\
\text { are not relevant to this review }\end{array}$ \\
\hline & $\begin{array}{l}\text { A cluster-RCT set in Ethiopia, this study had } 3 \text { arms: health belief model-based education; tradition- } \\
\text { al education; and control. } 180 \text { households with } 6 \text { - to } 18 \text {-month-old breastfed children were select- } \\
\text { ed by systematic sampling. Outcomes were dietary diversity, knowledge, and perceptions about } \\
\text { complementary feeding }\end{array}$ \\
\hline Taylor 2017 & $\begin{array}{l}\text { Both control and intervention groups received nutrition education. The intervention group also re- } \\
\text { ceived some nutritional supplements }\end{array}$ \\
\hline Yousafzai 2014 & $\begin{array}{l}\text { This study was excluded as the intervention consisted of nutrition education plus food supple- } \\
\text { mentation (multiple-micronutrient powder) and a group that received education to promote care- } \\
\text { givers' sensitivity and responsiveness using developmentally appropriate play }\end{array}$ \\
\hline Zaman 2008 & $\begin{array}{l}\text { Intervention was aimed at training of healthcare workers rather than nutritional counselling for } \\
\text { women }\end{array}$ \\
\hline
\end{tabular}

BMI: body mass index.

HAZ: height-for-age $z$ score.

$\mathrm{RCT}$ : randomised controlled trial.

SD: standard deviation.

WAZ: weight-for-age z score.

WHO: World Health Organization.

WLZ: weight-for-length z score.

Characteristics of ongoing studies [ordered by study ID] 
Billah 2017

\begin{tabular}{|c|c|}
\hline Study name & $\begin{array}{l}\text { A community-based cluster-randomised controlled trial to evaluate the effectiveness of different } \\
\text { bundles of nutrition-specific interventions in improving mean length-for-age } z \text { score among chil- } \\
\text { dren at } 24 \text { months of age in rural Bangladesh }\end{array}$ \\
\hline Methods & Cluster-randomised controlled trial \\
\hline Participants & Pregnant women with their respective child in Bangladesh \\
\hline \multirow[t]{5}{*}{ Interventions } & 4 intervention arms vs control arm: \\
\hline & $\begin{array}{l}\text { 1. Behaviour change communication (BCC) on nutrition education, prenatal supplement (PNS), and } \\
\text { complementary food supplement (CFS) }\end{array}$ \\
\hline & 2. BCC and PNS \\
\hline & 3. BCC and CFS \\
\hline & 4. BCC alone \\
\hline \multirow[t]{3}{*}{ Outcomes } & Mean height-for-age $z$ score (HAZ) at 2 years \\
\hline & Weight-for-age $z$ score (WAZ) at 2 years \\
\hline & Breastfeeding practice \\
\hline Starting date & November 2015 \\
\hline Contact information & billah@icddrb.org \\
\hline Notes & \\
\hline
\end{tabular}

\section{CTRI/2018/01/011275}

\begin{tabular}{ll}
\hline Study name & $\begin{array}{l}\text { A study to assess the effectiveness of structured complementary feeding instructions on anthropo- } \\
\text { metric and morbidity status of infants and the level of knowledge of mothers of infants at a tertiary } \\
\text { referral hospital, Tamilnadu, India }\end{array}$ \\
\hline Methods & RCT \\
\hline Participants & 3- to 5-month old term infants who are exclusively or partially breastfed but have not been weaned \\
\hline Interventions & Structured complementary feeding instruction \\
\hline Outcomes & Growth parameters (weight, length, and head circumference) at 6, 9, and 12 months \\
\hline Starting date & Not yet recruiting \\
\hline Contact information & kogipalani@gmail.com \\
\hline Notes &
\end{tabular}


Gupta 2018

\begin{tabular}{ll}
\hline Study name & $\begin{array}{l}\text { A community-based trial to study the effectiveness of a culturally appropriate nutrition educational } \\
\text { intervention delivered through health services to improve growth and feeding of } 6 \text { month old to } 1 \\
\text { year old infants in Chandigarh }\end{array}$ \\
\hline Methods & RCT \\
\hline Participants & Mother-infant dyad between 4 and 6 months of age without cerebral palsy or congenital anomalies \\
\hline Interventions & Mothers will be provided nutrition education delivered by trained health workers \\
\hline Outcomes & Change in weight and length for age after 6 months \\
\hline Starting date & $16 / 6 / 2017$ \\
\hline Contact information & madhugupta21@gmail.com \\
\hline Notes &
\end{tabular}

\section{Helle 2017}

Study name
vention aiming to promote healthy food habits from early childhood

\begin{tabular}{ll}
\hline Methods & Randomised controlled trial \\
\hline Participants & $\begin{array}{l}\text { Parents of infants between } 3 \text { and } 5 \text { months recruited through child health centres and social media } \\
\text { in Norway }\end{array}$ \\
\hline Interventions & Monthly emails to age-appropriate websites \\
\hline Outcomes & Body mass index and weight at 1 year \\
\hline Starting date & Feeding practice \\
\hline Contact information & March 2016 \\
\hline
\end{tabular}

\section{Notes}

\section{Horodynski 2013}

\begin{tabular}{ll}
\hline Study name & $\begin{array}{l}\text { Healthy babies through infant-centred feeding protocol: an intervention targeting early childhood } \\
\text { obesity in vulnerable populations }\end{array}$ \\
\hline Methods & RCT \\
\hline Participants & Study setting: Colorado and Michigan, United States of America \\
& $\begin{array}{l}\text { Inclusion criteria: mothers over } 18 \text { years of age with infants younger than } 4 \text { months of age who } \\
\text { have not started solid foods and are of low income ( } \leq 185 \% \text { federal poverty level in the USA and eli- } \\
\text { gible for federal food assistance programmes) }\end{array}$ \\
& Exclusion criteria: mother or infant with diagnosed eating, physical, or chronic health problem
\end{tabular}


Horodynski 2013 (Continued)

394 mothers and infants are needed based on the power calculation
Intervention group: locally developed "Healthy Babies" intervention consisting of 6 in-home lessons delivered by a trained paraprofessional instructor followed by 3 reinforcement telephone calls

Control group: traditional nutrition education offered by the Expanded Food and Nutrition Education Programme

\begin{tabular}{ll}
\hline Outcomes & Maternal responsiveness \\
& Maternal satisfaction \\
& Feeding practices \\
& Infant growth patterns of weight and length and their feasibility \\
\hline Starting date & 2011 \\
\hline Contact information & millie@msu.edu \\
\hline Notes & Preliminary results $(n=170)$ available as an abstract which demonstrate the positive impact of nu- \\
trition education on the feeding practices. No growth parameter was reported.
\end{tabular}

Ingalls 2019

\begin{tabular}{ll}
\hline Study name & Preventing early childhood obesity, family spirit nurture, prenatal - 18 months \\
\hline Methods & Randomised controlled trial \\
\hline Participants & Pregnant women and their respective child up to 2 years of age \\
\hline Interventions & $\begin{array}{l}\text { Family spirit nurture (FSN) home-visiting module consists of 36 60-minute lessons delivered by } \\
\text { trained local family health coaches (FHCs), from } 28 \text { weeks' gestation to } 18 \text { months' postpartum. } \\
\text { Lessons focus on } 3 \text { key content domains: (1) promotion of optimal breastfeeding, complementary } \\
\text { and responsive feeding across early childhood; (2) promotion of healthy infant/toddler diet and } \\
\text { physical activity, as well as reduced screen time and sedentary lifestyle; and (3) promotion of ma- } \\
\text { ternal psychosocial well-being, optimisation of healthy food/beverage availability, and identifica- } \\
\text { tion/creation of safe play spaces in the home environment }\end{array}$
\end{tabular}

\begin{tabular}{ll}
\hline Outcomes & $\begin{array}{l}\text { Percentage of mothers who meet breastfeeding and complementary feeding recommendations } \\
\text { Mean BMI z score over } 2 \text { years of life }\end{array}$ \\
\hline Starting date & 25 September 2017 \\
\hline Contact information & $\begin{array}{l}\text { mailto:abarlow\%40jhu.edu?subject=NCT03334266, 7871, Preventing Early Childhood Obesity, Part } \\
\text { 2: Family Spirit Nurture, Prenatal - 18 Months }\end{array}$ \\
\hline
\end{tabular}

\section{ISRCTN10892553}

Study name
Delivering a contextualised package of care for child development (0-12 months) and maternal mental health in the camps for forcibly displaced Myanmar nationals in Bangladesh 
ISRCTN10892553 (Continued)
Methods
Cluster-RCT

Participants

Children younger than 6 weeks of age who are residents of Rohingya refugee camps in Bangladesh. Children with congenital abnormality, history of delayed cry or seizures, or cretinism are excluded

Interventions

Trained community-based care providers to visit and counsel each mother, on a quarterly basis, about nutrition, child development, and depression management care (using the intervention materials) for 1 year

\begin{tabular}{ll}
\hline Outcomes & Developmental outcome assessed by ASQ-3 questionnaire \\
& Height and weight \\
& Maternal depression assessed by PHQ-9 questionnaire \\
\hline Starting date & $01 / 02 / 2019$ \\
\hline Contact information & Association for Social Development, Street 48, House 12, Sector F7/4, 44210, Islamabad, Pakistan \\
\hline Notes & \\
\hline
\end{tabular}

\section{ISRCTN98898991}

\begin{tabular}{ll}
\hline Study name & $\begin{array}{l}\text { Healthy future: a community health worker programme to improve maternal, newborn, and child } \\
\text { health in rural China }\end{array}$ \\
\hline Methods & Cluster-RCT \\
\hline Participants & Pregnant women or mothers of children younger than 6 months of age \\
\hline Interventions & $\begin{array}{l}\text { Healthy Future programme for } 12 \text { months from May } 2019 \text { to May 2020. Participants will receive } \\
\text { nutrition and health education intervention through monthly home visits by trained community } \\
\text { health workers }\end{array}$
\end{tabular}

\begin{tabular}{ll}
\hline Outcomes & Exclusive breastfeeding at 6 months \\
& Haemoglobin concentration \\
& Body mass index \\
\hline Starting date & $04 / 04 / 2019$ \\
\hline Contact information & amedina5@stanford.edu \\
\hline Notes & \\
\hline
\end{tabular}

\section{NCTNCT03597061}

\begin{tabular}{ll}
\hline Study name & Healthy start to feeding intervention \\
\hline Methods & RCT \\
\hline
\end{tabular}




\section{NCTNCT03597061 (Continued)}

Participants

Term infants 2 to 3 months of age who have not been weaned and have weight for length above the 10th percentile

Interventions

3-Session obesity prevention programme targeting healthy introduction of solid foods in infancy for growth trajectories, appetite regulation, and diet

\section{Outcomes}

Growth parameters (weight for length)

Starting date $1 / 11 / 2018$

\section{Contact information}

\section{Notes}

\begin{tabular}{ll}
\hline Wasser $\mathbf{2 0 1 7}$ & Family-based obesity prevention for infants: design of the "Mothers \& Others" randomised trial \\
\hline Methods & Randomised controlled trial \\
\hline Participants & Pregnant African American women and their respective child \\
\hline Interventions & $\begin{array}{l}\text { Family-based multi-component intervention (home visits, newsletters, and text messages) for nu- } \\
\text { trition education }\end{array}$ \\
\hline Outcomes & Weight-for-height z scores at 15 months \\
\hline Starting date & Exclusive breastfeeding until 6 months \\
\hline Contact information & October 2013 \\
\hline Notes & wasser@email.unc.edu \\
\hline
\end{tabular}

ASQ-3: Ages and Stages Questionnaire.

BCC: behaviour change communication.

BMI: body mass index.

CFS: complementary food supplement.

FHC: family health coach.

FSN: family spirit nurture.

HAZ: height-for-age z score.

PHQ-9: Patient Health Questionnaire-9.

PNS: prenatal supplement.

$\mathrm{RCT}$ : randomised controlled trial.

WAZ: weight-for-age z score.

\section{DATA AND ANALYSES}


Comparison 1. Nutrition education versus conventional management

\begin{tabular}{|c|c|c|c|c|}
\hline Outcome or subgroup title & $\begin{array}{l}\text { No. of } \\
\text { studies }\end{array}$ & $\begin{array}{l}\text { No. of } \\
\text { partici- } \\
\text { pants }\end{array}$ & Statistical method & Effect size \\
\hline $\begin{array}{l}1.1 \text { Change in weight in the first } 2 \text { years of } \\
\text { life }\end{array}$ & 4 & 2246 & Mean Difference (IV, Fixed, 95\% CI) & $0.03[-0.02,0.08]$ \\
\hline $\begin{array}{l}1.2 \text { Change in height in the first } 2 \text { years of } \\
\text { life }\end{array}$ & 4 & & Mean Difference (IV, Fixed, 95\% CI) & Subtotals only \\
\hline $\begin{array}{l}1.3 \text { Change in height in the first } 6 \text { years of } \\
\text { life }\end{array}$ & 1 & 50 & Mean Difference (IV, Fixed, 95\% CI) & $-0.22[-0.60,0.16]$ \\
\hline $\begin{array}{l}\text { 1.4 Weight-for-age } z \text { score at } 12 \text { months of } \\
\text { age }\end{array}$ & 6 & 2551 & Mean Difference (IV, Fixed, 95\% CI) & $0.15[0.07,0.22]$ \\
\hline $\begin{array}{l}1.5 \text { Weight-for-age } z \text { score at } 18 \text { months of } \\
\text { age }\end{array}$ & 4 & & Mean Difference (IV, Fixed, 95\% CI) & Subtotals only \\
\hline $\begin{array}{l}\text { 1.6 Height-for-age } z \text { score at } 12 \text { months of } \\
\text { age }\end{array}$ & 7 & 3620 & Mean Difference (IV, Fixed, 95\% CI) & $0.12[0.05,0.19]$ \\
\hline $\begin{array}{l}\text { 1.7 Height-for-age } z \text { score at } 18 \text { months of } \\
\text { age }\end{array}$ & 5 & 4813 & Mean Difference (IV, Fixed, 95\% CI) & $0.16[0.10,0.22]$ \\
\hline 1.8 Height-for-age $z$ score at 6 years of age & 1 & 50 & Mean Difference (IV, Fixed, 95\% CI) & $\begin{array}{l}-0.75[-1.25 \\
-0.25]\end{array}$ \\
\hline $\begin{array}{l}1.9 \text { Weight-for-height } z \text { score at } 12 \text { months } \\
\text { of age }\end{array}$ & 5 & 2831 & Mean Difference (IV, Fixed, 95\% CI) & $0.05[-0.03,0.13]$ \\
\hline $\begin{array}{l}1.10 \text { Weight-for-height } z \text { score at } 18 \text { months } \\
\text { of age }\end{array}$ & 5 & & Mean Difference (IV, Fixed, 95\% CI) & Subtotals only \\
\hline $1.11 \mathrm{BMI} z$ score at 6 years of age & 1 & 50 & Mean Difference (IV, Fixed, 95\% CI) & $-0.24[-0.75,0.27]$ \\
\hline $\begin{array}{l}1.12 \text { Prevalence of anaemia (serum haemo- } \\
\text { globin }<110 \mathrm{~g} / \mathrm{L} \text { ) at } 12 \text { months of age }\end{array}$ & 2 & 585 & Odds Ratio (M-H, Random, 95\% Cl) & $0.58[0.05,6.81]$ \\
\hline 1.13 Death before 1 year of age & 4 & 4234 & Risk Ratio (M-H, Fixed, 95\% Cl) & $0.69[0.44,1.08]$ \\
\hline $\begin{array}{l}\text { 1.14 Exclusive breastfeeding at } 6 \text { months of } \\
\text { age }\end{array}$ & 3 & & Risk Ratio (M-H, Fixed, 95\% Cl) & Subtotals only \\
\hline
\end{tabular}


Analysis 1.1. Comparison 1: Nutrition education versus conventional management, Outcome 1: Change in weight in the first 2 years of life

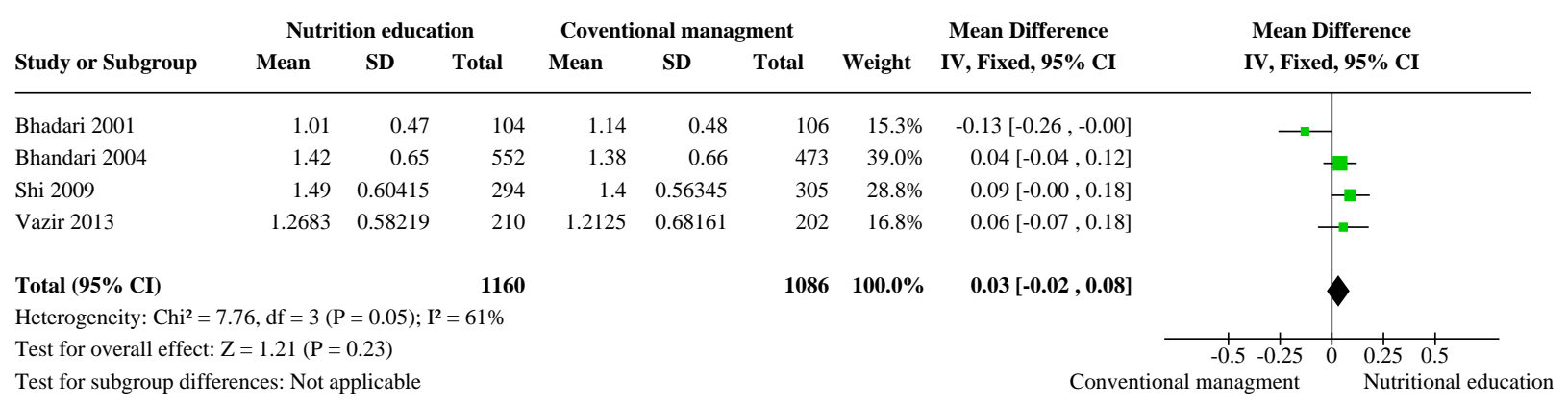

\section{Analysis 1.2. Comparison 1: Nutrition education versus conventional management, Outcome 2: Change in height in the first 2 years of life}

\begin{tabular}{ccccccccc} 
& \multicolumn{4}{c}{ Nutrition education } & \multicolumn{2}{c}{ Coventional managment } & Mean Difference & Mean Difference \\
Study or Subgroup & Mean & SD & Total & Mean & SD & Total & IV, Fixed, 95\% CI & IV, Fixed, 95\% CI
\end{tabular}

\begin{tabular}{lrrrrrrr}
\hline Bhadari 2001 & 5.9 & 1.15 & 104 & 6.1 & 1.13 & 106 & $-0.20[-0.51,0.11]$ \\
Shi 2009 & 7.58 & 1.11 & 294 & 7.27 & 1.09 & 305 & $0.31[0.13,0.49]$ \\
Bhandari 2004 & 6.68 & 1.98 & 552 & 6.41 & 1.77 & 473 & $0.27[0.04,0.50]$ \\
Vazir 2013 & 6.8161 & 1.55102 & 210 & 6.957 & 1.58192 & 202 & $-0.14[-0.44,0.16]$
\end{tabular}

Test for subgroup differences: Not applicable

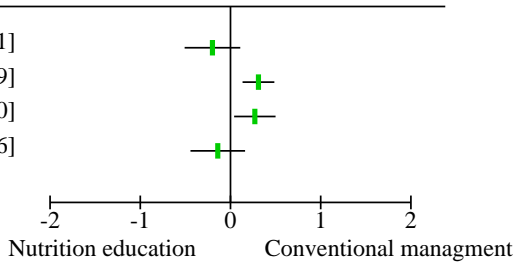

Analysis 1.3. Comparison 1: Nutrition education versus conventional management, Outcome 3: Change in height in the first 6 years of life

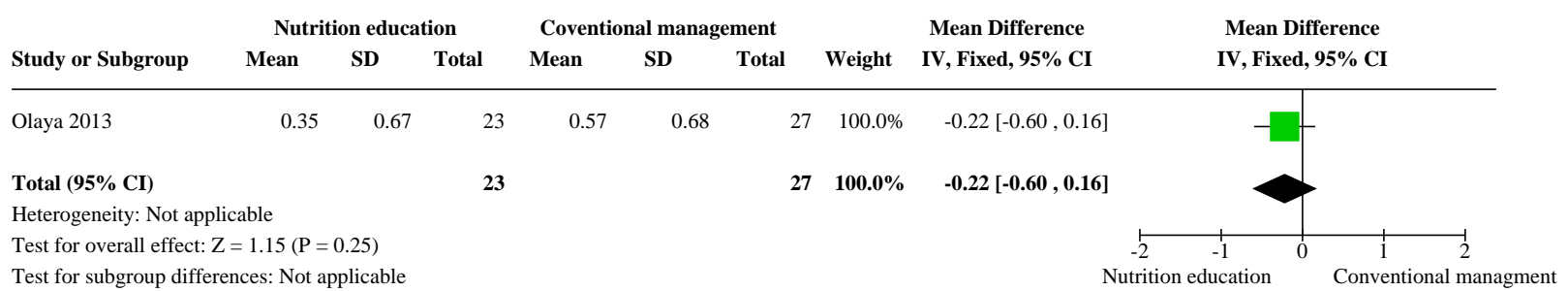


Analysis 1.4. Comparison 1: Nutrition education versus conventional management, Outcome 4: Weight-for-age z score at 12 months of age

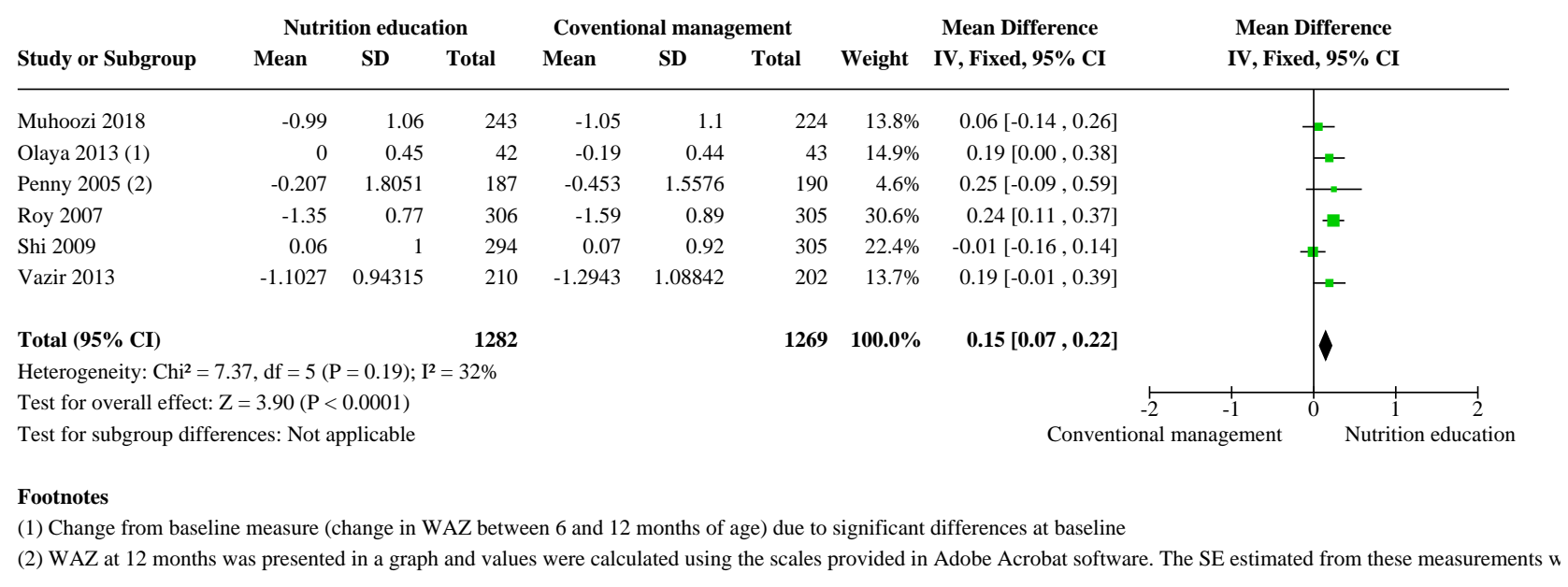

\section{Analysis 1.5. Comparison 1: Nutrition education versus conventional management, Outcome 5: Weight-for-age $z$ score at 18 months of age}

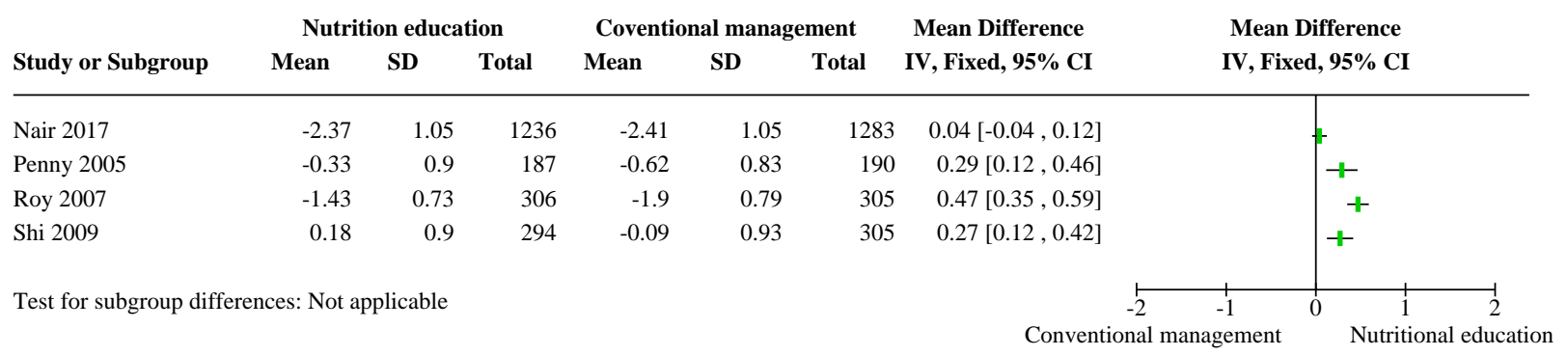

\section{Analysis 1.6. Comparison 1: Nutrition education versus conventional management, Outcome 6: Height-for-age z score at 12 months of age}

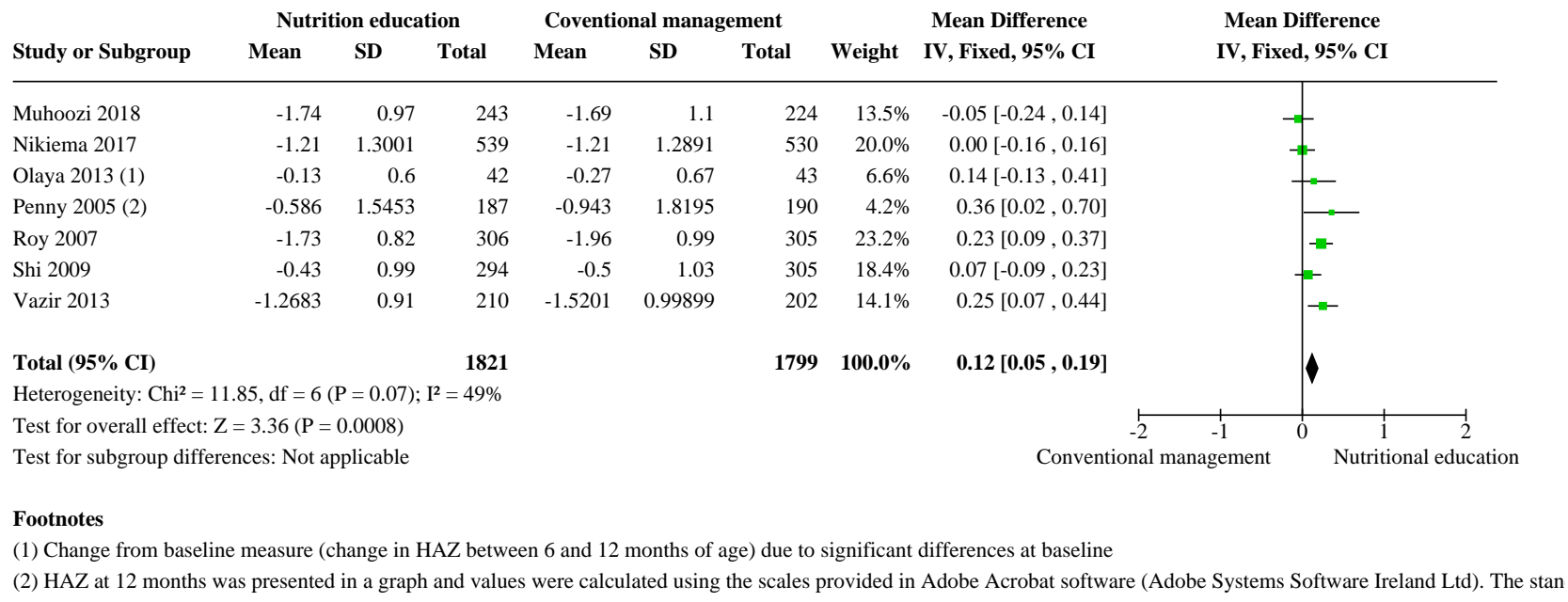


Analysis 1.7. Comparison 1: Nutrition education versus conventional management, Outcome 7: Height-for-age z score at 18 months of age

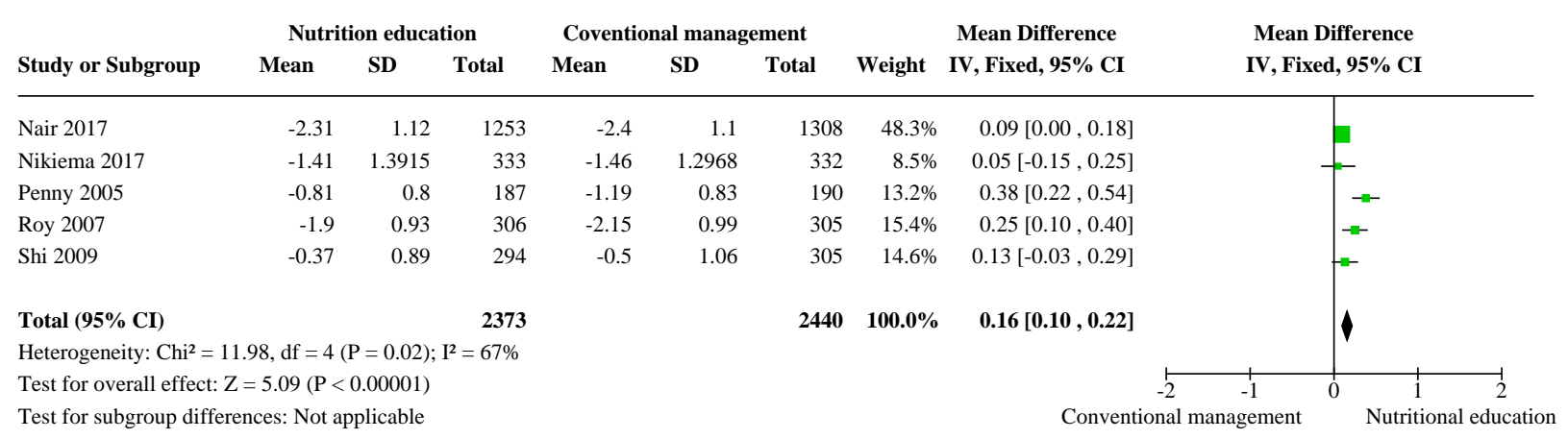

\section{Analysis 1.8. Comparison 1: Nutrition education versus conventional management, Outcome 8: Height-for-age $z$ score at 6 years of age}

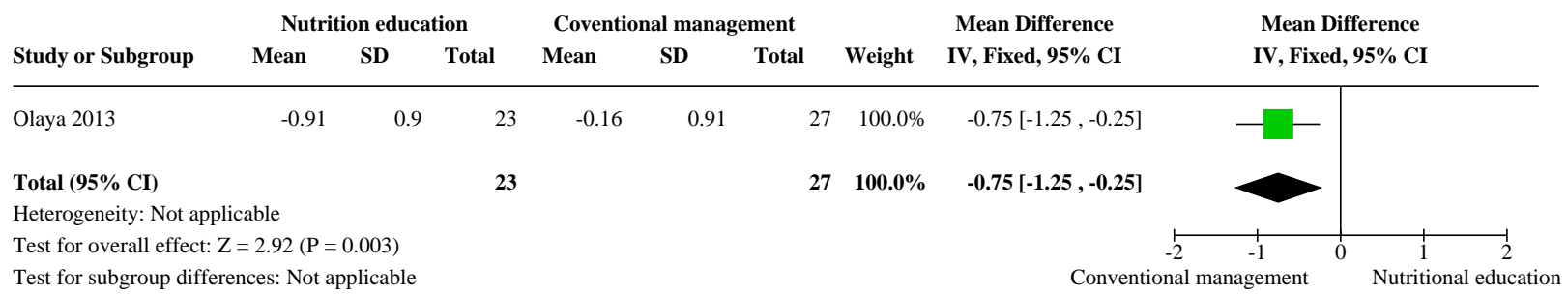

Analysis 1.9. Comparison 1: Nutrition education versus conventional management, Outcome 9: Weight-for-height z score at 12 months of age

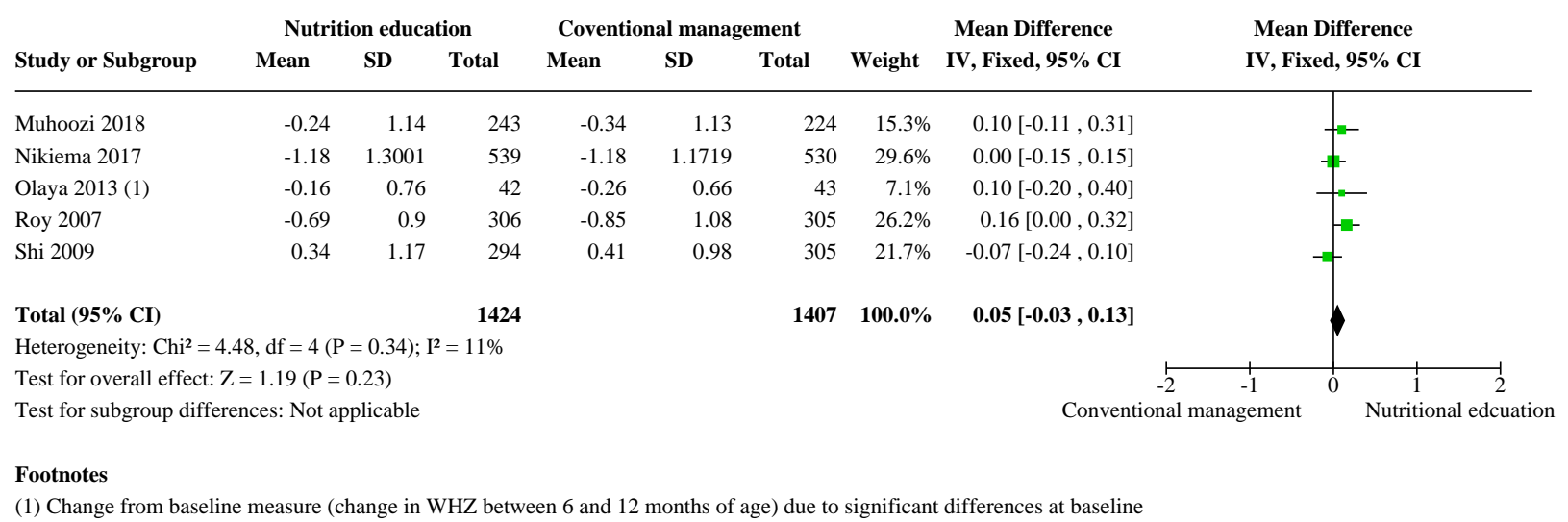


Analysis 1.10. Comparison 1: Nutrition education versus conventional management, Outcome 10: Weight-for-height z score at 18 months of age

\begin{tabular}{lcccccccc} 
& \multicolumn{2}{c}{ Nutrition education } & \multicolumn{2}{c}{ Coventional management } & Mean Difference & Mean Difference \\
Study or Subgroup & Mean & SD & Total & Mean & SD & Total & IV, Fixed, 95\% CI & IV, Fixed, 95\% CI
\end{tabular}

\begin{tabular}{lrrrrrrr}
\hline Nair 2017 & -1.76 & 1.04 & 1231 & -1.76 & 1.04 & 1279 & $0.00[-0.08,0.08]$ \\
Nikiema 2017 & -0.85 & 1.1132 & 333 & -1.01 & 1.1115 & 332 & $0.16[-0.01,0.33]$ \\
Penny 2005 & 0.15 & 0.87 & 187 & 0.05 & 0.79 & 190 & $0.10[-0.07,0.27]$ \\
Roy 2007 & -0.64 & 0.87 & 306 & -1.14 & 0.93 & 305 & $0.50[0.36,0.64]$ \\
Shi 2009 & 0.49 & 1.07 & 294 & 0.19 & 0.97 & 305 & $0.30[0.14,0.46]$
\end{tabular}

Test for subgroup differences: Not applicable

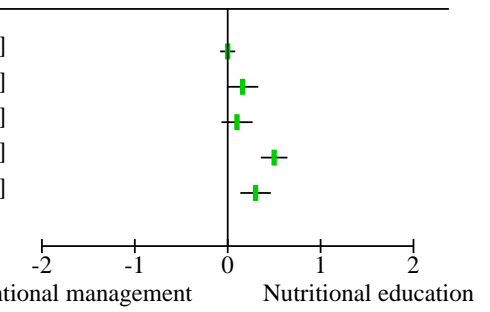

Analysis 1.11. Comparison 1: Nutrition education versus conventional management, Outcome 11: BMI z score at 6 years of age

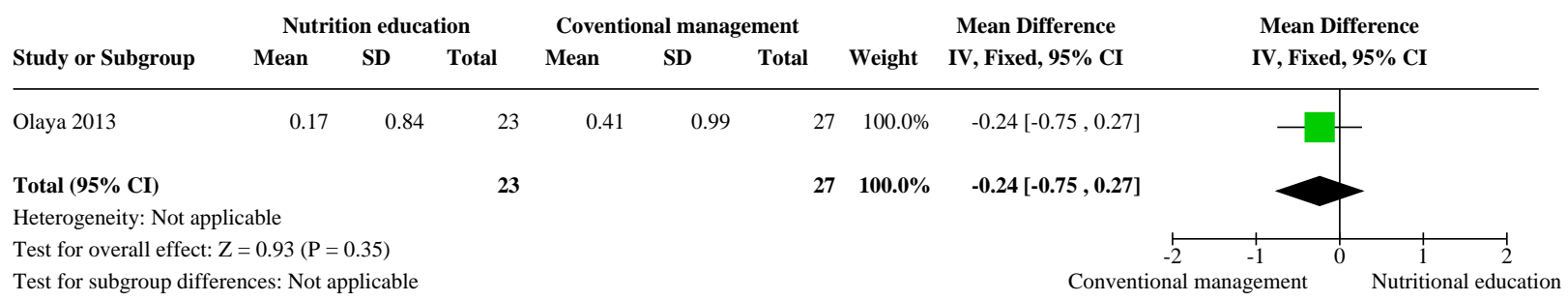

Analysis 1.12. Comparison 1: Nutrition education versus conventional management, Outcome 12: Prevalence of anaemia (serum haemoglobin $<110 \mathrm{~g} / \mathrm{L}$ ) at 12 months of age

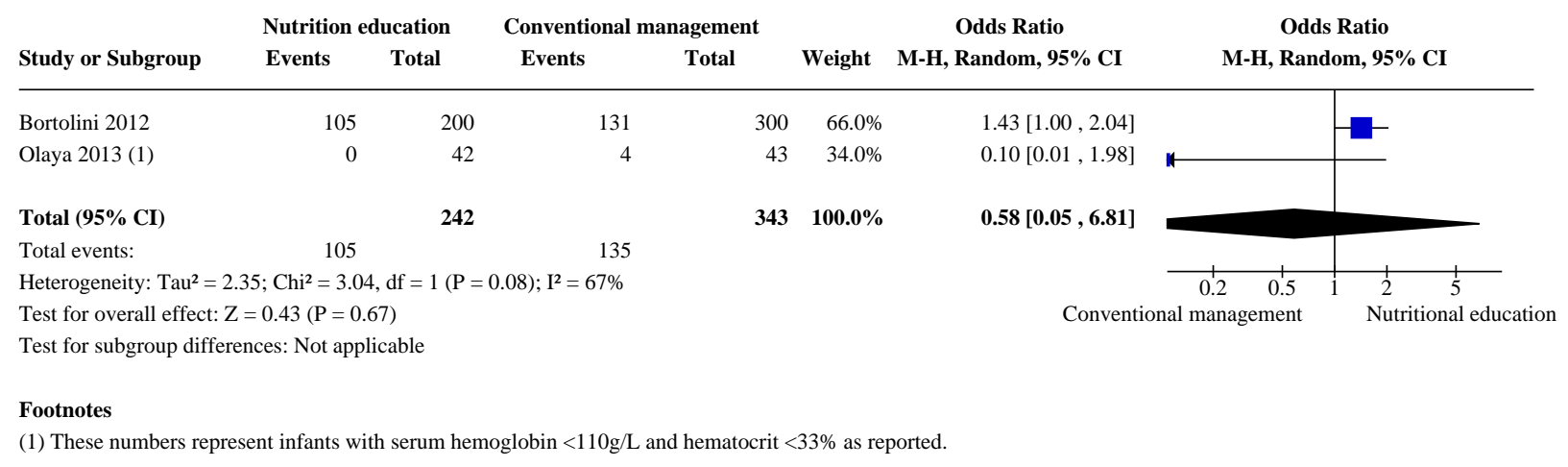


Analysis 1.13. Comparison 1: Nutrition education versus conventional management, Outcome 13: Death before 1 year of age

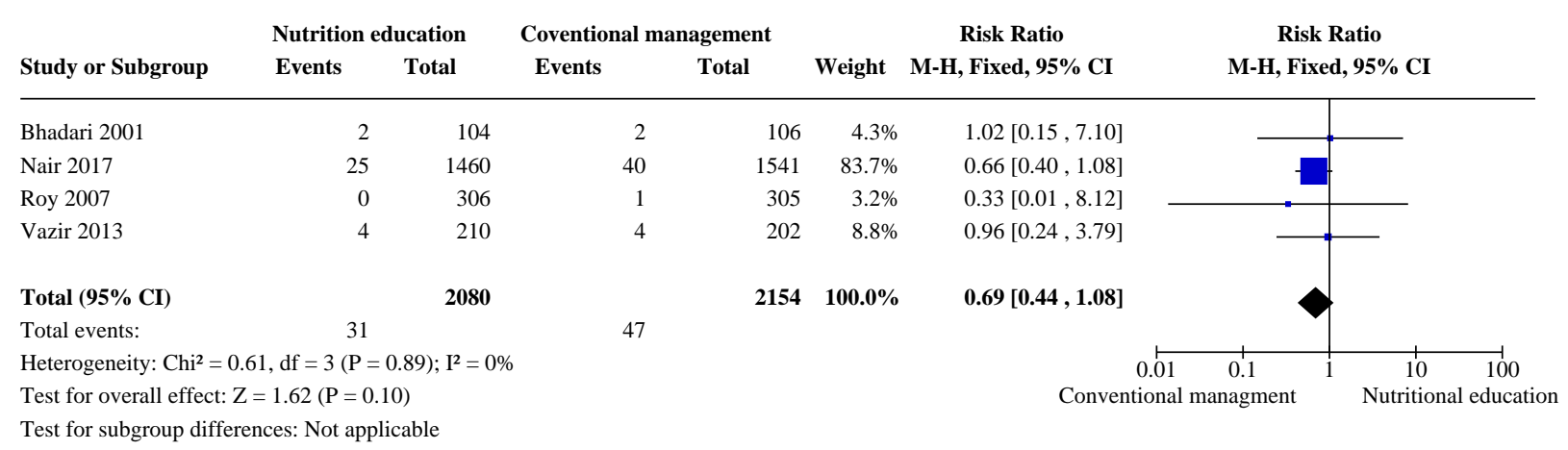

\section{Analysis 1.14. Comparison 1: Nutrition education versus conventional management, Outcome 14: Exclusive breastfeeding at 6 months of age}

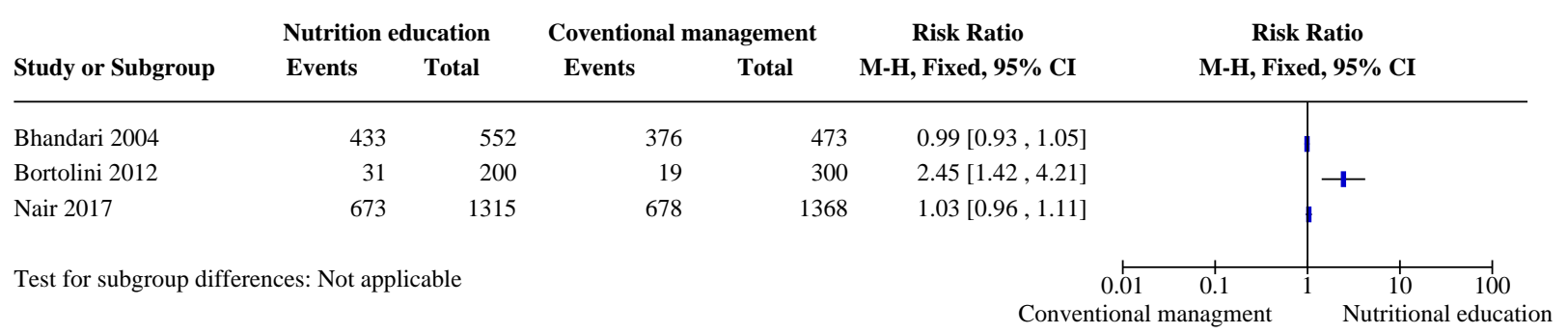

\section{Comparison 2. Correction for cluster effect}

\begin{tabular}{|c|c|c|c|c|}
\hline Outcome or subgroup title & $\begin{array}{l}\text { No. of } \\
\text { studies }\end{array}$ & $\begin{array}{l}\text { No. of } \\
\text { partici- } \\
\text { pants }\end{array}$ & Statistical method & Effect size \\
\hline $\begin{array}{l}2.1 \text { Change in weight in the first } 2 \text { years of } \\
\text { life }\end{array}$ & 4 & 795 & Mean Difference (IV, Fixed, 95\% CI) & $-0.01[-0.09,0.07]$ \\
\hline $\begin{array}{l}2.2 \text { Change in height in the first } 2 \text { years of } \\
\text { life }\end{array}$ & 4 & 795 & Mean Difference (IV, Fixed, 95\% CI) & $-0.02[-0.20,0.17]$ \\
\hline $\begin{array}{l}2.3 \text { Weight-for-age } z \text { score at } 12 \text { months of } \\
\text { age }\end{array}$ & 6 & 1330 & Mean Difference (IV, Fixed, 95\% CI) & $0.19[0.10,0.28]$ \\
\hline $\begin{array}{l}\text { 2.4 Weight-for-age } z \text { score at } 18 \text { months of } \\
\text { age }\end{array}$ & 4 & & Mean Difference (IV, Random, 95\% Cl) & Subtotals only \\
\hline $\begin{array}{l}2.5 \text { Height-for-age } z \text { score at } 12 \text { months of } \\
\text { age }\end{array}$ & 7 & 1433 & Mean Difference (IV, Fixed, 95\% CI) & $0.18[0.08,0.28]$ \\
\hline $\begin{array}{l}2.6 \text { Height-for-age } z \text { score at } 18 \text { months of } \\
\text { age }\end{array}$ & 5 & 2012 & Mean Difference (IV, Fixed, 95\% CI) & $0.17[0.08,0.26]$ \\
\hline $\begin{array}{l}2.7 \text { Weight-for-height } z \text { score at } 12 \\
\text { months of age }\end{array}$ & 5 & 966 & Mean Difference (IV, Fixed, 95\% CI) & $0.11[-0.02,0.23]$ \\
\hline
\end{tabular}




\begin{tabular}{lllll}
\hline Outcome or subgroup title & $\begin{array}{l}\text { No. of } \\
\text { studies }\end{array}$ & $\begin{array}{l}\text { No. of } \\
\text { partici- } \\
\text { pants }\end{array}$ & Statistical method & Effect size \\
\hline $\begin{array}{l}\text { 2.8 Weight-for-height z score at 18 } \\
\text { months of age }\end{array}$ & 5 & 1989 & Mean Difference (IV, Random, 95\% Cl) & $0.21[-0.04,0.47]$ \\
\hline $\begin{array}{l}2.9 \text { Death before 1 year of age } \\
2.10 \text { Exclusive breastfeeding at 6 months }\end{array}$ & 3 & 2400 & Risk Ratio (M-H, Fixed, 95\% Cl) & $0.70[0.37,1.29]$ \\
\hline \begin{tabular}{l} 
of age \\
\hline
\end{tabular} & 1859 & Risk Ratio (M-H, Random, 95\% Cl) & $1.36[0.73,2.56]$ \\
\hline
\end{tabular}

\section{Analysis 2.1. Comparison 2: Correction for cluster effect, Outcome 1: Change in weight in the first 2 years of life}

\begin{tabular}{|c|c|c|c|c|c|c|c|c|c|}
\hline \multirow[b]{2}{*}{ Study or Subgroup } & \multicolumn{3}{|c|}{ Nutrition education } & \multicolumn{3}{|c|}{ Coventional managment } & \multirow[b]{2}{*}{ Weight } & \multirow{2}{*}{$\begin{array}{c}\text { Mean Difference } \\
\text { IV, Fixed, 95\% CI }\end{array}$} & \multirow{2}{*}{$\begin{array}{l}\text { Mean Difference } \\
\text { IV, Fixed, 95\% CI }\end{array}$} \\
\hline & Mean & SD & Total & Mean & SD & Total & & & \\
\hline Bhadari 2001 & 1.01 & 0.47 & 104 & 1.14 & 0.48 & 106 & $38.5 \%$ & $-0.13[-0.26,-0.00]$ & \\
\hline Bhandari 2004 & 1.42 & 0.65 & 75 & 1.38 & 0.66 & 64 & $13.3 \%$ & $0.04[-0.18,0.26]$ & \\
\hline Shi 2009 & 1.49 & 0.60415 & 63 & 1.4 & 0.56345 & 65 & $15.5 \%$ & $0.09[-0.11,0.29]$ & \\
\hline Vazir 2013 & 1.2683 & 0.58219 & 162 & 1.2125 & 0.68161 & 156 & $32.7 \%$ & $0.06[-0.08,0.20]$ & $=$ \\
\hline Total $(95 \%$ CI $)$ & & & 404 & & & 391 & $100.0 \%$ & $-0.01[-0.09,0.07]$ & \\
\hline \multicolumn{10}{|c|}{ Heterogeneity: $\mathrm{Chi}^{2}=5.34, \mathrm{df}=3(\mathrm{P}=0.15) ; \mathrm{I}^{2}=44 \%$} \\
\hline \multirow{2}{*}{\multicolumn{9}{|c|}{ Test for overall effect: $\mathrm{Z}=0.31(\mathrm{P}=0.76)$}} & 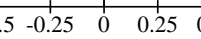 \\
\hline & & & & & & & & Conventi & lagment \\
\hline
\end{tabular}

\section{Analysis 2.2. Comparison 2: Correction for cluster effect, Outcome 2: Change in height in the first 2 years of life}

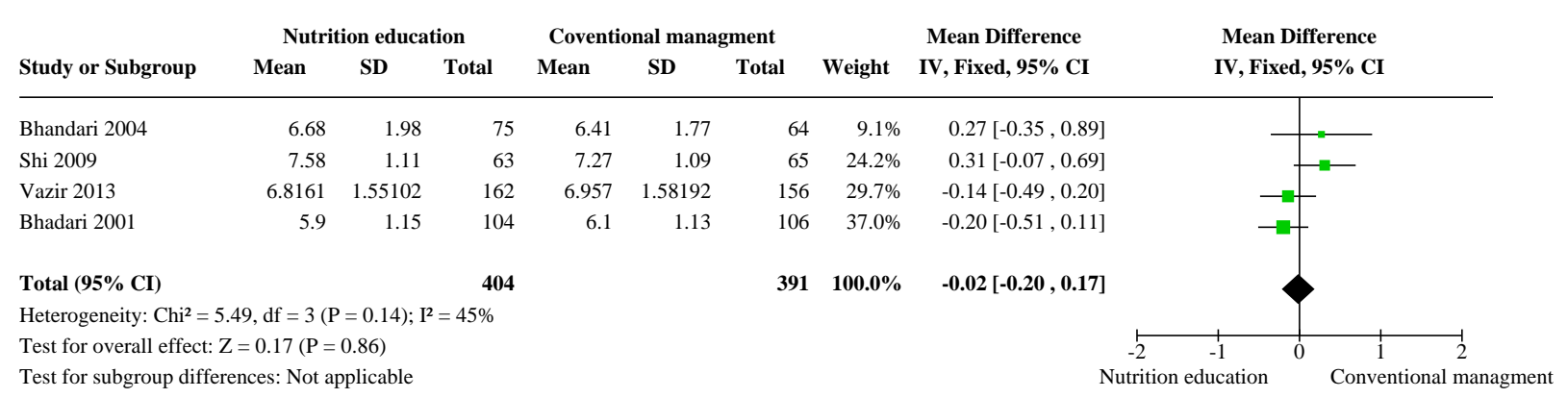


Analysis 2.3. Comparison 2: Correction for cluster effect, Outcome 3: Weight-for-age z score at 12 months of age

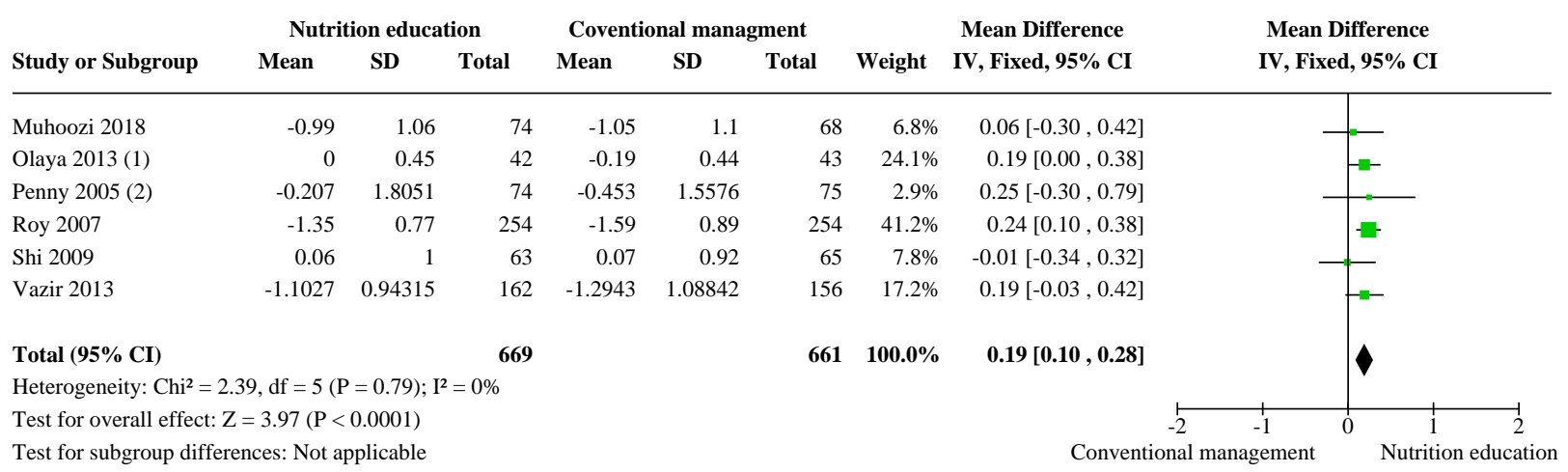

Footnotes

(1) Change from baseline measure (change in WAZ between 6 and 12 months of age) due to significant differences at baseline

(2) WAZ at 12 months was presented in a graph and values were calculated using the scales provided in Adobe Acrobat software. The SE estimated from these measurements

Analysis 2.4. Comparison 2: Correction for cluster effect, Outcome 4: Weight-for-age z score at 18 months of age

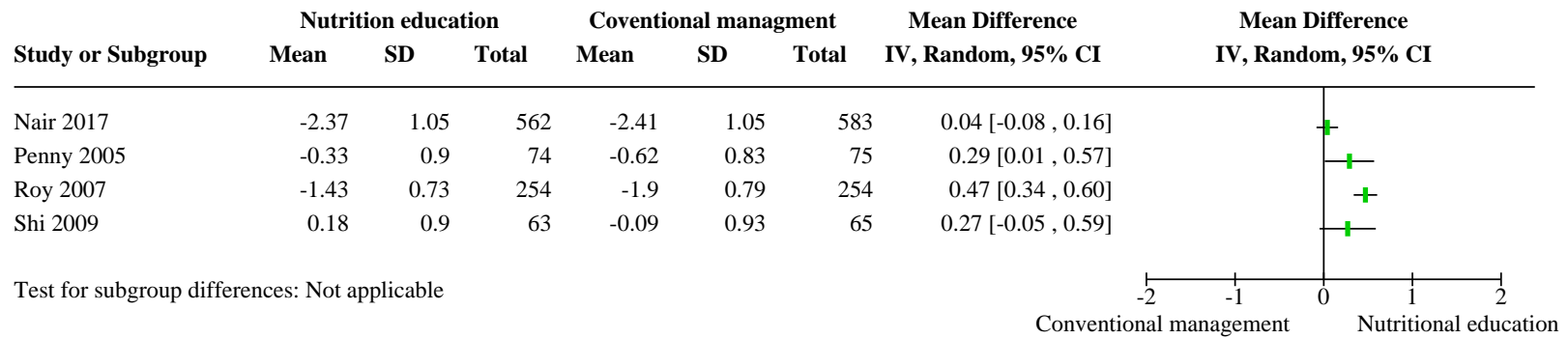

\section{Analysis 2.5. Comparison 2: Correction for cluster effect, Outcome 5: Height-for-age z score at 12 months of age}

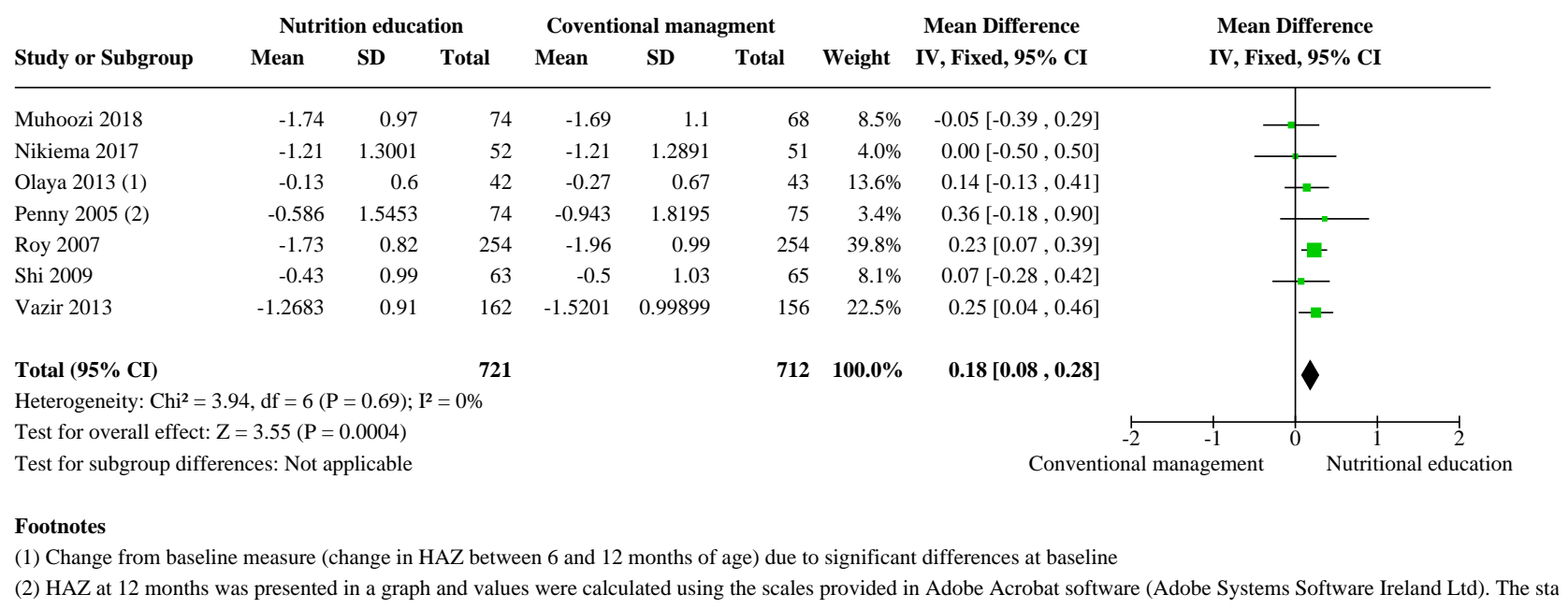


Analysis 2.6. Comparison 2: Correction for cluster effect, Outcome 6: Height-for-age z score at 18 months of age

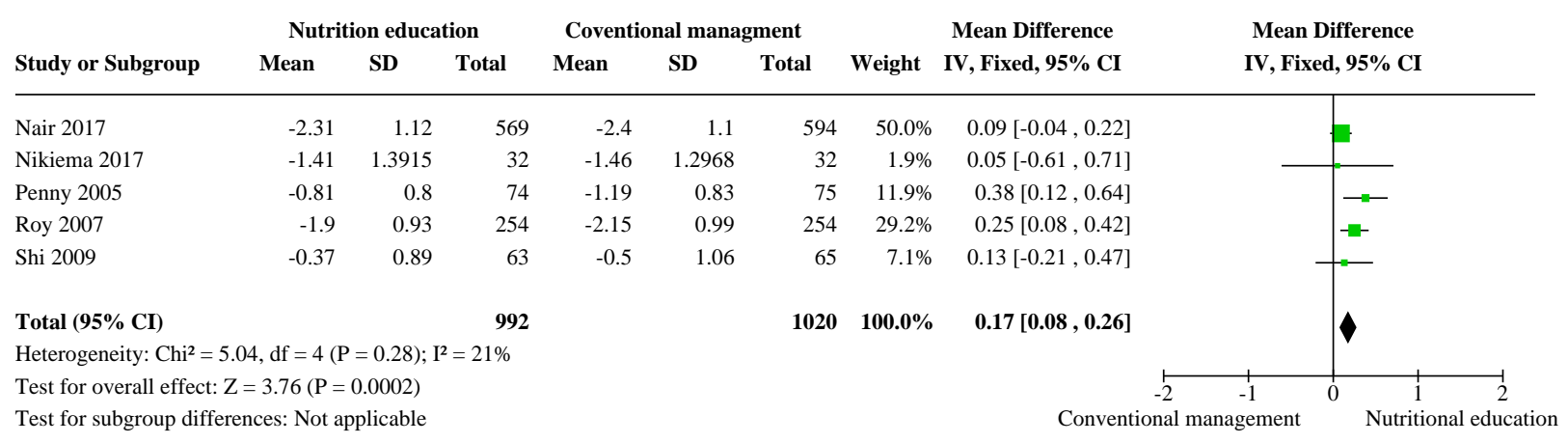

\section{Analysis 2.7. Comparison 2: Correction for cluster effect, Outcome 7: Weight-for-height z score at 12 months of age}

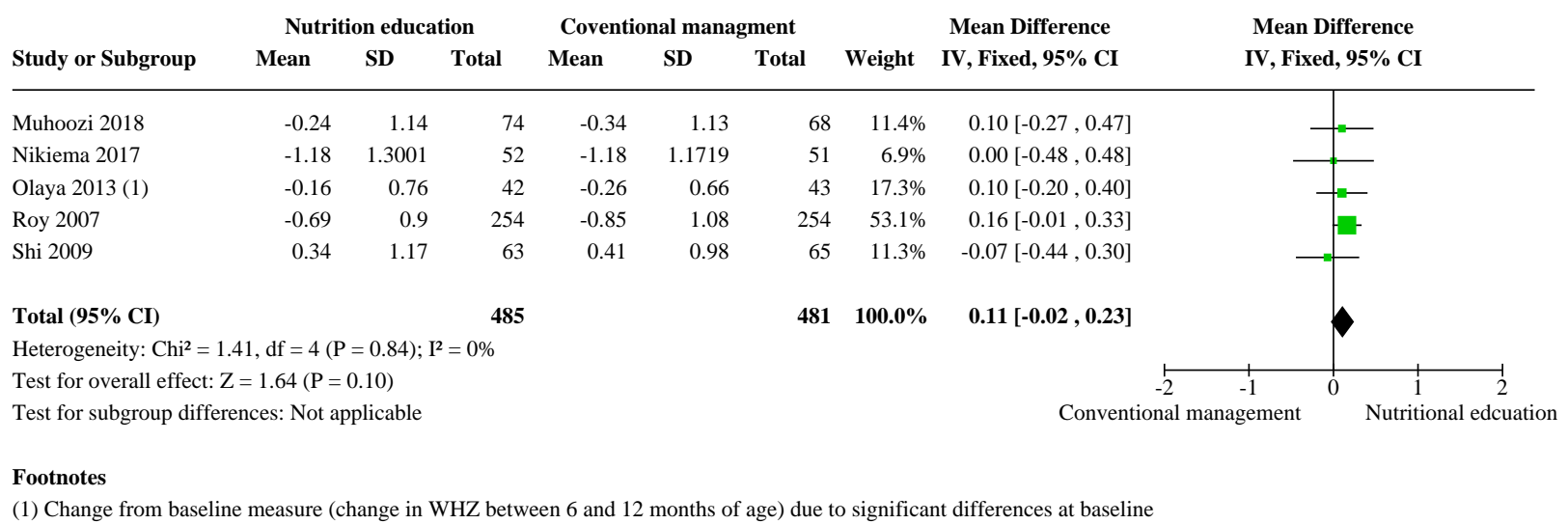

Analysis 2.8. Comparison 2: Correction for cluster effect, Outcome 8: Weight-for-height z score at 18 months of age

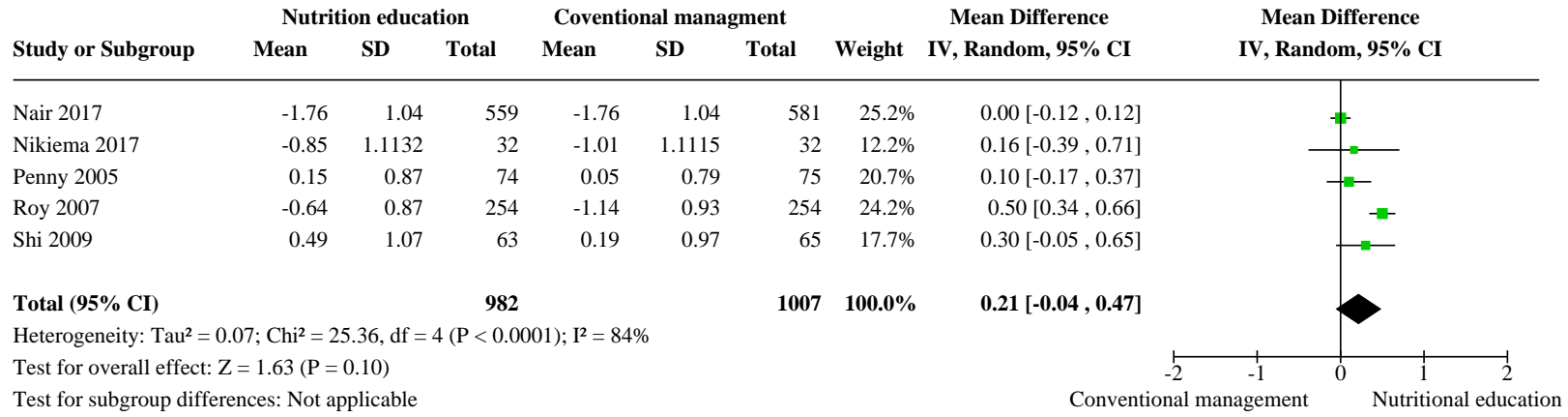




\section{Analysis 2.9. Comparison 2: Correction for cluster effect, Outcome 9: Death before 1 year of age}

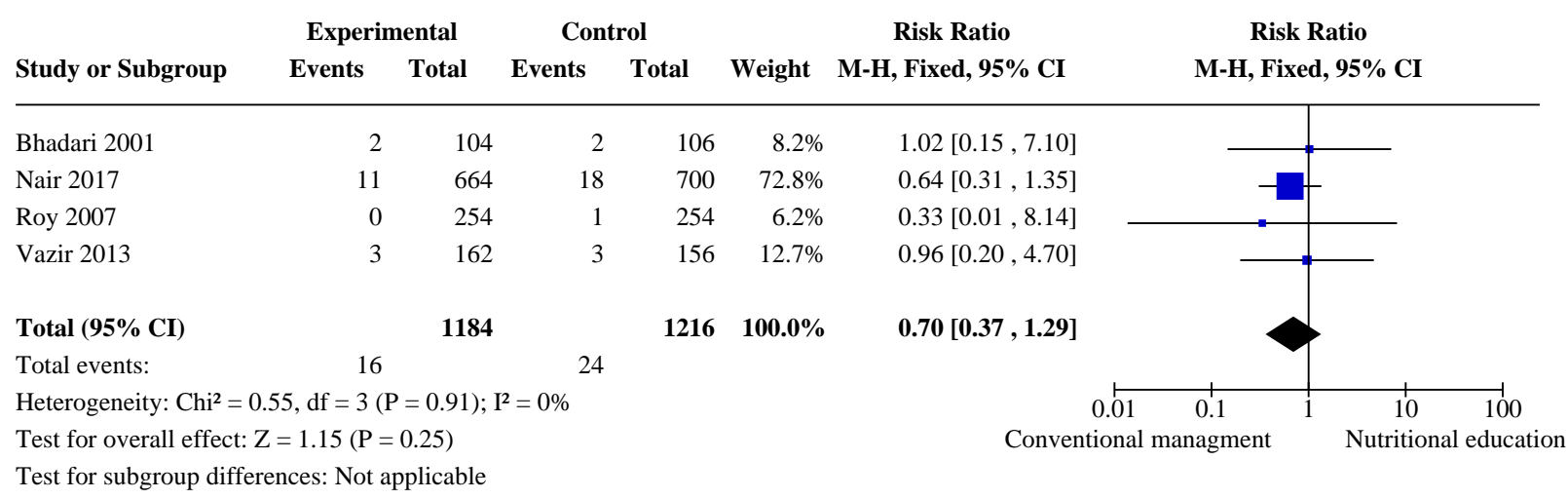

Analysis 2.10. Comparison 2: Correction for cluster effect, Outcome 10: Exclusive breastfeeding at 6 months of age

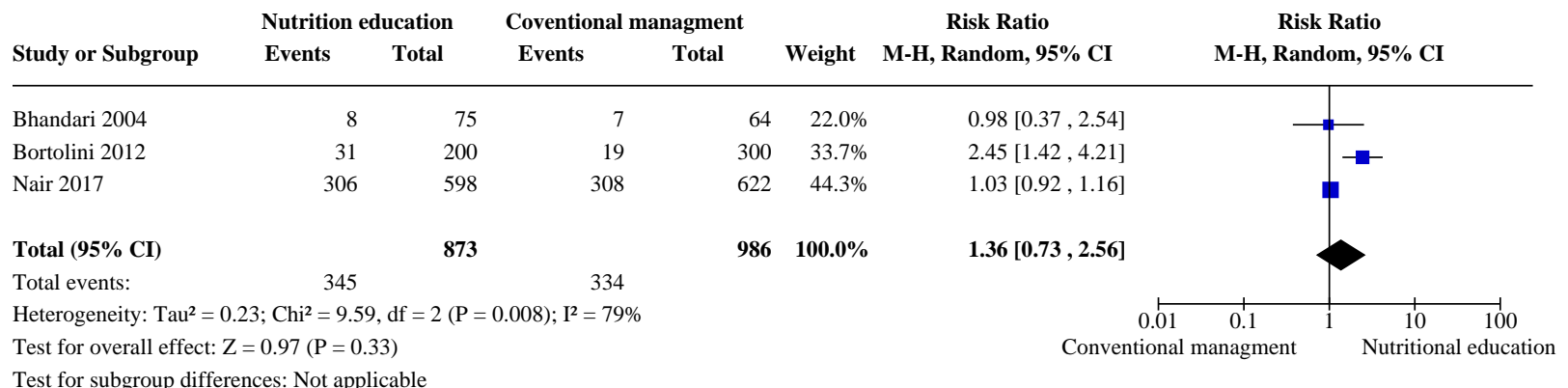

ADDITIONAL TABLES

Table 1. Average cluster size and design effect of cluster-randomised trials

\begin{tabular}{lllllll}
\hline Study & \multicolumn{2}{c}{ Original sample size } & $\begin{array}{l}\text { Number } \\
\text { of clus- } \\
\text { ters }\end{array}$ & $\begin{array}{l}\text { Average } \\
\text { cluster } \\
\text { size }\end{array}$ & $\begin{array}{l}\text { Intracluster correla- } \\
\text { tion coefficient }\end{array}$ & $\begin{array}{c}\text { Design ef- } \\
\text { fect }\end{array}$ \\
\cline { 2 - 6 } Muhoozi 2018 & 243 & 224 & 10 & 47 & 0.05 & 3.3 \\
\hline Bhandari 2004 & 552 & 473 & 8 & 128 & 0.05 & 7.4 \\
\hline Ferreira 2019 & 317 & 300 & 20 & 31 & 0.05 & 2.5 \\
\hline Morandi 2019 & 295 & 267 & 22 & 26 & 0.05 & 2.2 \\
\hline Nair 2017 & 1541 & 1460 & 120 & 25 & 0.05 & 2.2 \\
\hline Nikiema 2017 & 1083 & 1170 & 12 & 188 & 0.05 & 10.3 \\
\hline Penny 2005 & 187 & 190 & 12 & 31 & 0.05 & 2.5 \\
\hline Rafieya-Kopaei 2019 & 60 & 30 & 6 & 15 & 0.05 & 1.7 \\
\hline Roy 2007 & 306 & 305 & 121 & 5 & 0.05 & 1.2 \\
\hline
\end{tabular}


Table 1. Average cluster size and design effect of cluster-randomised trials (Continued)

\begin{tabular}{lcccccc} 
Saleem 2014 & 118 & 94 & 10 & 21 & 0.05 & 2.0 \\
\hline Shi 2009 & 294 & 305 & 8 & 75 & 0.05 & 4.7 \\
\hline Vazir 2013 & 210 & 202 & 60 & 7 & 0.05 & 1.3 \\
\hline
\end{tabular}

\section{APPENDICES}

\section{Appendix 1. Previous search methods}

PubMed: ((infant, newborn[MeSH] OR newborn OR neonate OR neonatal OR premature OR low birth weight OR VLBW OR LBW or infan* or neonat ${ }^{\star}$ ) AND (randomized controlled trial [pt] OR controlled clinical trial [pt] OR randomized [tiab] OR placebo [tiab] OR drug therapy [sh] OR randomly [tiab] OR trial [tiab] OR groups [tiab]) NOT (animals [mh] NOT humans [mh]))

Embase: (infant, newborn or newborn or neonate or neonatal or premature or very low birth weight or low birth weight or VLBW or LBW or Newborn or infan* or neonat*) AND (human not animal) AND (randomized controlled trial or controlled clinical trial or randomized or placebo or clinical trials as topic or randomly or trial or clinical trial)

CINAHL: (infant, newborn OR newborn OR neonate OR neonatal OR premature OR low birth weight OR VLBW OR LBW or Newborn or infan* or neonat ${ }^{\star}$ ) AND (randomized controlled trial OR controlled clinical trial OR randomized OR placebo OR clinical trials as topic OR randomly OR trial OR PT clinical trial)

Cochrane Library: (infant or newborn or neonate or neonatal or premature or preterm or very low birth weight or low birth weight or VLBW or LBW)

\section{Appendix 2. Search methods}

The RCT filters have been created using Cochrane's highly sensitive search strategies for identifying randomised trials (Higgins 2019). The neonatal filters were created and tested by the Cochrane Neonatal Information Specialist.

\section{CENTRAL via CRS Web}

Date ranges: 01 January 2018 to 12 December 2019

Terms:

1 MESH DESCRIPTOR Weaning EXPLODE ALL AND CENTRAL:TARGET

2 wean* AND CENTRAL:TARGET

3 ((feed* or food) and (complementary or supplementary)) AND CENTRAL:TARGET

4 \#1 OR \#2 OR \#3

5 MESH DESCRIPTOR Education EXPLODE ALL AND CENTRAL:TARGET

6 (program* or education* or training or intervention* or counseling or support or information or recommendation or guideline or advice) AND CENTRAL:TARGET

7 \#6 OR \#5

8 MESH DESCRIPTOR Infant, Newborn EXPLODE ALL AND CENTRAL:TARGET

9 infant or infants or infant's or "infant s" or infantile or infancy or newborn* or "new born" or "new borns" or "newly born" or neonat* or baby $^{\star}$ or babies or premature or prematures or prematurity or preterm or preterms or "pre term" or premies or "low birth weight" or "low birthweight" or VLBW or LBW or ELBW or NICU AND CENTRAL:TARGET

10 \#9 OR \#8 AND CENTRAL:TARGET

11 \#10 AND \#7 AND \#4

122018 TO 2019:YR AND CENTRAL:TARGET

13 \#12 AND \#11

\section{MEDLINE via Ovid}

Date ranges: 01 January 2018 to 12 December 2019

Terms:

1. exp Weaning/

2. wean ${ }^{\star} . \mathrm{mp}$.

3. ((feed ${ }^{\star}$ or food) and (complementary or supplementary)).ti,ab.

4. 1 or 2 or 3 
5. exp Education/

6. (program* or education* or training or intervention* or counseling or support or information or recommendation or guideline or advice).ti,ab.

7.5 or 6

8. exp infant, newborn/

9. (newborn* or new born or new borns or newly born or baby* or babies or premature or prematurity or preterm or pre term or low birth weight or low birthweight or VLBW or LBW or infant or infants or 'infant s' or infant's or infantile or infancy or neonat*).ti,ab.

10. 8 or 9

11. randomized controlled trial.pt.

12. controlled clinical trial.pt.

13. randomized.ab.

14. placebo.ab.

15. drug therapy.fs.

16. randomly.ab.

17. trial.ab.

18. groups.ab.

19. or/11-18

20. exp animals/ not humans.sh.

21. 19 not 20

22. 10 and 21

23. randomi?ed.ti,ab.

24. randomly.ti,ab.

25. trial.ti,ab.

26. groups.ti,ab.

27. ((single or doubl ${ }^{\star}$ or tripl $l^{\star}$ or treb $\left.b^{\star}\right)$ and (blind ${ }^{\star}$ or mask $\left.\left.k^{\star}\right)\right) . t i, a b$.

28. placebo*.ti,ab.

29.23 or 24 or 25 or 26 or 27 or 28

30.9 and 29

31. limit 30 to $y r=" 2018$-Current"

32. 22 or 31

33. 4 and 7 and 32

34. limit 33 to $y r=" 2018$-Current"

\section{CINAHL via EBSCOhost}

Date ranges: 01 January 2018 to 12 December 2019

Terms:

(wean* OR ((feed* OR food) AND (complementary OR supplementary)))

AND

(program* OR education* OR training OR intervention* OR counseling OR support OR information OR recommendation OR guideline OR advice)

AND

(infant or infants or infant's or infantile or infancy or newborn* or "new born" or "new borns" or "newly born" or neonat* or baby* or babies or premature or prematures or prematurity or preterm or preterms or "pre term" or premies or "low birth weight" or "low birthweight" or VLBW or LBW)

AND

(randomized controlled trial OR controlled clinical trial OR randomized OR randomised OR placebo OR clinical trials as topic OR randomly OR trial OR PT clinical trial)

Limiters - Published Date: 20180101-20191231

\section{ISRCTN}

Date ranges: 2018 to 2019

Terms:

Interventions: Feeding education AND Participant age range: Neonate

Interventions: Weaning education AND Participant age range: Neonate weaning within Interventions: Education AND Participant age range: Neonate feeding within Interventions: Education AND Participant age range: Neonate weaning education within Participant age range: Neonate feeding education within Participant age range: Neonate 


\section{Appendix 3. Risk of bias tool}

We used the standard methods of Cochrane and Cochrane Neonatal to assess the methodological quality of the trials. For each trial, we sought information regarding the method of randomisation, blinding and reporting of all outcomes of all the infants enrolled in the trial. We assessed each criterion as being at a low, high, or unclear risk of bias. Two review authors separately assessed each study. Disagreements were resolved by discussion. We added this information to the table Characteristics of included studies. We evaluated the following issues and enter the findings into the risk of bias table:

\section{Sequence generation (checking for possible selection bias). Was the allocation sequence adequately generated?}

For each included study, we categorised the method used to generate the allocation sequence as:

- low risk (any truly random process, e.g. random number table; computer random number generator);

- high risk (any non-random process, e.g. odd or even date of birth; hospital or clinic record number); or

- unclear risk.

\section{Allocation concealment (checking for possible selection bias). Was allocation adequately concealed?}

For each included study, we categorised the method used to conceal the allocation sequence as:

- low risk (e.g. telephone or central randomisation; consecutively numbered sealed opaque envelopes);

- high risk (open random allocation; unsealed or non-opaque envelopes, alternation; date of birth); or

- unclear risk

3. Blinding of participants and personnel (checking for possible performance bias). Was knowledge of the allocated intervention adequately prevented during the study?

For each included study, we categorised the methods used to blind study participants and personnel from knowledge of which intervention a participant received. Blinding was assessed separately for different outcomes or classes of outcomes. We categorised the methods as:

- low risk, high risk, or unclear risk for participants; and

- low risk, high risk, or unclear risk for personnel.

4. Blinding of outcome assessment (checking for possible detection bias). Was knowledge of the allocated intervention adequately prevented at the time of outcome assessment?

For each included study, we categorised the methods used to blind outcome assessment. Blinding was assessed separately for different outcomes or classes of outcomes. We categorised the methods as:

- low risk for outcome assessors;

- high risk for outcome assessors; or

- unclear risk for outcome assessors.

5. Incomplete outcome data (checking for possible attrition bias through withdrawals, dropouts, protocol deviations). Were incomplete outcome data adequately addressed?

For each included study and for each outcome, we described the completeness of data including attrition and exclusions from the analysis. We noted whether attrition and exclusions were reported, the numbers included in the analysis at each stage (compared with the total randomised participants), reasons for attrition or exclusion where reported, and whether missing data were balanced across groups or were related to outcomes. When sufficient information was reported or supplied by the trial authors, we re-included missing data in the analyses. We categorised the methods as:

- low risk (<20\% missing data);

- high risk ( $\geq 20 \%$ missing data); or

- unclear risk.

\section{Selective reporting bias. Are reports of the study free of the suggestion of selective outcome reporting?}

For each included study, we described how we investigated the possibility of selective outcome reporting bias and what we found. For studies in which study protocols were published in advance, we compared pre-specified outcomes versus outcomes eventually reported in the published results. If the study protocol was not published in advance, we contacted study authors to gain access to the study protocol. We assessed the methods as: 
- low risk (when it is clear that all of the study's pre-specified outcomes and all expected outcomes of interest to the review have been reported);

- high risk (when not all of the study's pre-specified outcomes have been reported; one or more reported primary outcomes were not pre-specified outcomes of interest and are reported incompletely and so cannot be used; study fails to include results of a key outcome that would have been expected to have been reported); or

- unclear risk.

\section{Other sources of bias. Was the study apparently free of other problems that could put it at high risk of bias?}

For each included study, we described any important concerns we had about other possible sources of bias (e.g. whether there was a potential source of bias related to the specific study design, whether the trial was stopped early due to some data-dependent process). We assessed whether each study was free of other problems that could put it at risk of bias as:

- low risk;

- high risk; or

- unclear risk.

If needed, we explored the impact of the level of bias by undertaking sensitivity analyses.

\section{H I S T O R Y}

Protocol first published: Issue 6, 2016

Review first published: Issue 7, 2020

\section{CONTRIBUTIONS OF AUTHORS}

Shalini Ojha: undertook literature search, screening of studies, critical appraisal of studies, and data analyses, and wrote the review.

Zenab Elfzzani: undertook literature search, screening of studies, critical appraisal of studies, and data extraction.

Tng Chang Kwok: undertook literature search, screening of studies, critical appraisal of studies, data extraction, and data analyses for repeat search between July 2017 and 12 December 2019.

Jon Dorling: oversaw the project, resolved differences, and co-wrote the review.

\section{DECLARATIONS OF INTEREST}

Shalini Ojha: none to declare.

Zenab Elfzzani: none to declare

Tng Chang Kwok: none to declare.

Jon Dorling: none to declare.

\section{SOURCES OF SUPPORT}

\section{Internal sources}

- No sources of support supplied

\section{External sources}

- National Institute for Health Research, UK

Editorial support for Cochrane Neonatal has been provided through funds from a UK National Institute of Health Research Grant (NIHR) Cochrane Programme Grant (13/89/12). The views expressed in this publication are those of the authors and not necessarily those of the NHS, the NIHR, or the UK Department of Health.

- Vermont Oxford Network, USA

Cochrane Neonatal Reviews are produced with support from Vermont Oxford Network, a worldwide collaboration of health professionals dedicated to providing evidence-based care of the highest quality for newborn infants and their families.

\section{DIFFERENCES BETWEEN PROTOCOLANDREVIEW}

We made the following changes to the published protocol (Elfzzani 2016). 
1. We did not use a summary measurement from each cluster and use the cluster as the unit of analysis as this would have considerably and unnecessarily reduced the power of the studies (Higgins 2019). Instead, we carried out 'approximate analyses' to obtain the 'effective sample sizes' (Higgins 2019). Further subgroup analyses were carried out a posteriori to explore reasons for heterogeneity in the included studies.

2. As of July 2019, Cochrane Neonatal no longer searches Embase for its reviews. Randomised controlled trials (RCTs) and controlled clinical trials (CCTs) from Embase are added to the Cochrane Central Register of Controlled Trials (CENTRAL) via a robust process (see How CENTRAL is created). Cochrane Neonatal has validated its searches to ensure that relevant Embase records are found while searching CENTRAL.

3. Also starting in July 2019, Cochrane Neonatal no longer searches for RCTs and CCTs on the following platforms: ClinicalTrials.gov or the World Health Organization International Clinical Trials Registry Platform (ICTRP), as records from both platforms are added to CENTRAL on a monthly basis (see How CENTRAL is created). Comprehensive search strategies are executed in CENTRAL to retrieve relevant records. The ISRCTN (at www.isrctn.com/, formerly Controlled-trials.com) is searched separately.

4. For the 2019 update, we developed a new search strategy. The previous search methods are available in Appendix 1. 